UNIVERSIDAD NACIONAL DE LA PLATA

FACULTAD DE HUMANIDADES Y CIENCIAS DE LA EDUCACIÓN SECRETARÍa de Posgrado

\title{
De las formas jugadas al deporte formal.
}

La iniciación deportiva y

la enseñanza de los deportes de conjunto

en las edades formativas.

El caso especial del handball infantil

Héctor Talpone

Tesis para optar al grado de Magister en Deporte

Director: Prof. Mg. Carlos Carballo

Viernes 12 de octubre de 2019 


\section{DEDICATORIAS}

Dedico esta tesis a mis padres Coca y Tito,

a la luz de mi vida, mis hijos Camila y Guido,

y al ser hermoso, que me sostiene, me guía, me cuida,

con el que juntos construimos un camino sostenido en el respeto y el amor, a mi esposa Sandra Vivian Onetti. 


\section{ÍNDICE}

CAPÍTULO 1: DOS RELATOS PARA CONSTRUIR UN ESTADO DE LA CUESTIÓN

1.1. ¿POR QUÉ DOS RELATOS?

1.2. EN PRIMERA PERSONA: MI EXPERIENCIA COMO JUGADOR Y ENTRENADOR

1.3. EN TERCERA PERSONA: LO QUE DICE LA BIBLIOGRAFÍA SOBRE EL TEMA

1.4. BIBLIOGRAFÍA DEL CAPÍTULO

CAPÍTULO 2: DOS APROXIMACIONES PARA ENTENDER UN FENÓMENO COMPLEJO

2.1. EL DEPORTE ES UN CONCEPTO POLISÉMICO

2.2. APROXIMACIÓN ONTOLÓGICA

2.3. APROXIMACIÓN CRÍTICA

2.4. BIBLIOGRAFÍA DEL CAPÍTULO

CAPÍTULO 3: CARACTERÍSTICAS DE LOS DEPORTES DE CONJUNTO. INCIDENCIAS EN LA ENSEÑANZA 43-70

3.1. CARACTERÍSTICAS GENERALES

3.2. PERSPECTIVA DE LA TÉCNICA

3.3. PERSPECTIVA DE LA TAREA MOTRIZ

3.4. PERSPECTIVA DE LA TÁCTICA

3.5. PERSPECTIVA ESTRUCTURAL

3.6. PERSPECTIVA ESTRUCTURALFUNCIONALISTA 
CAPÍTULO 4: INICIACIÓN DEPORTIVA

4.1. ALGUNOS CONCEPTOS

4.2. FACTORES INTERVINIENTES EN LA INICIACIÓN DEPORTIVA

4.3. OTROS ASPECTOS A TENER EN CUENTA EN LA INICIACIÓN DEPORTIVA

4.4. ETAPAS DE LA INICIACIÓN DEPORTIVA

4.5. EL PROCESO DE LA INICIACIÓN

4.6. PROGRAMAR LA INICIACIÓN

4.7. BIBLIOGRAFÍA DEL CAPÍTULO

CAPÍTULO 5: MÉTODOS DE ENSEÑANZA

5.1. RESOLUCIÓN DE PROBLEMAS

5.2. INSTRUCCIÓN DIRECTA

5.3. MODELO COMPRENSIVO

5.4. MODELO ESTRUCTURAL

5.5. BIBLIOGRAFÍA DEL CAPÍTULO

CAPÍTULO 6: CONCLUSIONES

6.1. EN RESPUESTA A LAS PREGUNTAS DE INVESTIGACIÓN

6.2. CONSIDERACIONES FINALES

BIBLIOGRAFÍA GENERAL

$122-127$

AGRADECIMIENTOS 
CAPÍTULO 1:

\section{DOS RELATOS PARA CONSTRUIR UN ESTADO DE LA CUESTIÓN}

\section{1. ¿POR QUÉ DOS RELATOS?}

Tal como el título del capítulo lo anticipa, he tomado la decisión de plantear el estado de la cuestión a partir de dos registros, de dos aproximaciones, muy distintas entre sí. Fui jugador de handball, en diversas categorías y clubes inclusive, en la selección nacional-, he sido entrenador en ese deporte en clubes y seleccionados $y$, desde hace un tiempo, lo enseño también en la universidad a los estudiantes de Educación Física. La experiencia vivida y los requerimientos de la vida académica aparecen ante mí como dos mundos que, por momentos, se distancian y, otras veces, se superponen casi a la perfección, como ocurre con esas transparencias que, al yuxtaponerse, dan una imagen nueva, más compleja y rica que aquellas que le dieron origen. Es también por esa razón que, para esta primera sección, elijo el relato en primera persona del singular porque, aunque el cambio de etilo no parezca muy adecuado, me resulta más natural, más acorde con la propia experiencia.

\subsection{EN PRIMERA PERSONA: MI EXPERIENCIA COMO JUGADOR Y ENTRENADOR}

Elegir recorrer mi propia experiencia como jugador, como entrenador y como docente, me lleva a escribir una suerte de "estado de la cuestión en clave autobiográfica". No se trata de hacer prevalecer esa experiencia como una autorreferencia autorizada. Por el contrario, poner en primera persona estos problemas -entiendo- me ayudarán a guardar la distancia epistemológica, "a objetivar lo subjetivo"; o, al decir de Willis (1980), hacer la correspondiente "confesión teórica". Sin embargo, es preciso reconocer elementos del contexto que trascienden la experiencia personal.

Ubicarnos en un determinado contexto puede ayudar a entender el por qué de la elección de un tema, así como conocer los distintos cambios que se produjeron 
en la iniciación deportiva durante los últimos cuarenta años y las razones de la transformación de la enseñanza en los deportes abiertos. ${ }^{1}$ Estos van tomando una dimensión que no se puede visualizar si no entendemos los cambios de modelos que se produjeron en el tiempo. En la actualidad, en la formación inicial de los deportes, han cobrado capital importancia elementos ligados a la percepción de la situación y a la toma de decisiones (qué y cómo se percibe la información; cómo se interpreta y resuelve esa información; qué decisiones se adoptan; cómo se comprende el juego y -para los enseñantes- la forma en que es posible transmitir los contenidos).

Todas estas preguntas presentes en los responsables de la formación no siempre se formulan con la necesaria claridad al momento de comenzar a trabajar con un grupo. Durante mi formación profesional, esos interrogantes atravesaron y atraviesan cada proyecto con la expectativa de transformar las distintas formas de enseñar los deportes abiertos, las mismas que mencionaré e intentaré explicar en este trabajo, con especial mención en el handball. Si todo esto pudiera ser un aporte para que los profesores y entrenadores se permitan cuestionar y reflexionar sus estructuras de enseñanza, me sentiría muy satisfecho.

En los tiempos que corren debemos adaptarnos con rapidez e intentar darnos cuenta que es muy importante trabajar con un criterio más amplio, incorporando otras escenas y otros actores en la formación de esos futuros deportistas, ya que todas las estructuras fueron modificando sus contenidos de cara a la formación. No obstante, sin entrar de modo prematuro en el debate acerca de las ventajas y desventajas de cada modelo, es necesario reconocer que debemos acompañar la enseñanza práctica con una variada y criteriosa apoyatura teórica, y así

\footnotetext{
${ }^{1}$ Preferimos la denominación de deporte abierto tomando en consideración los aportes de la praxiología motriz, disciplina desde la cual se taxonomiza a los deportes en dos grandes ramas: deportes abiertos (o de habilidad abierta) y deportes cerrados (o de habilidad cerrada). Los primeros son aquellos en los cuales las acciones no son predecibles en función de las acciones del oponente (lo cual se traduce en términos praxiológicos como comunicación y contracomunicación motriz). Por su parte, dentro de los deportes abiertos, el handball corresponde al subtipo de deportes de invasión de campo, puesto que los desplazamientos de los jugadores no quedan restringidos a una zona correspondiente y exclusiva de su propio equipo.
} 
identificar los motivos por los cuales hemos de utilizar una determinada manera de trabajar para la formación.

Pero volvamos al relato sobre los modos de enseñanza en base a mi propia trayectoria. El sentido común parece indicar que si se consiguen logros deportivos, si se alcanza el éxito, eso justifica o autoriza el trabajo realizado. Me permito poner en duda esa afirmación y sospechar que el éxito depende de muchos factores -incluso, el fracaso ajeno- y que alcanzarlo no es más que el comienzo de un nuevo trabajo, de un nuevo desafío, de un nuevo planteo de lo que vendrá para las próximas temporadas. Con ese norte, es claro que las preguntas surgirán una tras otra: ¿Cómo puedo mejorar las resoluciones tácticas del juego? ¿Cómo puedo mejorar la toma de decisión de mis jugadores? ¿Qué tan bien entienden el juego en todas sus fases y sub-fases? ¿Comprenden todos del mismo modo a qué estamos jugando? ¿Por qué comienzan jugando veinte y terminan ocho? Estas son algunas de las preguntas que surgieron al momento de gestar este estudio; por ello, para empezar esta tesis se me ocurrió contar cómo fueron los distintos modelos por los cuales fui atravesando (o fui atravesado) en el desarrollo de mi formación deportiva y profesional.

En el año 1974 se da mi primer contacto con el handball, de la mano de mi profesor en Educación Física en la escuela, Ricardo Wrotniack, quien me lleva al Club Estudiantes de La Plata, inicorporándome en la categoría menores 12/13 años (se desprende de esa edad de iniciación que yo no transité la formación de mini e infantiles de este deporte, que soy uno de los tantos que comenzó con la actividad ya cursando los estudios secundarios). Sin embargo, a pesar del tardío comienzo, considero que tuve un desarrollo motriz básico bastante completo para la edad, pues había jugado al básquetbol desde los 8/9 años en el Club Atlético 9 de Julio, mi primer contacto con el deporte competitivo. Allí también hice mis primeros pasos en el modelo de enseñanza vigente en ese momento, el repetitivo, donde la imitación del modelo y la repetición de gestos técnicos era todo. Las consignas eran muy claras: “¡Dribling con mano derecha!” "¡Ahora con mano izquierda!” “¡En zigzag y finalizar con bandeja!” Recuerdo vagamente entrenar siempre lo mismo, circuitos cerrados de entrenamiento. El mejor jugador era aquel que lograba alcanzar el mejor gesto técnico: la perfección de 
éstos lo posicionaban frente al resto como un jugador diferente. Si se perdía un partido era sólo porque el rival estaba mejor preparado que nosotros técnicamente. Ahora, entender el juego, saber a qué jugábamos... para eso faltaba mucho.

Pasar al handball no modificó mucho lo aprendido en el básquetbol, ya que saber cómo hacer un gesto técnico también lo era todo: debíamos mejorar (repitiendo una y otra vez) las acciones para ser cada día mejores deportistas. De ese modo, realizar un pase que no estuviera contemplado en los libros era perder el tiempo; eso no estaba dentro de la lógica de los formadores. Si se producía esta situación, esta anomalía, el entrenador interrumpía la práctica para mostrar (una vez más) la técnica. Aquello que yo aceptaba con naturalidad en aquel momento, ahora me obliga a preguntar: ese gesto, ese modelo técnico, ¿era el correcto? ¿Por qué? Otro ejemplo de la época era que el zurdo debía pasar con tu "mano hábil”, como si la otra no fuese hábil; el manejar ambas manos era algo que podía molestar a muchos entrenadores: no importaba si lograbas el objetivo usando cualquiera de tus manos. Pero algo aún más extraño ocurría con el dribling, que sí se debía entrenar con ambas manos. Botar la pelota con ambas manos era correcto, pasar con ambas manos, no. Sólo después de cambiar de rol (de jugador a entrenador) me empecé a preguntar por qué. Y la respuesta inicial me pareció evidente: los formadores copiaban muchos ejercicios del básquetbol, y hasta para explicar el deporte nos decían que era una mezcla de fútbol y básquetbol. Un buen gesto técnico de pase y su recepción, un lanzamiento a pie firme o en salto podían llevar horas de repeticiones, para lograr una mejor calidad técnica; pero claro, nunca en situación real de juego. Por lo tanto, en el momento del juego formal la adaptación estaba siempre basada en los gestos ya aprendidos, que nos llevaban a desarrollar un juego lento, con muchas pausas... y sin sorpresas.

Desde la perspectiva que presento, los equipos más favorecidos durante el juego eran siempre los que menos errores cometían; podría pensarse que siempre era así. Es verdad: pero en la etapa de formación eran más los partidos que se ganaban por fallas del rival que por los aciertos propios. En síntesis, ganaba el que menos errores técnicos cometía; pero la mayoría seguíamos sin saber a qué 
jugábamos, sin comprender el sentido del juego. Quiero decir que no sólo quedaba comprometida la necesaria creatividad: estaba severamente dificultada la propia toma de decisiones.

En estas categorías de formación el pasar enfrentados, el lanzar, el salir de contraataque, eran situaciones pocas veces trabajadas con oposición en los entrenamientos: no jugábamos al handball, hacíamos que jugamos al handball. Se trataba de un simulacro de juego. Un entrenamiento era igual al otro: sabíamos que después de correr y realizar algunos desplazamientos coreográficos -sólo diferentes estéticamente a los de un bailarín del Bolshoi, pero igualmente estructurados, secuenciados y repetidos- vendrían los lanzamientos a los arqueros, unos contraataques y después, jugar. ¿Jugar? El orden de los factores no alteraba el producto, pues pasar y recibir, lanzar primero a pie firme y luego en salto, respetar el ciclo de pasos -si eras diestro debías hacer izquierdo/derecho/izquierdo y si eras zurdo, derecho/izquierdo/derecho-, no modificaba el sentido mecánico de la formación. No se podía salir o apartarse de ese modelo de entrenamiento, un modelo aburrido, repetitivo, donde siempre se presentaba la misma estructura, y donde se esperaba poder llegar al final del mismo para poder jugar 6 vs 6 y pasar a las diferentes fases y subfases del juego. ${ }^{2}$ De este modo, resolver distintas situaciones de juego es una situación que quedaba sólo para los partidos; allí debíamos arreglarnos con lo aprendido: si la respuesta no llegaba desde nosotros mismos (los jugadores), era muy normal mirar al banco (a nuestro entrenador), y así buscar ese auxilio, esa respuesta que sólo él tenía para ese momento.

Al llegar a la categoría de juveniles y juniors, los entrenamientos se modificaron un poco, sólo un poco. Aparecen en escena las "sistemáticas", jugadas preestablecidas. En parte las conocíamos, pues habíamos visto algo: las hacían

\footnotetext{
2 Existen discusiones en torno a cómo organizar o diferenciar las diferentes fases del juego. Sólo a los fines de dejar claro mi posición al respecto, me gustaría presentar las fases fundamentales del juego como dos: ataque (cuando el equipo está en dominio de la pelota) y defensa (cuando se ha perdido el control de la pelota). Los otros momentos considerados también como fases por diferentes autores (Laguna, Espar, entre otros) prefiero, de cara al sentido general de este trabajo -cuyo eje es la enseñanza- tratarlos como subfases. Tal es el caso del contraataque o del juego posicional (como subfases del ataque) y del repliegue y la oposición con repliegue (subfases de la defensa).
} 
los jugadores formados, los de primera división, los que pensaban el deporte "de otra manera". Hoy me pregunto si pensaban de otra manera o sólo repetían un repertorio apenas más amplio. Nosotros estábamos ahí, listos para trabajar como ellos, o mejor que ellos. Dar nuestros primeros pasos en esta etapa era como llegar a tocar el cielo con las manos, era el tiempo de incorporar nuevos conocimientos, era nuestro momento. Queríamos escuchar las palabras mágicas: "¡Va la cuatro!" "¡Hacemos la catorce!” Las mismas que escuchábamos de los jugadores de primera, y que sólo el armador central se encargaba de pronunciar. La orden llegaba y debíamos realizar todo en el momento justo, la disciplina era todo. Mentiría si dijera que nosotros no queríamos hacer "sistemáticas". Si realizábamos una jugada y la misma llegaba a su fin con un saldo positivo, era posible escuchar " “Cómo juegan estos chicos!" Una vez más: ¿Cómo juegan o qué tan bien repiten? Pero sí, jugábamos, porque así era el deporte de ese momento, fue el deporte que nos marcó un camino para ser mejores en el futuro que no tardaría mucho en venir. La percepción subjetiva era que eso era un juego, así lo experimentábamos.

Debíamos cumplir en un ciento por ciento con lo que habíamos hablado y entrenado hasta el cansancio, de todas formas rara vez salía bien. Se escuchaba "si el extremo circula, vos debés pasar por delante de la defensa, después del cruce entre central y lateral, debe recibir el pivote y lanzar". No existían posibilidades de hacer grandes modificaciones, se veía mal la no finalización de la jugada, tanto por los compañeros como por el entrenador: no importaba cómo finalizaba sino si se llevaba adelante el plan trabajado. Eso era lo que se había trabajado durante semanas: había que ser un equipo disciplinado, ordenado, prolijo. Los más atrevidos eran los que intentaban romper esas estructuras, y cuando las rompían... mejor que terminaran bien. Se podía escuchar: "¡Bravo!" "¡Muy bien!" Todos los felicitaban; pero siempre venía la recriminación del entrenador: "Bien... pero, seguí la jugada"; o de tus mismos compañeros: "Sí, fue gol. Pero la próxima seguí la jugada." No importaba si era gol, si tu decisión fue correcta o no, lo importante era hacer lo que estaba planificado. En esta etapa se acentuó más la preparación física para obtener una mayor potencia en las técnicas específicas del deporte. 
Durante el año 1980 me convocaron a la Selección Argentina Junior, cuyo destino final era formar parte del equipo adulto que disputaría en nuestro país el Segundo Torneo Panamericano Adulto clasificatorio para el mundial de Alemania. Así fue como comenzamos a entrenar todos los días. Mi expectativa era muy grande: después de unos meses de entrenar observé que, si se respetaban las formas, mis posibilidades de ser parte de esa selección eran muchas. Los entrenamientos eran siempre iguales: se hacía un acondicionamiento previo, luego ejercicios de pasar y recibir (primero en el lugar, después en movimiento), lanzamientos a los arqueros (seguido de lanzamientos desde los puestos específicos), un poco de contraataque, las sistemáticas (que siempre eran las mismas que hacían todos los clubes) y por último defensa y ataque (por separado primero, y luego el 6 vs 6: todo un clásico de la época). Era como entrenar en tu club, pero con los mejores jugadores de ese momento. Con el tiempo esta escuela desarrollada por los países de Europa del Este, potenciaron la técnica y la disciplina como eje central de todo. De este modo, tanto Alemania, Rusia como Yugoslavia logran sus títulos mundiales con esta estructura de trabajo y formación. Es ahí donde se hace más fuerte la idea del desarrollo de la técnica sobre la táctica; la repetición estaba por encima de todo; la calidad que se necesitaba para jugar la debíamos encontrar en el orden y la disciplina; lo que se hacía durante todos los entrenamientos, debíamos repetirlo en los partidos; si perdíamos con el rival era porque entrenaban más horas que nosotros; ellos con su juego lento, con gestos técnicos de libro, con todo muy previsible, igual eran los mejores del mundo.

Los autores de la época (Lasierra, Pons, de Andrés, García Cuesta) le dedicaban hojas y hojas a explicar cómo debían ser cada uno de los movimientos técnicos, cómo se debía colocar la pierna de pique, cómo se debía poner la pierna de apoyo, cómo debía ser el salto. Y cómo defendían, atacaban, se replegaban y contraatacaban Rusia, Alemania y la misma Yugoslavia. Copiar y repetir hasta lograr ser como ellos, pero cuando alcanzábamos su estructura deportiva ellos ya estaban cambiando, estaban en otra fase de su desarrollo. ¿Cuándo buscaríamos nosotros nuestra propia identidad de juego y formación? Debemos saber que en esa década se consideraba que todo lo que venía de Europa era 
mucho mejor y por esa razón, esta escuela marcó todo una época: las defensas 6-0 eran muy cerradas; los jugadores debían ser altos, de 1,90 m como mínimo; los bloques defensivos eran muy compactos; los equipos debían tener lanzadores potentes, sobre todo muy explosivos, para poder después del ciclo de pasos ejecutar un lanzamiento perfecto. Esto llevaba a la mejora de los saltos y los lanzamientos, que debían ser perfectos técnicamente; por su parte, la fuerza y la potencia conformaban una combinación letal para la época.

A partir del año 1985, el club Estudiantes de La Plata comienza a cambiar sus entrenamientos. Esto coincide con el regreso al club, después de su paso por España como jugador, el profesor Mauricio Torres. La dirigencia le ofrece tomar la dirección técnica del equipo de primera división y coordinar la formación de las categorías inferiores. El primer gran cambio que vimos fue la incorporación a los entrenamientos de muchos trabajos físicos con la pelota, dentro del campo de juego. Se agregan muchas horas de gimnasio: hasta ese momento, ese entrenamiento solo parecía adecuado para los jugadores de rugby y los deportes de combate; las pesas eran un tema del que no se podía hablar, porque -decíante quitarían movilidad y generarían en tus movimientos gestos muy rudimentarios. Pues bien, ahora debíamos estar muy fuertes, así como estaban los europeos. Cambiar nuestras estructuras de trabajo no fue fácil, fue toda una etapa de adaptación la cual nos trajo muy buenos resultados.

Me gradué como profesor en educación Física a fines de 1984. Luego la vida me lleva a radicarme en la ciudad de Buenos Aires y en el año 1989 comienzo a jugar en la Unión General Armenia de Cultura Física. Este club estaba conducido técnicamente por el profesor y entrenador Enrique Menéndez, quien a su vez conducía la Selección Argentina de Mayores. La adaptación fue muy difícil para mí, pasé de un sistema de entrenamientos estructurado a algo muy diferente. Desde el comienzo la preparación física estaba dentro de la cancha, en el rectángulo de juego. A los entrenamientos de adaptación al balón que todos teníamos, le incorporábamos trabajos de coordinación individual, en parejas; el balón formaba parte de nosotros todo el tiempo (es más: cada uno tenía su propio balón y era responsable del mismo), debíamos sentirlo como un miembro más de nuestro cuerpo. Recuerdo hacer giras y que cada jugador debía llevar 
en su bolso su balón, limpiarlo después de cada entrenamiento. El balón siempre presente en todos los trabajos, de eso se trataba: que el elemento sea una motivación más a la hora de trabajar.

A pocos meses de estar en mi nuevo club, soy convocado nuevamente a la Selección Argentina, los trabajos en este momento no me resultaron tan difíciles, ya que el entrenador era el mismo que tenía en el club. Menéndez tenía una forma muy particular de entrenar y conocer su trabajo me ayudó a que mi adaptación fuera mucho más rápida. Otros jugadores, los convocados del Club Ferrocarril Oeste, que trabajaban con el profesor Jorge Meccia -segundo entrenador de la selección Argentina en ese momento y primer asistente durante doce años de Menéndez- pasaron por procesos similares a los míos. Esta etapa que duró cuatro años fue un antes y un después en mi formación deportiva y profesional. Sin dudas se operó un cambio en la manera de observar el deporte. Los trabajos ya no eran de 6 vs 6 ya que en ese momento se diversificaban los trabajos: las defensas y los ataques no se separaban, comenzábamos con 1 vs 1,2 vs 1,2 vs 2,3 vs 2 y así sucesivamente. Las defensas eran siempre en inferioridad numérica, pues la idea era favorecer al ataque y estimular la movilidad defensiva; los trabajos de disuasión, de interceptación, de acoso, comienzan a tener una importancia fundamental, la incorporación de los gestos defensivos que debían ser ordenados y coordinados con las ayudas de nuestros compañeros. Se hacían trabajos por sectores específicos, debíamos conocer y trabajar en todos los espacios, se priorizaba el juego en relación, los compañeros colindantes, cada uno de nosotros era el verdadero jugador universal: podía y debía jugar en cualquier puesto más allá de su puesto específico.

El handball había cambiado, por lo menos para mí era otro deporte. Ya no el deporte lento, con técnicas repetidas: era un deporte de mucha velocidad de reacción, fuerza explosiva y potencia; con resolución de situaciones tácticas, y ya no con sistemáticas preestablecidas, pues las respuestas debían ser rápidas, todo un desafío. "Si me apuro, me equivoco." Por ejemplo: desde ese momento, un buen armador lateral no era solo aquel que podía lanzar en salto y ser efectivo, también lo era aquel que la misma dinámica del juego lo ponía en el extremo o en el pivote después de un desdoblamiento; entonces debía saber 
lanzar de esos puestos de los cuales nunca hubiese pensado que podía llegar a lanzar.

Mientras continuaba jugando en la selección y en el club, entrenaba las categorías de menores, cadetes y juveniles, de la Unión General Armenia. Este fue el trampolín que me arrojó a bucear en la formación, semanalmente nos reuníamos a estudiar con Menéndez, quien no solo nos explicaba el por qué y para que de cada trabajo, sino que nos daba su amplia bibliografía para que consultemos.

En 1992 Enrique Menéndez se aleja del club y deja de ser el entrenador. Y es ahí donde comienza una nueva etapa con un referente del handball mundial, como jugador y entrenador de Selecciones: el cubano Roberto Casuso Mariño, quien ejerció más influencia en lo grupal que en lo técnico -a pesar de traer la metodología de trabajo propia de los países de Europa del Este y de su gran experiencia como jugador y entrenador internacional-. Pocos años después, en 1995/96, el presidente del club me ofrece, y dirigir a mis propios compañeros. Ese ofrecimiento junto con la evidencia de que mis 35 años me pasaban factura todos los partidos hizo que mi decisión sea rápida y contundente: dejar de jugar y dedicarme a dirigir a mis propios compañeros. No resultó sencillo, dado que éramos no solo compañeros en el club sino también en la selección argentina con cinco de ellos. Continué entonces con el modelo de trabajo que teníamos tanto en el club como en la Selección. Pero mi trabajo era muy desordenado, era una mezcla de modelos; tenía las ideas, pero no podía sistematizarlas. Gracias a la tolerancia y al afecto de mis compañeros pude sortear las dificultades y disimular los errores. Pero un día, un gran amigo -por añadidura, compañero de selección, del club, profesor en Educación Física-, Gonzalo Osores Soler, me pide hablar. La reunión se realizó en el bar del club. Gonzalo llega con un libro, según él, "un tesoro", y me dice: "Esto es para vos". Se trataba de De la escuela a las instituciones deportivas, de J. Marriot. Me recomendó leerlo y comenzar a trabajar desde la toma de decisión, desde la organización del entrenamiento, del cómo, del por qué y para qué hacíamos las cosas. Aún conservo ese tesoro. Además, fue, sin lugar a dudas, un grupo brillante, de esos grupos que hacen historia, un grupo que me brindó una gran ayuda en ese momento de mi 
formación. Ese año logramos tres campeonatos, y un subcampeonato, sobre un total de cuatro torneos disputados.

En paralelo con esta posibilidad de entrenar a un gran equipo de primera, me surge la alternativa de poder trabajar en el colegio Parroquial San Pablo Apóstol, en el nivel primario, donde decido poner en práctica unas ideas que venía madurando para la enseñanza del deporte en la escuela. Pero allí el desafío se hace más complejo, pues con clases mixtas, enseñar un deporte con mucho contacto físico no parecía muy conveniente en ese entonces. A esto se sumaba una opinión negativa de la directora de ese momento, quien opinaba que las características físicas muy distintas entre ambos sexos y el reducido espacio cerraban el paso a esa práctica en la escuela.

Más allá de esas dificultades, y a pesar de que había un mandamiento implícito ("queda terminantemente prohibido decir que el handball es jugar al fútbol con la mano"), la manera más fácil de explicar el juego seguía siendo la que yo mismo había aprendido a los doce años: una fusión de básquetbol y fútbol. Entonces recordé a mi profesor de sóftbol de la Universidad, quien nos enseñó a jugar ese deporte comenzando con una pelota de fútbol, la cual se pateaba para abrir el juego en lugar de golpearla con un bate. Me pregunté por qué no hacer algo similar y los resultados no tardaron en llegar, gracias a la decisión simple de partir de un deporte conocido o popular para desarrollar otro menos conocido. La explicación de ese trabajo quedará para otro momento; pero, descubrir que los alumnos de $4^{\circ}$ y $5^{\circ}$ grado comprendían el juego, que se divertían, que no dejaban el club, y que fundamentalmente cumplían con los principios del deporte tanto en ataque como en defensa, me daban ese aire que necesitaba para seguir explorando ese camino, una manera distinta de enseñar el handball.

En resumidas cuentas, esa manera estaba relacionada con el juego; pero no con el juego formal, sino con juegos de cooperación y oposición. Lo conocido, lo significativo de las actividades, me daban la posibilidad de incorporar reglas básicas del deporte y algunos limitantes para un mejor desarrollo de las actividades planteadas. Comenzaba a romper mi círculo de confort, salir del espacio donde durante muchos años me había manejado sin problemas, a 
ordenar nuevos pensamientos. De alguna manera, contrarié el refrán: preferí lo bueno por conocer...

Llega el año 2001. A algunos entrenadores se nos brinda la posibilidad de viajar a a Madrid con el objetivo de participar en el Curso de Entrenador Nacional Español que dicta la Real Federación Española de Balonmano, Nivel 1. Finalizado el mismo, pudimos asistir a las semifinales, al partido por el $3^{\circ}$ puesto y a la final del Mundial Adultos Caballeros que se estaban disputando en Paris; y así pudimos ver en el estadio, al mayor nivel internacional, lo que nos habían presentado en el aula y en el gimnasio. Fue una ocasión única: tomar clases con los autores que había leído, tenerlos a mano para sacarme todas las dudas, que en rigor de verdad fueron muchas. Eran los mejores entrenadores: Paco Sánchez, César Argiles, Juan de Dios; pero, sobre todo, Manolo Laguna Elzaurdía, un gran entrenador y mejor amigo, que me llevó a comprender este deporte y entender a Marriot, Martiniuk, Xesco Espar y tantos otros. Él lo decía así: "Hacer fácil lo difícil".

A partir de esa experiencia, todos los que participamos de ella comenzábamos a preguntarnos: ¿Qué aprende el que aprende? ¿Cómo aprende el que aprende? ¿Cuándo aprende el que aprende? ¿Qué percibe el que juega? ¿Cómo desarrolla la toma de decisión el que juega? ¿Cuándo por qué puede mejorar esa toma de decisión? Me fui convenciendo que si el que enseña observa al que aprende, juntos pueden construir un camino para la formación. La teoría aprendida comenzaba a respirar la práctica del juego y a transformarse en un proceso vital.

Como si el destino jugara en mi equipo, después de aquella instancia de formación, fui nuevamente convocado a la selección argentina, pero ya no como jugador sino como primer entrenador de las categorías de cadetes y juveniles de damas, y como entrenador asistente en juniors y mayores. A la felicidad que representaba semejante reconocimiento se sumaba la oportunidad de llevar a la práctica estos conocimientos incorporados pero siempre con la intención de marcar una línea diferente. 
El Campeonato Mundial de Francia de 2001 dejó en el análisis que ya no ganaban los que mejor técnica dominaban: el predominio de la técnica sobre la táctica estaba en su final, por lo menos en ese momento de la historia. Los franceses comenzaban a imponer su trabajo: la táctica sobre la técnica. Ya no es tan importante una técnica bien desarrollada, una técnica de libro, sino adaptar gestos para lograr un objetivo: la mejor técnica es aquella que es efectiva. Y pude ver el nacimiento del nuevo balonmano. Francia y su escuela de formación marcaron un camino que no deja de sorprendernos: campeón mundial en su casa en 2001 y, desde ese momento, campeón en tres juegos olímpicos, seis mundiales, copas europeas, y cuanta competencia se presentaran. Francia marcó una manera de jugar y de hacer escuela; la formación inicial, su forma de trabajo organizado baja de la federación francesa para todas sus asociadas, todos los clubes trabajan igual, todos con una idea clara de qué y cómo se debe trabajar en cada categoría. No es exagerado suponer que esa organización llevó a ese país a ser potencia en este deporte, tanto en la rama masculina como femenina.

Después de entrenar varios equipos de Liga de Honor, Selecciones Nacionales masculinas como la de Argentina y la de Chile y la Selección Argentina femenina universitaria de handball (campeona sudamericana en 2016), puedo afirmar que, en definitiva, "se juega como se entrena". Por esa razón, el presente trabajo tiene como objetivo el análisis de la iniciación deportiva y de los distintos modelos de enseñanza del deporte, en particular en el handball, para generar un aporte a las prácticas de la enseñanza. Como se puede advertir, la perspectiva de la que parto es la de la complementariedad de los distintos enfoques y modelos investigados, pero haciendo eje en el modelo comprensivo, el modelo estructural, la resolución de problemas y, en ocasiones, la instrucción directa. En el trabajo se enfatiza que dichos modelos buscan resolver los diferentes problemas de la enseñanza desde enfoques diferentes, perspectivas que muchas veces erróneamente se perciben como antagónicas. Por esa razón, la presente investigación se orienta a las posibles articulaciones de los modelos de enseñanza que los formadores pueden ofrecer, para poder abarcar las múltiples 
necesidades de los alumnos al momento de aprender, prestando especial atención a las estrategias visuales puestas en juego.

Siempre nos preguntamos qué debemos enseñar primero a los niños que recién comienzan con la actividad. La variedad de autores que se presentan en las bibliografías de iniciación de deportes de conjunto y en especial de invasión de territorio como lo es el handball nos presentan etapas o modelos estructurados como algo cierto y fina. Pero, ¿debo enseñar esto o aquello forzosamente en esta etapa? ¿Por qué? ¿O debemos los docentes y los entrenadores pensar la formación desde otros ángulos posibles? Salir del modelo único tal vez sea un buen camino.

\subsection{EN TERCERA PERSONA: LO QUE DICE LA BIBLIOGRAFÍA SOBRE EL TEMA}

En el armado de un estado de la cuestión, la primera cuestión a relevar es la caracterización de los deportes de conjunto. Cavalli (2008) afirma que, a la hora de mirar y analizar la estructura y el desarrollo de las acciones motrices de los deportes de conjunto, algunos analistas han observado que los objetivos de estos juegos deportivos se alcanzan, básicamente, a través de la ejecución de un conjunto de gestos técnicos, bien coordinados y encadenados. Otros han observado que tales fines se consiguen, fundamentalmente, a través de la puesta en acto de unos procesos mentales basados en una correcta lectura del juego y toma de decisión. Están también aquellos que han advertido que la base del juego se construye a partir de una clara comprensión de sus principios tácticos, y por últimos, los que, desde una mirada más holística, pensaron que el éxito en la consecución de dichas metas depende de la interacción de un conjunto de elementos o factores que conforman una estructura.

A su vez Blázquez Sánchez (1986), dice que, para poder elaborar una acción pedagógica integrada en una educación física, es necesario, precisar las características diferenciales de cada actividad física. El mencionado autor describe que la opinión vulgar y más generalizada sobre el concepto de los deportes en conjunto es que el equipo es una suma de jugadores, es decir, que 
la calidad del equipo está en función del conjunto de las cualidades de los jugadores que lo componen. Sin embargo, esta opinión general, que suele ser la del público, no responde exactamente a la realidad. La suma de las partes no es igual al todo. Un jugador juega "junto a otros" y "frente a sus adversarios". Un partido es la confrontación de dos grupos de fuerza.

Muchos entrenadores creen comprender y conocer la noción de equipo a través de las recetas extraídas a otros equipos superiores. Su bagaje de conocimientos está compuesto, muy a menudo, por pequeños trucos, y algunos conceptos tácticos extraídos de algún manual. El entrenador crea los sistemas de juego a partir de las características de los jugadores. El entrenador intenta que sus jugadores asimilen y memoricen los patrones de juego considerados indispensables. El "experto" modela a sus jugadores según ciertos estereotipos motores, subordinando a los jugadores a normas aceptadas, tanto sobre el plano técnico, táctico o de preparación individual. De esta manera, la motricidad del jugador se debe someter a los "conocimientos" del entrenador.

Volviendo a Cavalli, en los deportes de conjunto se pueden identificar los debates en torno a la incidencia de diferentes elementos en los cuales hace eje la enseñanza: la técnica (tradicional), la tarea motriz (Le Boulch), la táctica (Bayer), la perspectiva estructural (Parlebas) o la estructura funcional del deporte (Blázquez Sánchez).

Para continuar con el armado de un estado de la cuestión, la segunda cuestión a relevar es la problematización de la iniciación deportiva. Según Blázquez Sánchez (1986) desde el punto de vista educativo, el proceso de iniciación deportiva no debe entenderse como el momento en que se empieza la práctica deportiva, sino como una acción pedagógica que, teniendo en cuenta las características del niño y los fines a conseguir, van evolucionando progresivamente hasta llegar al dominio de cada especialidad. Para precisar más detenidamente este proceso, es necesario tener presente diferentes aspectos: relativos al niño (el grado de desarrollo o maduración, el grado de estimulación que se le proporciona, el grado de experimentación) y relativos a la pedagogía utilizada (método tradicional o método activo). 
Hernández Moreno (2000:11) afirma que el período en el que el individuo empieza a aprender de forma específica la práctica de un deporte o conjunto de deportes es lo que se conoce como Iniciación Deportiva. Sin embargo, contraponiéndose a esta idea, Diem (citado en Hernández Moreno, 2000), afirma que la iniciación deportiva puede producirse mucho antes que el sujeto tenga contacto con ese deporte en concreto, a través de actividades facilitadoras para la posterior práctica deportiva. Hernández Moreno (1986) prefiere afirmar que "La iniciación deportiva es el proceso de enseñanza-aprendizaje, seguido por un individuo, para la adquisición de la capacidad de ejecución práctica y conocimiento de un deporte. Este conocimiento abarca desde que el individuo toma contacto con el deporte hasta que es capaz de jugarlo con adecuación a su estructura funcional”. Así, un sujeto está iniciado en un deporte, cuando, tras un proceso de aprendizaje, adquiere los patrones básicos requeridos por la situación motriz específica y por la especialidad de un deporte, de manera tal que además de conocer sus reglas y comportamientos estratégicos motores fundamentales, sabe ejecutar sus técnicas, moverse en el espacio deportivo con sentido del tiempo, de las acciones y situaciones, sabiendo leer e interpretar las comunicaciones motrices emitidas por el resto de los participantes en el desarrollo de las acciones motrices.

Entre los factores a tener en cuenta en la iniciación deportiva, siguiendo a Hernández Moreno -quien a su vez toma sus ideas de Parlebas-, se pueden reconocer el sujeto, el deporte específico y el contexto. Por su parte, Blázquez Sánchez (1986) alude a los siguientes elementos: el niño (maduración y desarrollo), lo pedagógico (periodos críticos), la estimulación y la experimentación, los métodos (tradicionales y activos).

Otro debate de interés en la Iniciación Deportiva es el relativo a las etapas. Recorriendo las diferentes propuestas -como las de Hernández Moreno (2000), Leali (2000) o Mondini (1983)-, entendemos que existe una posición bastante generalizada en torno a reconocer una etapa de Formación Básica, una etapa de Formación Específica y una etapa de Perfeccionamiento Deportivo. Esta cuestión de las etapas centradas en los procesos de quien aprende puede combinarse con la perspectiva de la estructura de los deportes. Así lo entiende 
Wein (citado en Hernández Moreno, 2000), para quien existen diferentes niveles. $1^{\circ}$ nivel: juego de habilidad y capacitación de base (juegos polivalentes y habilidades básicas); $2^{\circ}$ nivel: juego simplificado (prácticas simplificadas de juegos similares al deporte que se aprende); $3^{\circ}$ nivel: minideporte (el deporte de que se trate con número reducido de participantes); $4^{\circ}$ nivel: juego modificado (simplificación de las reglas de juego del deporte); y $5^{\circ}$ nivel: juego reglamentado (práctica del deporte como tal). Por último, Vankersschaver (1982) expone una estructuraron en tres fases: $1^{\circ}$ Fase: centración (familiarización con el espacio, técnicas básicas y elementales, estrategias simples, reglas fundamentales e interacciones sustantivas); $2^{\circ}$ fase: descentración (espacio específico básico, técnicas aplicadas, estrategias combinadas e interacciones combinadas); y $3^{\circ}$ fase: estructuración (espacios combinados y aplicados, técnicas en función de la estrategia, estrategias complejas e interacciones complejas).

Para finalizar el armado de un estado de la cuestión, la tercera cuestión a relevar es la enumeración crítica de los métodos de enseñanza. Uno de los modelos a considerar es el de la resolución de problemas. Según Sánchez Bañuelos (1992) la enseñanza mediante la búsqueda es una idea interesante y muy sugestiva para el docente dentro del campo de la Educación Física y el deporte, ya que desde el punto de vista educativo pedagógico ofrece una serie de ventajas importantes que no concurren en otras técnicas de enseñanza, entre las cuales podemos citar que: establece una relación clara entre actividad física y actividad cognitiva, destaca aspectos de la educación física de carácter intelectual, justifica la idea de que la Educación Física no está preocupada solamente por el desarrollo muscular, favorece un proceso emancipatorio concediendo al alumno una capacidad de decisión significativa, amplía el campo de acción de la docencia en la Educación Física y el deporte a aspectos no tenidos en cuenta hasta la aparición de este concepto de enseñanza e individualiza la enseñanza. También se refieren a este estilo Cavalli (2008), Rubenstein (citado en Cavalli, 2008), Riviere (citado en Sánchez Bañuelos, 1992), Marteniuk (citado en Sánchez Bañuelos, 1992) y Onofre (1998).

Un modelo tal vez contrastante con el anterior es el de la instrucción directa. Siguiendo a Sánchez Bañuelos (1992), se observa que en muchas tareas 
motrices, el rendimiento mecánico es un factor vital para que el objeto propuesto se pueda conseguir eficazmente. Si para muchos problemas existen multitud de soluciones, cuando pesa el factor rendimiento, en menos tiempo, con el menor esfuerzo posible, las soluciones válidas se reducirán a muy pocas. Este tipo de problemas motores se le plantean al niño muy pronto y en general, no tiene mucha dificultad en descubrir por sí mismo, a partir de la información que el medio ambiente le proporciona, una serie de soluciones. El mecanismo de aprendizaje por imitación es de gran importancia en este sentido: el niño se encuentra con unas dificultades que superar, percibe como los otros las resuelven y trata de imitarlos. La mayoría de los problemas motores que se plantean de forma natural exigen un cierto grado de eficacia; esto hace que una serie de soluciones idóneas se acepten de modo generalizado. Cuando en la realización de una tarea motriz interviene además el componente lúdicocompetitivo, la necesidad de rendimiento alcanza su máxima expresión. Se sabe que hay problemas motores cuya solución eficiente se concreta en una alternativa de ejecución motriz que puede ser bien definida. Cuando el profesor ante la enseñanza de este tipo de problemas motores proporciona al alumno una información directa sobre la solución de ese problema, indicando cómo debe realizar su ejecución, diremos que está utilizando una técnica de enseñanza mediante instrucción directa. Esta técnica define un procedimiento de enseñanza muy concreto y bien conocido, con dos puntos de arranque que pueden sintetizarse de la siguiente forma: existencia de una solución de probado rendimiento y bien definida y comunicación por parte del profesor al alumno de esa solución. También reflexiona sobre este método Cavalli (2008).

Un modelo alternativo a los mencionados es el conocido como comprensivo. Opina Cavalli (2008) que los principios tácticos no se adquieren de forma aislada, sino que se aprenden, normalmente, en los contextos mismos del juego. Por medio de estos últimos, se favorece y estimula la posibilidad de que los alumnos los descubran por sí mismos, e identifiquen las situaciones motrices en las cuales deben aplicarlos. Según investigaciones realizadas en Inglaterra a principios de la década del 70 , se vino desarrollando un enfoque para la enseñanza de los deportes de conjunto dominado comprensivo o centrado en la táctica. Este 
enfoque hunde sus raíces en la psicología de la Gestalt. El punto de partida de esta corriente psicológica es que los objetos y los acontecimientos se perciben como un todo organizado. Partiendo entonces de los supuestos que la conducta es una totalidad organizada y que la comprensión parcelada y fraccionaria de la realidad deforma y distorsiona la significación del conjunto, postularon que tan importante o más que entender los elementos aislados de la conducta, tiene que ser comprender las relaciones de codeterminación que se establecen entre los mismos a la hora de formar una totalidad significativa. En el marco de estas ideas, se apoya uno de los postulados centrales del enfoque comprensivo para la enseñanza de los deportes de conjunto y, más específicamente, de los aspectos tácticos. El contexto y los problemas del juego son inseparables y ambos se relacionan con su táctica hasta el punto en que, para resolver los problemas motrices que surgen dentro del contexto de juego, será necesario comprender los principios tácticos básicos. Por lo tanto, una enseñanza para la comprensión en los juegos deportivos debe abordar el aprendizaje de los aspectos tácticos. Desde esta última visión, la comprensión es entendida como la habilidad de pensar y actuar con flexibilidad a partir de lo que uno sabe. La asunción de una visión de la comprensión vinculada con el desempeño ha permitido pensar en la posibilidad de la transferencia de los principios tácticos al interior de un conjunto de deportes cuya naturaleza problemática es similar. En suma, la lógica del modelo comprensivo enfatiza, en primera instancia, la necesidad de pensar la enseñanza desde los contextos mismos de juego, en tanto los aprendizajes aislados no tendrían sentido para los jugadores. $Y$ en segunda, el requisito de desarrollar, a partir de tales situaciones, los procesos de reconocimiento y comprensión de los principios tácticos comunes a cada categoría en los que se dividen los juegos deportivos. Otros autores que hablan del modelo de la comprensión son Arnold (1991) y Devís Devís y Peiro Velert (1992).

Por último, relevaremos el modelo estructural. Hernández Moreno (2000) opina que, en la enseñanza de la actividad física y deportiva, es necesario hacer una transformación radical de la gran mayoría de los conceptos en uso, de manera que se acepte que no se enseñan tareas, gestos, fragmentos de habilidades, 
montajes comportamentales, sino estructuras, incluso reglas o principios organizadores de nuestros movimientos. Según Cavalli (2008) las bases del modelo estructural pueden hallarse en el rechazo a dos supuestos: por un lado, que el conocimiento tiene una naturaleza acumulativa, y por otro, que cualquier actividad o conducta puede descomponerse en sus partes constitutivas. En oposición al elementalismo y al asociacionismo, los partidarios de esta corriente se empeñan en estudiar los rasgos estructurales y globales de los deportes de conjunto. Al admitir que estos últimos no son simples acumulaciones de elementos o rasgos desvinculados entre sí, el modelo estructural deviene en un enfoque de tipo molar que se preocupa por estudiar los fenómenos en su totalidad. A su vez, estos principios y postulados apoyan la creencia de que solo la adquisición de los rasgos estructurales de estos deportes permite la solución de los problemas que emanan del juego. Uniendo estos conceptos con propuestas de enseñanza, Hernández Moreno (citado en Cavalli, 2008) sostiene que éstas deben asumir una orientación particular, siendo así que las tareas que se diseñen deben, por lo general, tener significación práxica, para que así los practicantes se enfrenten a la resolución de situaciones motrices en las que predomine la adquisición de conceptos y estructuras en vez de la realización de ejercicios y gestos. La difusión de estos estudios ha permitido tomar conciencia de que los deportes de conjunto presentan como rasgo más significativo el hecho de que se da simultáneamente la cooperación y la oposición entre individuos, con lo que las interacciones son a la vez negativas y positivas, y que como consecuencia de ello el factor de decisión o comportamiento estratégico se convierte en predominante para la puesta en acción o desarrollo practico. También se refieren a esta perspectiva Bonnefoy, Lahuppe y $\mathrm{Ne}$ (2000).

A modo de anexo y dado que hemos aludido a la cuestión estructural, es oportuno señalar que Blázquez Sánchez (1999) establece otra estructura funcional de los deportes de equipo, teniendo en cuenta las posturas de varios autores que han estudiado los componentes comunes a los deportes de equipo $y$, basándose en una concepción estructuralista, han determinado que existen unos elementos que se repiten y que conforman la realidad del juego. 
Desde esta perspectiva, afirman que todos los deportes de equipo están sometidos a principios comunes e idénticos: es lo que se denomina "estructura funcional". Estos principios varían según el enfoque sobre el que se apoya cada tendencia. Una primera aproximación la constituirá aquella que se centra sobre la noción de duelo; es decir, el carácter de colaboración y oposición, de ataque y defensa. En este planteamiento, la estrategia o el acto táctico ocupan el centro de atención. Una segunda perspectiva sería la que gira en torno a la comunicación, positiva o negativa entre los jugadores que participan, creando un lenguaje motriz insólito y específico de los deportes de equipo. Una tercera propuesta ve en la utilización del espacio la forma de materializar de forma intencional la interpretación de un mensaje y su respuesta en forma estratégica. Por último, se situaría el reglamento, que constituye el sistema de reglas capaz de regular el funcionamiento del juego y de determinar cómo se gana o cómo se pierde.

Todos ellos pueden ser útiles para ayudar a construir y regular acciones que permitan progresar al niño hacia la comprensión de la lógica interna del juego, así como ser el punto de partida para la acción motriz. Así pues, se asienta la estructura funcional de los deportes de equipo sobre estos principios. El espacio, terreno cerrado, más o menos grande, en el interior de cual se desarrolla la competición. Constituye el límite de acción de los jugadores. La estrategia, tipos de conducta que puede utilizar el jugador en cuanto a las diferentes formas de actuar en ataque o defensa. La comunicación motriz, lenguaje que utilizan los jugadores para realizar las acciones de comunicación o de oposición. Las limitaciones reglamentarias, que varían según los diferentes deportes, aunque manteniendo unas características comunes.

De todos estos elementos analizaremos, a modo de ejemplo, el espacio. Blázquez Sánchez (1999) describe que, el lugar o espacio de acción donde se desarrolla cualquiera de los deportes de equipo posee unas características constantes; es cerrado, institucionalizado, y sus dimensiones son estrictas y precisas. Su superficie se presenta marcada por líneas en el suelo que limitan las acciones de cada jugador. El terreno suele estar dividido en sub-espacios, "áreas" o "zonas" diversas. A su vez, intervienen de forma estandarizada, 
obstáculos (redes), metas u objetivos (postes, porterías, cestas, etc.) que distribuyen o dividen este espacio, incitando a organizar una acción coherente. Cada jugador debe compartir este espacio con el resto de sus compañeros. Aun siendo imposible poder fragmentar el espacio deportivo como escenario de toda la acción, si se puede distinguir para su estudio varios tipos de espacio que poseen características muy diferenciadas.

El espacio como distancia a franquear o recorrer: todo espacio deportivo posee unas dimensiones exactas en las cuales el jugador debe moverse o franquearlas. La táctica está basada en unas distancias sobre las que hay que desenvolverse: desmarcar, intercambiar, combinaciones a dos, a tres, a cuatro, etcétera. Estas distancias no sólo tienen importancia en el sentido propiamente espacial, sino de una forma importante sobre las exigencias fisiológicas.

El espacio dividido en subespacios diferenciados: cada jugador se encuentra enfrentado a espacios dinámicos funcionalmente unidos entre ellos, que toman un sentido propio en función de la evolución del juego y que va a condicionar su situación sobre el terreno. Entre estas zonas para poder moverse se pueden hacer distinciones. Por un lado, encontramos las zonas fijas (prohibidas: superficies donde el jugador no puede evolucionar; zonas en cuyo interior los jugadores están sometidos a ciertas reglas); zonas variables (prohibidas: zonas móviles que dependen del desplazamiento de los atacantes o de los defensores, en el interior de las cuales el jugador no tiene posibilidad de jugar; a utilizar por los atacantes: todos los espacios libres que, situados delante del jugador que lleva el balón, constituyen zonas de apoyo; a vigilar, es decir, zonas de las que por su peligrosidad el defensor va a ocuparse particularmente, para oponerse al paso del balón o del adversario). La distribución del espacio deportivo en emplazamientos diferenciados es uno de los factores que determinan la lógica del juego.

El espacio como meta u objetivo a lograr. Para ganar un partido es necesario marcar más puntos o tantos que el contrario, es decir, lograr que el balón llegue a penetrar, tocar o traspasar un blanco preciso. Estos blancos son espacios siempre fijos y corresponden a lugares preparados. Para los otros deportes 
colectivos, el objetivo es una portería (fútbol, handball, etc.), o una canasta (básquetbol). En cualquier caso, el punto o tanto se logra cuando el balón toma contacto con una zona de terreno o cuando franquea un plano vertical $u$ horizontal.

\subsection{BIBLIOGRAFÍA DEL CAPÍTULO}

Arnold, P.J. (1990) Educación Física, movimiento y curriculum. Buenos Aires: Morata.

Bayer, C. (1987) Técnicas del balonmano. Barcelona: Hispano-Europea.

Bayer, C. (1992) La enseñanza de los juegos deportivos colectivos. Barcelona: Hispano Europea.

Blázquez Sánchez, D. (1986) Iniciación a los deportes de equipo. Barcelona: Martínez Roca.

Blázquez Sánchez, D. (Dir) (1999) La iniciación deportiva y el deporte escolar. Barcelona: INDE.

Bonnefoy, G., H. Lahuppe, y R. Ne (2000) Enseñar Balonmano para jugar en Equipo. Barcelona: INDE.

Devís Devís, J. y R. Sánchez (1996) "La enseñanza alternativa de los juegos deportivos: antecedentes, modelos actuales de iniciación y reflexiones finales", en Moreno Murcia, J.A. y P. L. Rodríguez (Eds.) Aprendizaje deportivo. Murcia: Universidad de Murcia.

Cavalli. D. (2013) Didáctica de los deportes de conjunto. Enfoques, problemas y modelos de Enseñanza. Buenos Aires: Stadium.

Cavalli D. (2014) Enseñar Handball en la escuela. Una aproximación lúdica e inclusiva. Buenos Aires: Stadium.

Hernández Moreno, J. (1999) La diversidad de prácticas. Análisis de la estructura de los deportes para su aplicación a la iniciación deportiva. Barcelona: INDE. 
Hernández Moreno, J. (2000) La iniciación a los deportes desde su estructura y Dinámica. Barcelona: INDE.

Laguna Elzaurdía, M. (1996) Clinic deporte de base. Madrid: Real Federación Española de Balonmano.

Laguna Elzaurdía, M. (2001) “Jugar y hacer jugar”, en: Comunicación N 425. Madrid: Real Federación Española de Balonmano.

Lasierra, G., J. M. Ponz y F. Andrés (1995) 1013 ejercicios y juegos aplicados al balonmano. Volumen I. Barcelona: Paidotribo.

Lasierra, G., J. M. Ponz y F. Andrés (1995) 1013 ejercicios y juegos aplicados al balonmano. Volumen II. Barcelona: Paidotribo.

Le Boulch, J. (1991a) El deporte educativo. Psicocinética y aprendizaje Motor. Barcelona: Paidós.

Le Boulch, J. (1991b) Hacia una ciencia del movimiento humano. Barcelona: Paidós.

Mahlo, F. (1969) La acción táctica en el juego. La Habana: Pueblo y Educación. Marriot, J. (1995) Balonmano. De la escuela... a las asociaciones deportivas. Lérida: Agonos.

Parlebas, P. (2001) Juegos, deportes y sociedades. Léxico de praxiología motriz. Barcelona: Paidotribo.

Sánchez Bañuelos, F. (1992) Bases para una didáctica de la educación física y los deportes. Madrid: Gymnos.

Vankersschaver, J. (1982) Football. La formation dans l'école ou dans le club. Partie 1. Paris: Education Physique et Sport.

Velert Peiró, C. (1992) Nuevas perspectivas curriculares en educación física: la salud y los juegos modificados. Barcelona: INDE.

Willis, P. (1980) "Notas sobre el método", en: Hall, S. et al. (ed.) Culture, Media, Lenguaje. Londres: Hutchinson. 
CAPÍTULO 2:

DOS APROXIMACIONES PARA ENTENDER UN FENÓMENO COMPLEJO

\subsection{EL DEPORTE ES UN CONCEPTO POLISÉMICO}

No resulta sencillo establecer qué es el deporte por diversas razones. Por un lado, es una práctica tan extendida y naturalizada, una pauta de comportamiento social tan habitual y tan universalmente instalada, que, como sucede con todo aquello a lo que estamos habituados no se nos ocurre que tengamos que definirlo o caracterizarlo: constituye un sobreentendido social. Pero por otro, la carga axiológica positiva, atribuida sin más al deporte -multiplicada por los discursos de educadores, comunicadores sociales, profesionales de la salud, políticos- omite análisis críticos sobre la naturaleza social y cultural del fenómeno en cuestión.

En función de lo analizado, plantearemos dos dimensiones de análisis diferentes. La primera de ellas -a la que denominaremos aproximación ontológica- recupera una serie de expresiones que permiten reconocer y distinguir al deporte como fenómeno en sí a partir de sus rasgos materiales. La segunda -a la que preferimos llamar aproximación crítica- recorre un tándem de reflexiones centradas en el carácter histórico, social y cultural del deporte, lo cual derrama en el campo político, económico y educacional.

\subsection{APROXIMACIÓN ONTOLÓGICA}

Si consultamos el Diccionario de la Lengua Española de la RAE (1992: 482), nos encontramos con que en su primera acepción el término deporte significa "recreación, pasatiempo, placer, diversión o ejercicio físico, por lo común al aire libre". Mientras que en su segundo significado hace referencia a la "actividad física, ejercida como juego o competición, cuya práctica supone entrenamiento y sujeción a normas". Como podemos comprobar, el término deporte se caracteriza por los siguientes aspectos: actividad física y mental, reglas o normas, competición, diversión, juego. 
Para Coubertin (1960), citado por Hernández Moreno (1994: 14), principal responsable de la instauración de las Juegos Olímpicos Modernos en 1896, el deporte es "culto voluntario y habitual del intenso ejercicio muscular, apoyado en el deseo de progresar y que puede llegar hasta el riesgo".

José María Cagigal (1985) en la ponencia que iba a exponer en Italia, adonde se dirigía cuando tuvo el fatal accidente, "el deporte es aquella competición organizada que va desde el gran espectáculo hasta la competición de nivel modesto; también es cada tipo de actividad física realizada con el deseo de compararse, de superar a otros o a sí mismo, o realizada en general con aspectos de expresión, lúdicos, gratificadores, a pesar del esfuerzo". Por su parte, Parlebas (1981), citado por Hernández Moreno (1994: 15) define el deporte como "situación motriz de competición reglada e institucionalizada" a la que el mismo Hernández Moreno (1994: 15) añade el aspecto lúdico, quedando la definición de deporte integrada de la siguiente manera: "situación motriz de competición, reglada, de carácter lúdico e institucionalizada".

García Ferrando (1990: 31), entiende que en todo deporte aparecen tres elementos esenciales, definiéndolo como "una actividad física e intelectual, humana, de naturaleza competitiva y gobernada por reglas institucionalizadas".

Sánchez Bañuelos (1992), al definir el término deporte dice que éste está relacionado con "toda actividad física, que el individuo asume como esparcimiento y que suponga para él un cierto compromiso de superación de metas, compromiso que en un principio no es necesario que se establezca más que con uno mismo". También se destaca la elaborada por Romero Granados (2001: 17), quien dice que el deporte es "cualquier actividad, organizada o no, que implique movimiento mediante el juego con objeto de superación o de victoria a título individual o de grupo".

Castejón (2001: 17) aporta una nueva definición del deporte bastante amplia en la que tiene cabida cualquier disciplina deportiva: "actividad física donde la persona elabora y manifiesta un conjunto de movimientos o un control voluntario de los movimientos, aprovechando sus características individuales y/o en cooperación con otro/ s, de manera que pueda competir consigo mismo, con el 
medio o contra otro/ $\mathrm{s}$ tratando de superar sus propios límites, asumiendo que existen unas normas que deben respetarse en todo momento y que también, en determinadas circunstancias, puede valerse de algún tipo de material para practicarlo".

Hernández Moreno (1994: 16) siguiendo a algunos de los autores anteriormente citados resalta los siguientes rasgos que nos permite aproximarnos al concepto deporte.

\begin{tabular}{|c|c|l|}
\hline \multirow{2}{*}{ DEPORTE } & Juego & $\begin{array}{l}\text { Todos los deportes } \\
\text { nacen como juegos, con } \\
\text { carácter lúdico }\end{array}$ \\
\cline { 2 - 3 } & Situación Motriz & $\begin{array}{l}\text { Implican ejercicio físico y } \\
\text { motricidad más compleja }\end{array}$ \\
\cline { 2 - 3 } & Competición & $\begin{array}{l}\text { Superar una marca o a } \\
\text { un(os) adversario(s) }\end{array}$ \\
\hline Reglas & $\begin{array}{l}\text { Reglas codificadas y } \\
\text { estandarizadas }\end{array}$ \\
\cline { 2 - 3 } & Institucionalización & $\begin{array}{l}\text { Está regido por } \\
\text { instituciones oficiales } \\
\text { (federaciones, etc.) }\end{array}$ \\
\hline
\end{tabular}

Cuadro 1. Características del concepto deporte Hernández Moreno (1994: 16). Clasificación de los deportes

Autores como Cagigal (1979) optaron por clasificar el deporte según su orientación y ámbito de práctica. De esta manera nos encontramos con los siguientes conceptos:

Deporte escolar: se trata de todo deporte practicado en la escuela durante las sesiones de Educación Física programadas por el centro escolar. Aquí también entrarían aquellas actividades deportivas llevadas a cabo fuera de la institución escolar pero que hayan sido planificadas y programadas por el centro dentro del horario lectivo del mismo. 
Deporte en edad escolar: hace referencia a las actividades deportivas realizadas por los niños y niñas que están en edad escolar al margen del centro escolar, y por tanto, de las clases de Educación Física. Se trataría de aquellas prácticas deportivas realizadas en escuelas deportivas, clubes deportivos, etc.

Respecto a los tipos de deporte anteriores, tenemos que decir que, al igual que en muchos aspectos relacionados con el deporte, no todos los estudiosos del fenómeno deportivo comparten esta distinción, ya que, por ejemplo, para Gómez y García (1993), citados por Blázquez (1999: 24), y para el mismo Blázquez, el deporte escolar es "toda actividad físico-deportiva realizada por niños/as y jóvenes en edad escolar, dentro y fuera del centro escolar, incluso la desarrollada en el ámbito de los clubes o de otras entidades públicas o privadas, considerando, por tanto, deporte escolar como sinónimo de deporte en edad escolar". Por su parte, para De la Rica (1993), el deporte escolar se refiere a las actividades físicas y deportivas llevadas organizadas por los centros escolares, fuera del horario lectivo, como actividad complementaria. Para esta autora, el deporte escolar debe contemplarse desde un prisma pedagógico y relacionado con la asignatura de Educación Física.

Deporte para todos: esta orientación nació como un eslogan y como una reivindicación, porque en el pasado sólo podían acceder a la práctica deportiva unos pocos. Por tanto, el movimiento a favor del Deporte para Todos nace como una reivindicación del derecho a la realización de actividad física y deporte (Sánchez Bañuelos, 2000). Según Cagigal (1979), este tipo de deportes intenta saciar la necesidad humana de movimiento lúdico-competitivo, pero tiene en cuenta los valores humanos y sociales del deporte, es decir, la salud, el esparcimiento, la socialización, el descanso, etc. Además el concepto de Deporte para todos hace alusión al hecho de que toda persona tiene el derecho de practicar una actividad deportiva independientemente de su clase socioeconómica, sexo, etc., (Giménez, 2002).

Deporte recreativo: según Blázquez (1999:22), el deporte recreativo "es aquél que es practicado por placer y diversión, sin ninguna intención de competir o superar a un adversario, únicamente por disfrute o goce". Pretende que el 
individuo se entretenga y se divierta corporalmente de manera que logre su equilibrio personal. Se trata de una práctica abierta, donde nada está prefijado con anterioridad y donde lo que menos importa es el resultado (Blázquez, 1999).

Deporte competitivo: hace referencia a aquellas prácticas deportivas en la que el objetivo consiste en superar, vencer a un contrario o a sí mismo (Blázquez, 1999). En esta concepción del deporte lo importante es conseguir grandes e importantes resultados, muchas veces sin importar el medio, lo cual conlleva un gran sacrificio por parte de los participantes y un entrenamiento sistemático para lograr los fines deseados. Según Sánchez Bañuelos (2000), esta orientación se rige por el principio de selectividad, de forma que la elite deportiva constituye un colectivo minoritario por definición, y comporta un gran sacrificio.

Deporte educativo: siguiendo a Blázquez (1999), en este tipo de deporte lo que importa es la persona que realiza la actividad deportiva, es decir, el deportista. De esta manera, el deporte educativo ha de fomentar el desarrollo y la mejora de las distintas capacidades cognitivas, afectivas, sociales, motrices y psicomotrices de la persona que lo realiza. En este sentido y conforme con Giménez (2002), pensamos que el deporte que se proponga a niños/as y a jóvenes debe basarse en un planteamiento estrictamente educativo.

Deporte de iniciación o iniciación deportiva: Hernández y Cols. (2001), definen la iniciación deportiva como "el proceso de enseñanza- aprendizaje, seguido por un individuo, para la adquisición de la capacidad de ejecución práctica y conocimiento de un deporte. Este conocimiento abarca desde que el individuo toma contacto con el deporte hasta que es capaz de jugarlo con adecuación a su estructura funcional”. Por su parte Sánchez Bañuelos (1992: 181), entiende que un individuo está iniciado cuando "es capaz de tener una operatividad básica, sobre el conjunto global de la actividad deportiva, en la situación real de juego o competición”. Según Romero Cerezo (1997), la iniciación deportiva corresponde a la etapa en la cual el niño/a comienza a aprender de forma específica una práctica deportiva concreta, debiéndose entender ésta como un período que favorece y facilita una especialización ulterior.

Deporte adaptado: se trata de todas aquellas actividades deportivas en las es necesario reestructurar, acomodar y ajustar las condiciones de práctica, es decir, 
las normas y reglas, los móviles o aparatos, la técnica o formas de ejecución, el espacio y el tiempo de juego, etc., para que puedan ser practicadas por las personas que presentan alguna discapacidad física, psíquica o psicofísica. Lógicamente, como ya podíamos haber intuido antes, las distintas orientaciones expuestas más arriba tienen interacciones, pudiéndonos encontrar en muchas ocasiones una práctica deportiva que reúne características de dos o más orientaciones del deporte, como puede ocurrir, por ejemplo, en el caso del deporte para todos, el deporte recreativo y el deporte educativo.

Autores como Bouet (1968), Durand (1968) o Blázquez y Hernández (1984) entre otros optaron por clasificaciones más profundas dependiendo de la especificidad, vivencia, u orientación pedagógica del deporte practicado:

\begin{tabular}{|c|c|c|c|}
\hline \multirow{8}{*}{$\begin{array}{l}\text { Bouet } \\
(1968)\end{array}$} & \multirow{2}{*}{$\begin{array}{l}\text { Deportes } \\
\text { de combate }\end{array}$} & Con implemento & \multirow{2}{*}{$\begin{array}{l}\text { Existe contacto } \\
\text { físico. El cuerpo } \\
\text { como referencia }\end{array}$} \\
\hline & & Sin implemento & \\
\hline & \multirow{2}{*}{$\begin{array}{l}\text { Deportes } \\
\text { de balón o pelota }\end{array}$} & Colectivos & \multirow{2}{*}{$\begin{array}{l}\text { El balón es el } \\
\text { factor relacional } \\
\text { del deporte }\end{array}$} \\
\hline & & Individuales & \\
\hline & \multirow{2}{*}{$\begin{array}{l}\text { Deportes } \\
\text { atléticos o gimnásticos }\end{array}$} & $\begin{array}{l}\text { Atlético, de } \\
\text { medición objetiva }\end{array}$ & \multirow{2}{*}{$\begin{array}{l}\text { Las posibilidades } \\
\text { humanas como } \\
\text { referencia. Gesto } \\
\text { técnico importante }\end{array}$} \\
\hline & & $\begin{array}{l}\text { Gimnástico, de } \\
\text { medición subjetiva }\end{array}$ & \\
\hline & $\begin{array}{l}\text { Deportes } \\
\text { en la naturaleza }\end{array}$ & \multicolumn{2}{|c|}{$\begin{array}{l}\text { La referencia común es la práctica en } \\
\text { el medio natural y el riesgo }\end{array}$} \\
\hline & $\begin{array}{l}\text { Deportes } \\
\text { mecánicos }\end{array}$ & \multicolumn{2}{|c|}{$\begin{array}{l}\text { Se caracterizan por el empleo de } \\
\text { máquinas que el hombre controla y } \\
\text { dirige }\end{array}$} \\
\hline
\end{tabular}

Cuadro 2. Clasificación del deporte según Bouet (1968)

Por otra parte, se atribuye el nombre de cíclico a todo aquel deporte que se caracteriza por basar su práctica en el uso de un modelo de movimiento muy sencillo llamado ciclo, el cual acaba en la misma posición donde empezó para facilitar así su encadenamiento sucesivo (movimiento cíclico). Dentro de dicho 
concepto pueden encuadrarse deportes como la natación, el atletismo, remo o ciclismo. La metodología de enseñanza que se aplica en dichos deportes recibe el nombre de enfoque tradicional o técnico, basado principalmente en el aprendizaje, adquisición, consolidación y optimización de los gestos motrices específicos a utilizar, entes de llevarlo a la situación de juego real. Por otro lado el deporte acíclico o de situación, es aquel en el que "todo gesto motriz que se aplica va a estar influenciado directamente por la situación de juego en la cual el participante se encuentra inmerso". La metodología de enseñanza recibe el nombre de enfoque alternativo el cual se asocia a la pedagogía del descubrimiento y está fundamentado en la propuesta de experiencias motrices lúdicas vinculadas al contexto real de juego desde el primer momento, o sea que no solo se centra en la ejecución motriz sino también en la elaboración de una decisión en función del análisis de la situación de juego.

Para finalizar este apartado es necesario establecer que todo lo hasta aquí reseñado es gran utilidad para: a) identificar el fenómeno deportivo, distinguiéndolo en sus formas de otras prácticas sociales; b) reconocer y apreciar la variedad y complejidad de disciplinas deportivas; c) inferir que detrás de diversidad motriz y agonal de los deportes quedan implicadas formas $\mathrm{y}$ estrategias distintas y complejas para su enseñanza.

Como contraparte de lo expresado en el párrafo anterior, las posiciones expuestas no logran explicar: a) el enorme crecimiento -tanto de practicantes como de espectadores- del fenómeno deportivo y su arraigo en la sociedad de masas; b) el creciente interés político y económico por parte de estados y empresas en el deporte; c) la incidencia que esta práctica social y cultural puede tener en la educación.

\subsection{APROXIMACIÓN CRÍTICA}

El espacio al que denominamos crítico está conformado por un amplio arco de autores y posiciones de muy diversas tradiciones teóricas. Los signos en común que permiten realizar este agrupamiento son: la idea de desnaturalizar al deporte, dejando de suponerlo una actividad connatural de la especie, es decir, 
reconociendo su carácter histórico, social y cultural; la necesidad de contextualizar en tiempo y espacio al deporte, reconociendo su historicidad y territorialidad; por la misma razón, el afán por establecer los vasos comunicantes entre el deporte y otras manifestaciones de la cultura y la sociedad, incluyendo las dimensiones política y económica; el impulso por reconstruir la génesis y desarrollo del deporte en clave de conflicto, entendiendo al deporte como campo. En este amplio escenario, las posiciones son múltiples y complejas. Analizaremos algunas de ellas.

Siguiendo a Barbero González (1993), quien a su vez se inspira en las ideas de Foucault, se puede entender al deporte como un dispositivo de control social; es decir, se puede reconocer que su origen es el encendido de un modo de operar en los demás a fin de disciplinar las conductas cotidianas y tornarlas funcionales. Barbero sitúa el inicio del deporte en la Inglaterra de la primera mitad del siglo XIX, especialmente en el contexto de las Public Schools. Los jóvenes estudiantes internados allí -hijos de la alta burguesía y de la aristocracia británicas- aceptan tempranamente pasar a intramuros la práctica de unos juegos algo brutales que desarrollaban en sus ocasionales salidas fuera de la escuela. Pero en ese pasaje, esa actividad transgresora se va transformando en una práctica asimilada a las normas institucionales hasta convertirse en parte del curriculum escolar. Esos jóvenes que peleaban entre sí y dirimían conflictos a partir de la riña y del sometimiento por la fuerza de los más débiles, comienzan a autocontrolarse por imperio del espacio institucional, a pesar de que las autoridades académicas no regulaban esa práctica. Más tarde, atentos a los resultados obtenidos en sus propios hijos, las clases dominantes instalan el deporte en el medio fabril para, ahora sí deliberadamente, controlar el tiempo libre de la nueva clase emergente: el proletariado.

En base a este análisis, Carballo y Hernández (2003) juzgan que el deporte, siguiendo la lógica del control social, se expande como anillos concéntricos cada vez más amplios: el deporte de las Public Schools era un fenómeno inicialmente pequeño, que comprometía a una clase social específica en un solo país; el pasaje del deporte a las fábricas implica, aun dentro de los límites de un estado nacional, la extensión del fenómeno a otras clases sociales; la creación de los 
Juegos Olímpicos por parte de Coubertin configuraría un anillo aún más amplio, dado que el deporte se internacionaliza (no sólo su práctica, sino sus instituciones rectoras); y, finalmente, la exitosa asociación entre deporte y medios masivos de comunicación hace del deporte un fenómeno de consumo masivo a nivel planetario. Si se observa con detenimiento, este curso de acciones -desde el ingreso del deporte como tal a las escuelas a las transmisiones en directo de los eventos- llevó más o menos un siglo: se trata, pues, de uno de los fenómenos sociales y culturales de más rápida expansión en la historia.

El deporte es también un campo. Así lo piensa Bourdieu (1990 y 1993) al percibir al deporte como un entorno de actores, escenas, reglas, conflictos, con una dinámica propia, en parte correlacionada con el resto de la dinámica social y en parte con una cierta autonomía. También para el autor, el deporte es un distintivo de clase, al correlacionar el deporte con el conjunto de prácticas sociales que conforman un determinado capital cultural; ese capital se pone en juego en las más variadas situaciones sociales $\mathrm{y}$, en el caso del deporte, forma parte del habitus, entendido éste como una disposición socialmente determinada. Por su parte, Brohm (1993) no sólo ve en el deporte un elemento que nace con el signo de la clase dominante, sino una práctica social que subalterniza a los sectores vulnerables y a las mujeres (imponiendo la hegemonía del varón de clase alta) y que deserotiza al cuerpo (por reemplazar el movimiento placentero por un doloroso). Estas ideas son coherentes con la postura general del autor para quien, el deporte corre en el mismo sentido que el desarrollo del capitalismo y el imperialismo, lo cual implica considerar los modos y las relaciones de producción (y reproducción) que convierten al deportista (profesional) en un trabajador asalariado (y alienado).

Otro elemento a considerar a la hora de someter a juicio crítico al deporte y su desarrollo es el tema de la relación con la violencia. Ciertamente es Dunning (1993) quien retomando las enseñanzas de Elias ubica el tema de la violencia en el centro de la escena. Los procesos civilizatorios a los que alude su maestro en la Inglaterra de la segunda mitad del siglo XVIII se podrían reducir a dos fenómenos concurrentes: el refinamiento de la costumbres (con el consecuente 
traspaso de los manners and morals aristocráticos a las clases subalternas, comportamientos socialmente aceptados como vehículos de los valores dominantes) y el control de la violencia (lo cual no implica su reducción, sino su sometimiento a un orden racional y legítimo). El deporte colabora decididamente y es profundamente solidario con el proceso civilizador: no reclama menos violencia, sino que somete a ésta a las reglas morales y al buen gusto (véase también Elias y Dunning, 1986).

Otro capítulo clásico en los estudios críticos del deporte lo representan aquellos que vinculan al deporte con la economía y, particularmente, con el desarrollo del fenómeno industrial. Probablemente haya sido Volpicelli (1967) uno de los primeros en abordar sistemáticamente este tema. Este estudioso italiano interpreta que las vinculaciones entre deporte e industria son múltiples, encontrando en primer lugar las más superficiales, aquellas en las cuales la industria ofrece tecnología (en los materiales deportivos, en la indumentaria, en el calzado, en los instrumentos de medición y registro) y el deporte devuelve con espacios de publicidad de formidables niveles de penetración social (lo que incluyó, hasta hace no mucho tiempo, la publicidad de productos reñidos con el mensaje deportivo de una vida sana, como el tabaco y el alcohol). Pero, prosigue Volpicelli, lo que la industria brinda la deporte es más profundo, pues se trata de un modo de producción basado en la especialización temprana y la división del trabajo. El corolario del autor es que el deporte está fuerte unido al estado y a la empresa en el concepto de democracia industrial: así como pocos producen los bienes industriales que todos consumimos, así el espectáculo deportivo es producido por pocos consagrados y consumido por las masas (ya sea en la compra de tickets, abonos televisivos, indumentaria, viajes y todo tipo de merchandising).

También es posible analizar desde una perspectiva crítica las particulares relaciones entre el deporte y el estado. Rodríguez (1996) opina que el deporte no es un hecho que pueda comprenderse si se lo separa de los procesos de consolidación del estado nación y de la sociedad de masas. El deporte, según la autora, viene a reforzar esos procesos: a) aportando escenarios simbólicos en los cuales se representen los valores nacionales y la cohesión en torno a la idea 
de nación (seleccionados nacionales de diferentes deportes, grandes competencias internacionales); b) consolidando el ideario del igualitarismo republicano (en el entendimiento de que, así como en la república todos los ciudadanos son iguales ante la ley, en el deporte todos los deportistas se someten a un único código reglamentario); c) controlando la violencia (al transformar el quantum de violencia material potencial en violencia simbólica); d) desarrollando una pedagogía del esfuerzo y del trabajo (así como el trabajo permite el ahorro y el ahorro genera la fortuna, del mismo modo el esfuerzo -y hasta el sacrificio- constituyen la base del éxito). La misma Rodríguez y Carballo (2015) opinan que los procesos de autonomización o autarquización del deporte traspasan los límites de lo jurídico para internarse en las arenas de lo político, transformándose las instituciones deportivas en actores clave en la disputa del poder.

No creemos relevante recuperar algunos textos que, a estas alturas, podrían considerarse clásicos. Nos referimos a obras que a pesar del interés que despertaron y del lugar que ocuparon en la trayectoria de los estudios históricos, sociales y culturales del deporte, no propusieron una mirada crítica más o menos integral, sino que dieron cuenta de estudios e investigaciones de carácter "micro"; tal es el caso de Sociología del deporte de Lüschen y Weis (1976), de Antropología del deporte de Blanchard y Cheska (1986) o de Sociología del deporte de Thomas, Haumont y Levet (1988). Por esa misma razón no se incorporan a este inventario los trabajos de Durantez Corral (1965), Diem (1966) o Mayer (1967).

Existe finalmente un campo de estudios sociales del deporte en Argentina que conviene reconocer, pero se trata de abordajes particulares, que se comprometen con temas específicos que se alejan de esta tesis y cuyo análisis no tiene incidencia en los problemas de la enseñanza y de la iniciación a los deportes de conjunto. Una ligera enumeración de temas y autores podría ser la siguiente: deporte, género, masculinidad-feminidad y/o sexismo (Archetti, 1995 y 1997; Tamburrini, 1999; Conde y Rodríguez, 2002; Scharagrodsky, 2004 y 2016); deporte y clase social (Archetti, 2001; Frydenberg, 1997); deporte con grupos sociales e identidades sociales y trabajos sobre niñez y juventud en 
situación de vulnerabilidad y exclusión, vinculados al deporte (Aisenstein, 2006; Chaves, 2007; Cachorro, 2013; Katz, 2015; Rausky, 2015; Saraví, J., 2017); deporte y segregación, nacionalismo, xenofobia o racismo (Romero, 1985; Alabarces, 2002; Villena Fengo, 2000); violencia e hinchadas (barras) (Alabarces, 2005; Garriga Zucal, 2007, 2011 y 2013; Zambaglione, 2011; deporte, Educación Física y políticas públicas (Martínez Álvarez y Gómez, 2009; Levoratti, 2015 y 2016; Levoratti y Zambaglione, 2015); deporte y modalidades de gestión, como sociedades anónimas o como sociedades civiles sin fines de lucro (Daskal y Moreira, 2017).

\subsection{BIBLIOGRAFÍA DEL CAPÍTULO}

Barbero González, J. I. (1993) "Introducción”, en Barbero González, J. I. (comp.), Materiales de sociología del deporte. Madrid: Ediciones de la Piqueta.

Blanchard, K. y A. Cheska (1986) Antropología del deporte. Barcelona: Ediciones Bellaterra.

Blázquez, d. (1999) “A modo de introducción”, en: Blázquez (Ed.) La iniciación deportiva y el deporte escolar. Barcelona: INDE.

Blázquez, D. y J. Hernández, (1984) "Clasificación o taxonomías deportivas" (monografía). Barcelona: INEF.

Bouet, M. (1968) Signification du sport. París: PUF.

Bourdieu, P. (1990) “¿Cómo se puede ser deportista?”, en Sociología y Cultura. México: Grijalbo.

Brohm, J-M. (1993) "20 Tesis sobre el deporte”, en Barbero González, J. I. (comp.), Materiales de sociología del deporte. Madrid: Ediciones de la Piqueta.

Cagigal, J. M. (1979) Cultura intelectual y cultura física. Buenos Aires: Kapelusz.

Cagigal, J. M. (1985) “Pedagogía del deporte como educación”, en: Revista de Educación Física. Renovación de teoría y práctica (3). Madrid.

Carballo, C. y N. Hernández (1999) "Acerca del concepto de deporte. Alcances de su(s) significado(s)", en: Educación Física \& Ciencia, año 6. La Plata: 
Departamento de Educación Física, Facultad de Humanidades y Ciencias de la Educación, Universidad Nacional de La Plata.

Castejón, F. J. (2001). Iniciación deportiva. Aprendizaje y enseñanza. Madrid: Pila Teleña (edición electrónica).

De la Rica, M. J. (1993) "El deporte en la educación física", en: AA.VV. (Ed.) Fundamentos de Educación Física para enseñanza primaria (Vol. II). Barcelona: INDE.

Dunning (1993) "Reflexiones sociológicas sobre el deporte, la violencia y la civilización” en Barbero González, J. I. (comp.), Materiales de sociología del deporte. Madrid: Ediciones de la Piqueta.

Durand, G. (1968) El adolescente y los deportes. Barcelona: Paideia.

Elias, N. y E. Dunning (1986) Deporte y ocio en el proceso de la civilización. Madrid: Fondo de Cultura Económica.

García Ferrando, M. (1990) Aspectos sociales del deporte: una reflexión sociológica. Madrid: Alianza.

Giménez, F. J. (2002). "El deporte dentro del ámbito recreativo: iniciación deportiva para todos", en: Rebollo (Ed.) Deporte para todos. Huelva: Diputación de Huelva. Área de deportes.

Hernández Moreno, J. (1994) Fundamentos del deporte. Análisis de las estructuras del juego deportivo. Barcelona: INDE.

Hernández Moreno, J., U. Castro, G. Gil, H. Cruz, G. Guerra, M. Quiroga y Cols. (2001). "La iniciación a los deportes de equipo de cooperación/oposición desde la estructura y dinámica de la acción de juego: un nuevo enfoque", en: Lecturas: Educación Física y Deportes, Revista digital, 33. http://www.efdeportes.com/efd33/inicdep.htm Lüschen, G.y K. Weiss (1976) Sociología del deporte. Valladolid: Miñón. RAE (1992) Diccionario de la Lengua Española. Madrid: Espasa Calpe. 
Rodríguez, M. G. (1996) "Minuto, juez. Deporte, sociedad y escuela", en: Revista CD Books en la Educación Física y el Deporte, número octubre 1996. Buenos Aires: CD Books.

Rodríguez, M. G. y C. Carballo (2015) "Deporte Moderno, Deporte Federado, Deporte Espectáculo y de Alto Rendimiento", en: Carballo, C. (compiladoreditor) Diccionario Crítico de la Educación Física Académica. Rastreo y análisis de los debates y tensiones del campo académico de la educación física en Argentina. Buenos Aires: Prometeo Libros.

Romero Cerezo, C. (1997) "Una nueva perspectiva de iniciación al fútbol en la escuela", en: Training Fútbol (16).

Romero Granados, S. (2001) Formación deportiva: nuevos retos en educación. Sevilla: Universidad de Sevilla.

Sánchez Bañuelos, F. (1992. Bases para una didáctica de la educación física y el deporte. Madrid: Gymnos.

Sánchez Bañuelos, F. (2000) "Análisis del deporte en edad escolar y una alternativa para el futuro", en: Díaz García, J. (Ed.) Actas del I Congreso Nacional de Deporte en edad escolar. Dos Hermanas: Ayuntamiento de Dos Hermanas.

Thomas, R., A. Haumont y J. L. Levet (1988) Sociología del deporte. Barcelona: Ediciones Bellaterra.

Volpicelli, L. (1967) Industrialismo y deporte. Buenos Aires: Paidós. 
CAPÍTULO 3:

CARACTERÍSTICAS DE LOS DEPORTES DE CONJUNTO

INCIDENCIAS EN LA ENSEÑANZA

\subsection{CARACTERÍSTICAS GENERALES}

Cavalli (2008) establece que en el análisis de la estructura y el desarrollo de las acciones motrices de los deportes de conjunto, un grupo de especialistas ha observado que los objetivos de estos juegos se alcanzan por medio de la ejecución de un conjunto de gestos técnicos articulados; otros, sin embargo, opinan que esos fines se consiguen a través de la puesta en acto de unos procesos mentales basados en una correcta lectura del juego y toma de decisión; están aquellos que han advertido que la base del juego se construye a partir de una clara comprensión de sus principios tácticos; y finalmente, se encuentra a los que desde una mirada más holística, pensaron que el éxito en la consecución de dichas metas depende de la interacción de un conjunto de elementos o factores que conforman una estructura.

Los deportes como el balonmano se caracterizan por ser abiertos, generando en cada pasaje del juego gran incertidumbre: la capacidad de interpretación y adaptación son fundamentales para lograr alcanzar los objetivos que la actividad propone. Para ello, la táctica individual es fundamental, mientras que la técnica debe ser adaptativa y estar abierta a cambios constantes según la exigencia que se presente.

La influencia francesa fue determinante en la evolución de la enseñanza de los deportes hacia formas más significativas. Esta influencia penetró, especialmente a través del movimiento psicomotricista, que advirtió que había otras maneras de entender la actividad física, el cuerpo y el cuerpo en movimiento. Su principal representante fue Jean Le Boulch, autor que dio un giro decisivo -en su momento- a la Educación Física.

Pero fue su discípulo Claude Bayer, quien construyó una perspectiva de enseñanza de los juegos deportivos, iniciada primero en el balonmano y después 
ampliada al grupo de los deportes colectivos, especialmente los de invasión (Bayer, 1986). La noción de transferencia -que es de carácter controversial y no es objeto de debate en este trabajo- y el análisis estructural y funcional de los juegos deportivos son pilares sobre los que sustenta su perspectiva.

El proceso de enseñanza se basa en la sucesión de situaciones de juego, pero considerando esquemas más fáciles que se adapten a las posibilidades de los practicantes, para así aprender los principios tácticos transferibles a contextos diferentes de juego.

Parlebas $(1988,1989)$ propone la construcción de una ciencia de la acción motriz -Praxiología motriz-, de especial aplicación al análisis de la interacción en los juegos deportivos. Esta forma de abordar la enseñanza se caracteriza por orientarla básicamente de la táctica a la técnica mediante el uso de juegos modificados, que poseen similitudes tácticas con los deportes en su formato estándar.

Mientras tanto, Arnold (1991) propone que las habilidades técnicas implicadas en un juego deportivo son capacidades adquiridas contextualmente. Es decir, se diferencian de los hábitos en que éstos se limitan a procedimientos relativamente rígidos y rutinarios, mientras que aquéllas exigen que el agente supervise de manera inteligente lo que está haciendo mientras lo ejecuta, junto con una capacidad para adaptarse a las circunstancias cambiantes cuando así se requiera. Pretende así decirnos que una habilidad técnica sólo tiene sentido dentro de un contexto y es dentro de él donde debe aprenderse y donde adquiere significado. Si realizamos una actividad física orientada a la enseñanza de las habilidades, pero separada de su contexto, la actividad se convierte en meramente instrumental, repetitiva y difícilmente comprensible dentro de un contexto de juego que no se conoce. $Y$ es posible constatar que así se han enseñado los deportes de equipo: el error ha sido la enseñanza analítica de los deportes a través de las técnicas o habilidades motrices específicas, descontextualizadas, de las situaciones tácticas en las que tienen que ser utilizadas. Dicho de otro modo, los juegos son contextos fundamentalmente sociales y en ellos cada participante interacciona con los demás y con el objeto 
o los objetos. Asimismo, el contexto del juego conforma el medio donde aparecen los problemas y donde éstos adquieren completo significado.

El contexto y los problemas del juego son inseparables y ambos se relacionan con su táctica hasta el punto que, para resolver los problemas motrices surgidos dentro del contexto del juego, será necesario comprender los principios o aspectos tácticos básicos. Por lo tanto, una enseñanza para la compresión en los juegos deportivos implica abordar el aprendizaje de los aspectos tácticos. Tanto es así que el aprendizaje de los juegos deportivos progresará de la táctica a la técnica. Esto no significa olvidar la técnica, como pensaron muchos erróneamente en un primer momento, sino introducirla posteriormente o una vez que se está dentro de un juego. Lo importante, dentro de esta perspectiva, es ser capaces de reconocer las estructuras básicas de los deportes y, a partir de ello, ser capaces de enseñarlas sin que se pierda de vista su naturaleza o carácter, es decir, su contenido táctico o intencional, sabiendo que cualquier modificación en la práctica debe obedecer a una secuencia de dificultades hacia el dominio del deporte en cuestión.

A partir de un mínimo conocimiento de las acciones motrices básicas se puede afrontar el aprendizaje táctico mediante juego o ejercicios significativos para los alumnos, en los cuales la táctica compleja se presenta en pasos más sencillos a los de la situación real del juego. Estos juegos que en sí mismos pueden tener uno o varios de los contenidos tácticos y técnicos de los deportes, son más asequibles en su comprensión y más fácilmente transferibles -opinan los partidarios de este concepto- al deporte de que se trate.

Respecto a la estructura de la que se hace mención en el párrafo anterior podemos agregar que debe ajustarse a reglas, las que ofrecerán la posibilidad de coordinar acciones, tomar decisiones en tiempo y espacio según la problemática del objetivo en el momento de la invasión del territorio contrario, generando técnicas flexibles y automatismos plásticos siempre vinculados con el poder de decisión desarrollado en los jugadores.

Blázquez Sánchez (1986), opina que, para poder elaborar una acción pedagógica integrada en una Educación Física, es preciso establecer las 
características diferenciales de cada actividad física. Describe que la opinión generalizada sobre el concepto de los deportes en conjunto es que el equipo es una suma de jugadores, de suerte tal que la calidad del equipo depende del conjunto de las cualidades de los jugadores que lo componen. No obstante, esta percepción, no resulta adecuada, ya que la suma de las partes no es igual al todo: un jugador juega junto a otros y frente a sus adversarios y un partido es la confrontación de dos grupos de fuerza.

Muchos entrenadores creen comprender y conocer la noción de equipo a través de fórmulas copiadas a otros equipos superiores. Ese bagaje de conocimientos está compuesto, muy a menudo, por pequeños trucos, y algunos conceptos tácticos extraídos de algún manual. Pero esperamos que el entrenador cree los sistemas de juego a partir de las características de los jugadores y que intente que sus jugadores asimilen los patrones de juego considerados indispensables. No obstante, es fácil observar que el experto modela a sus jugadores según ciertos estereotipos motores, subordinando a los jugadores a normas aceptadas, tanto sobre el plano técnico, táctico o de preparación individual. De esta manera, la motricidad del jugador se debe someter a los conocimientos del entrenador.

En otro orden, resulta ampliamente aceptado que para generar una arquitectura pedagógica habría que ofrecer situaciones de aprendizaje que permanentemente recurran al par cooperación-oposición, y para ello, los conocimientos se deben enderezarse hacia los desplazamientos con mucha movilidad de atacantes y defensores y los constantes cambios de espacios que eso produce. Los juegos organizados en un espacio orientado a uno o dos arcos, para que el jugador se sitúe en el espacio en relación a su medio inmediato, lo estructura con la ayuda de un continuo ir y venir que le permitirá adecuarse al espacio en relación con el número de jugadores. En este marco, la información que brindada a niños y niñas no debería ser ni demasiado densa ni demasiado débil, ya que en la primera la saturación que puede producir pude producir una crisis en el tiempo de inhibición motriz, y en la segunda el trabajo se vería deformado en relación con la realidad. Resulta clave, en este sentido, que los docentes estén preparados para enseñar a descubrir "indicios" pertinentes comprendidos en las situaciones de aprendizaje, repitiendo estos elementos 
cargados de sentidos con el fin de que pueda memorizarlos y construir un lenguaje que se adapte al deporte colectivo; esto se considera clave, porque será el paso a la mejora de las futuras estrategia visuales. Es ésta la razón por la cual, cuando se pretende que los niños y las niñas aprendan un gesto técnico o descubran las conductas que resuelven los problemas planteados, el principal recurso a emplear no es la descripción detallada por parte del entrenador, sino las condiciones impuestas por el propio ejercicio. Las situaciones de juego reducido pueden facilitar la tarea, pero son necesarias muchas repeticiones y una gran variedad de situaciones de aprendizaje para que las adquisiciones sean duraderas y transferibles.

Por ello, los formadores suelen resaltar la importancia de desarrollar en niños y niñas, en el entorno de juegos, la capacidad de discernir o de tomar decisiones, para que así puedan incorporar reglas simples y sin restricciones en la organización de los juegos motores, contrariamente a como ocurre en los deportes, para adecuarlos al estado madurativo y evolutivo del niño con el fin de contribuir a la mejora de su proceso de desarrollo del conocimiento a través del juego.

\subsection{PERSPECTIVA DE LA TÉCNICA}

Tradicionalmente, se ha relacionado el aprendizaje de habilidades técnicas en el deporte con las teorías conexionistas o asociacionistas. Aprender asociando no significa otra cosa que enlazar o conectar un estímulo con una respuesta. Habitualmente se ha tratado de enseñar el balonmano -y otros contenidos motrices y cognitivos-, a través de este sistema. El entrenamiento técnico-táctico individual posiblemente haya sido uno de los contenidos del juego sobre el que más publicaciones han aparecido hasta fines de los años ochenta. La enseñanza de la técnica individual ha sido entendida como el paso previo e imprescindible sin el cual el jugador no podía progresar ni acceder a otras adquisiciones más complejas.

La técnica suponía el elemento clave sobre el que giraba el resto de los contenidos del juego, de tal forma que, en los primeros años de aprendizaje, los 
sujetos desarrollaban mayoritariamente tareas en las cuales el objetivo principal era el dominio de los patrones técnicos del juego. Distintas fueron las razones por las que se llegó a plantear el entrenamiento de la técnica centrándose en los aspectos mecánicos del gesto, y otorgándole a la repetición y a la imitación un papel primordial en el aprendizaje.

Por otro lado, las ideas de aprendizaje por imitación (Bandura y Walters, 1974), hicieron que la concepción de los aprendizajes, tanto motrices como cognitivos, se basara en la división de partes de la tarea final y en el aprendizaje parcial de estas partes, para unirlas finalmente en un todo. Esta visión del aprendizaje fragmentado en contenidos más fáciles y sencillo encontró un extraordinario caldo de cultivo en el mundo del deporte.

El profesor-entrenador organiza a su grupo (14 jugadores) para el entrenamiento: los mismos fueron llegando en distintos momentos por lo que entendemos debe ser algo problemático organizar la actividad. En un principio organizó la tarea con 3 grupos de 4 jugadores y al arribo de los otros jugadores los agregó uno a cada grupo, quedando dos de 5 y uno de 4 jugadores. Estos se disponen en una zona delimitada por conos la cual tiene forma de cuadrado. En cada uno de estos debe estar un jugador: este debe defender esa zona, es el responsable de la misma. Mientras que dos pasan el balón, el cuarto en cuestión debe llegar a apoyar el balón detrás de una línea imaginaria que está a espaldas del defensor. Los que pasan el balón solo están forzando que el defensor concentre su trabajo en su atacante (...) El defensor debe estar con ambas manos detrás solo puede impedir el paso con su cuerpo, después de pasar todos por las distintas posiciones se incrementa el trabajo. (...) Ahora son dos cuadrados con dos defensores... [la consigna ahora es que los defensores nunca pueden estar los dos en el mismo cuadrado, mientras que los atacantes solo pueden estar en el mismo cuadrado 3"] Para los atacantes la problemática de apoyar el balón ahora es llegar al lugar solo con pase y recepción. En la siguiente tarea ya los defensores podían utilizar los brazos para controlar a los jugadores de ataque y además podían interceptar el balón, de hacer efectiva la intercepción se cambiaba de rol.

2016: Observación de entrenamiento (categoría infantiles y menores, Club M) con asistencia de estudiantes de EF de la UNPAZ. 
Bandura $(1984,1986)$ propuso al aprendizaje social como el medio por el que los sujetos lograban distintos aprendizajes, y donde la observación y la imitación cobraban un papel determinante en la adquisición de nuevas conductas. Estas ideas fortalecieron aún más la toma de posición a favor de la imitación de respuestas preestablecidas. Así, apareció el modelado como técnica común a la hora de promover determinadas adquisiciones.

Para Pozo (1996), siguiendo las ideas de Bandura, esta técnica de modelado se puede dividir en cinco grandes fases:

- Información verbal sobre las habilidades entrenadas y sus objetivos.

- Presentación de un modelo eficaz.

- Práctica de la habilidad entrenada por parte del aprendiz en condiciones simuladas o reales.

- Corrección y, en su caso, reforzamiento de esas habilidades por parte del maestro.

- Mantenimiento y generalización de esa habilidad a nueva situaciones.

Según Cavalli (2008), para estos autores han sido los gestos técnicos, exigidos por cada disciplina deportiva, los elementos prioritarios en la determinación de la estructura y el desarrollo de las acciones de juego de los deportes de conjunto. En función de ello, la mayoría de los estudios que se desprenden de esta perspectiva presentan, por un lado, una fragmentación de la totalidad de las prácticas deportivas en un conjunto de técnicas -con sus respectivas variantesque conforman el esqueleto de las acciones de juego y, por otro, unos detallados y minuciosos análisis de cada una de ellas, que permiten observar y comprender la evolución de sus patrones de movimiento. Estos últimos tipos de análisis permiten, sobre todo, determinar la estructura y la temporalidad de los técnicos, es decir, dilucidar el número y la secuencia de sus fases constitutivas.

Gestos técnicos: Ofensivos $1-2-3-4-5$

$$
1.1-1.2-1.3-1 . n
$$

Defensivos $a-b-c-d-e$

$$
\text { a. } 1 \text { - a.2 - a.3 - a.n }
$$


Según este esquema, podemos llamar gesto técnico ofensivo "1" al lanzamiento, que, a su vez, en atención al desarrollo individual de cada jugador, podrá desagregarse en "1.1" lanzamiento con dos manos a pie firme; "2.2" lanzamiento con una mano pie firme; etc. A esto puede agregarse el lanzamiento en salto, lanzamiento con oposición, etc. Es importante recalcar que la secuencia no es fija, sino que varía conforme al momento de desarrollo de cada jugador.

Le Boulch (citado en Cavalli, 2008), dice que para alcanzar estos niveles de precisión, muchas veces se sirven de videos donde mediante el montaje de cálculos mecánicos realizados sobre las trayectorias de los diferentes segmentos corporales del deportista de elite -preferentemente el campeón- se puede establecer, por una parte, el gesto técnico ideal y, por otra, unos criterios

para confrontar con las ejecuciones de los alumnos de modo de determinar "a ciencia cierta" si sus realizaciones son correctas. Lo que se obtiene, en definitiva, es el modelo estándar con el que se puede comparar a los demás.

Cuando se aborda de este modo el análisis de las acciones de los deportes de conjunto, no es casual que las preocupaciones en torno de la enseñanza se orientan, básicamente, a poder dar cuenta del problema de la optimización de las realizaciones motrices. De hecho, resulta casi esperable que quienes están convencidos de que este tipo de deportes se cimientan sobre las técnicas deportivas, dispongan buena parte de sus energías en abordar aquel problema de manera rigurosa y sistemática.

\subsection{PERSPECTIVA DE LA TAREA MOTRIZ}

Además, Cavalli (2008) plantea que otro conjunto de especialistas ha centrado su atención en las características de las tareas motrices involucradas en la acción de juego. La estructura de los deportes de conjunto, según estos últimos, está conformada básicamente para tareas motrices predominantemente perceptivas o abiertas, en las cuales el mecanismo de ejecución se encuentra siempre mediado por procesos perceptivos y de forma de decisión que resultan la clave del desarrollo de las acciones de juego. Ante ello, lo que propone generalmente este tipo de aproximaciones, es un análisis minucioso de los 
procesos mentales, que median entre los estímulos que recibe el jugador del escenario de juego y las respuestas motrices que emite a posteriori.

La adopción de este enfoque particular desplaza el problema de la enseñanza hacia las estructuras internas del sistema, es decir, hacia las numerosas "cajitas" que a modo de componentes mediacionales lo conforman. Por tanto, la cuestión que estos especialistas intentan abordar tiene más que ver con la cuestión de la optimización de los "procesos internos" que intervienen entre los estímulos del medio y las respuestas motrices que da el jugador, que con la idea de perfeccionar las "condiciones externas" de dichas respuestas -tal como lo propone la perspectiva de análisis basada en los gestos técnicos-.

Rink, French y Graham (1996) proponen que una mínima tasa de aprendizaje de técnicas al principio del proceso favorece la adquisición de estrategias generales. Aunque cuantificar ese mínimo aprendizaje no parece nada fácil. Ahora bien, de forma paralela a la organización de estas situaciones (aprendizaje de estrategias generales y tácticas especificas), deben aparecer situaciones que faciliten las herramientas o técnicas con las que realizar aquellas tácticas.

Marriot (1995) plantea y desarrolla en el balonmano el concepto de que en los primeros pasos del aprendizaje tiene más valor las intenciones tácticas con las que el sujeto intenta resolver un problema que la eficacia en la ejecución de las acciones, aunque sin olvidar el aprendizaje de las técnicas. En el balonmano, como en otros deportes de conjunto, es necesario automatizar técnicas que permitan solucionar los problemas en poco tiempo, ya que los jugadores no disponen de un tiempo ilimitado para resolver las situaciones que aparecen en el juego.

Al exponer esto se deduce que la orientación que debe tener la enseñanza y el aprendizaje debe conjugar tanto el aprender estrategias generales y específicas (tácticas) como la adquisición de habilidades técnicas. Si al principio del aprendizaje muchas situaciones constituyen problemas para los jugadores, parece razonable pensar que la forma óptima de aprender a solucionar problemas es mediante la enseñanza orientada hacia la táctica (aprendizaje por construcción), pero una vez que los problemas dejan de ser tales (ya que se ha 
entendido la situación y se ha obtenido la mejor respuesta para solucionarla), éstos se convierten en ejercicios para los que las formas de solución óptimas se relacionan con las habilidades técnicas. Evidentemente, esto no implica que el aprendizaje por construcción desaparezca, ya que aparecerán nuevos problemas más complejos que habrá que solucionar tácticamente.

Después de observar 40 entrenamientos durante los años 2016, 2017 y 2018 en la categoría minihandball, podemos decir que el $75 \%$ de los mismos fueron construidos por el profesor-entrenador de la misma forma:

Al comienzo del entrenamiento, propone realizar algún juego de movilidad con adaptabilidad al balón para tener a todos los jugadores en condiciones para poder comenzar a jugar: no a jugar partido, sino a jugar juegos deportivos de invasión de territorio, de cooperación y también de oposición; para los mismos, las reglas son simples y muchas de ellas están relacionadas directamente con el reglamento de minihandball, una manera que puede juzgarse eficaz para ir incorporando reglas del deporte en los juegos deportivos. Finalizados los juegos se realizaban trabajos de técnica individual, también de manera lúdica, para reforzar así el trabajo anteriormente realizado.

2018: Reporte de observaciones de entrenamientos (categoría minihandball, Club M, Club JU y Club MH).

Quizá la cuestión no deba plantearse en términos de qué debe enseñarse antes, la táctica o la técnica, sino que la orientación de la misma pueda dirigirse hacia los dos polos: aprender entendiendo, cuando la tarea resulte un problema para los jugadores, y aprender automatizando, cuando la situación sea sencilla y pueda resolverse fácilmente.

El problema se presenta cuando quien conduce la tarea da la orientación de cómo y cuándo se debe resolver dicha actividad; es aquí que el aprendizaje será un camino no construido ni transitado por el jugador en su totalidad, sino que caminará en gran medida por el ya construido y transitado por su entrenador. Existen numerosos ejemplos en las situaciones cotidianas que muestran el escaso espacio dado por los entrenadores a la toma de decisiones por parte de los jugadores. Es decir, plantean un tipo de actividad que contiene en sí misma 
la respuesta en lugar de que sea el jugador quien encuentre alternativas, un descubrimiento en el que reconocerá las herramientas que él crea son las oportunas para encontrar el camino a andar.

\subsection{PERSPECTIVA DE LA TÁCTICA}

Bayer (citado en Cavalli, 2008), señala que otros investigadores, han propuesto a la táctica como el núcleo referencial a partir del cual se genera el desarrollo de las acciones de juego de los deportes de conjunto: todos los juegos deportivos colectivos quedan sometidos a principios que se revelan comunes e idénticos, con algunas variantes peculiares en el vóleibol. Estos principios constituyen el punto de partida, la base; representan la fuente de la acción, definen las propiedades invariantes sobre las cuales se realizara la estructura fundamental del desarrollo de los acontecimientos.

En función de esta premisa, Bayer (citado en Cavalli, 2008), establece que los estudios encargados desde esta perspectiva han derivado su atención hacia el análisis y comprensión de tales principios que, como leyes primordiales, regulan -tanto en ataque como en defensa- las relaciones de los individuos en el seno del equipo y las relaciones de los dos equipos a lo largo del enfrentamiento. Pero Bayer, es quien construyó una perspectiva de enseñanza de los juegos deportivos, iniciada primero en el balonmano y después ampliada al grupo de de los deportes colectivos, especialmente los de invasión (Bayer, 1986). La noción de transferencia y el análisis estructural y funcional de los juegos deportivos son pilares sobre los que sustenta su perspectiva.

En línea con este enfoque y con las consideraciones previas, Devís Devís (1996) y Peiro Velert (1992) han sostenido que el contexto y los problemas de juego son inseparables y ambos se relacionan con su táctica hasta el punto que para resolver los problemas motrices que surgen dentro del contexto de juego, será necesario comprender los principios o aspectos tácticos básicos. El aporte fundamental de estos autores está relacionado con el hecho que han podido establecer, con una mayor precisión, las características de esos principios en función de la naturaleza problemática de los distintos deportes de conjunto. 
Tomando como referencia los desarrollos de numerosos investigadores Cavalli (2008: 26), entre otros, ha señalado algunos principios tácticos específicos para las distintas categorías en que dividen a los deportes de conjunto. Es así que, por ejemplo, para los juegos deportivos que se denominan "de invasión" básquetbol, fútbol, handball, hockey, rugby, etc.- los principios que formulan son: a) desmarcarse, b) buscar espacios libres y profundidad, c) apoyar al compañero, d) abrir el juego, etc. Para los "de campo dividido" -cuyo exponente en los deportes de conjunto es el vóleibol-, en cambio: a) enviar el móvil al espacio libre -lo más alejado del oponente-, b) neutralizar espacios para que el oponente no puntúe, etc. Las consideraciones precedentes permiten de alguna manera anticipar la importancia que asume, para todos estos investigadores, el abordaje del problema de la enseñanza de los principios tácticos. Su adquisición y comprensión por parte de los jugadores representa, según ellos, la variable clave a la hora de alcanzar los objetivos de estos deportes.

El balonmano tiene como fundamentales en el desarrollo de su enseñanza tres principios tanto en defensa como en ataque: en defensa, como primer paso, recuperar la pelota, luego obstaculizar e impedir la progresión del adversario y la pelota hacia el objetivo, y sin lugar a dudas, proteger el arco; en cambio los principios del ataque son conservar la pelota, progresar los jugadores y la pelota hacia el arco o meta contraria y lograr el objetivo (en este caso, marcar el gol). Estos principios se ven muy claros en todos los deportes de invasión de territorio, pero donde más claro se pueden apreciar es en el rugby, ya que una vez que el equipo tiene la posesión del balón intentará avanzar en el terreno contrario para lograr mi objetivo y es ahí donde el equipo rival utilizará todas las medidas reglamentarias para llevar lo más lejos posible del objetivo al conjunto contrario.

Finalizada esta tarea, el entrenador reúne a los jugadores y los organiza en equipos para jugar mini handball [5 vs 5 en campo reducido] con todas las reglas previstas en el reglamento. Los niños "juegan" durante ese tiempo final de la práctica partidos breves [esto es habitual en cada entrenamiento; los jugadores esperan ese momento con cierta ansiedad]. Durante esos partidos, el entrenador se mueve por el espacio dirigiendo preguntas breves a sus jugadores -a cada jugador o a cada equipo, indistintamente-. Al advertir que un 
jugador en defensa es superado por su oponente, se dirige a él y le pregunta: ¿¿En qué lugar te pararías para que eso no te pase de nuevo?' Al observar que un jugador en ataque pierde el balón, le pregunta: ‘¿De qué manera podés pasarle la pelota a tu compañero para que el jugador que tenés adelante no la intercepte?' Esta situación se produce sin interrupción de los partidos que se están llevando a cabo.

2017: Observación de entrenamiento (categoría infantiles y menores, Club M).

El fragmento puede mostrar para el ojo poco entrenado solo una fase final del entrenamiento, que privilegia lo lúdico como una suerte de "premio" al esfuerzo realizado. Pero, si se agudiza la percepción, el entrenador enfatiza en sus consignas -que adoptan la modalidad de interrogantes a resolver por medio de acciones- algunos de los principios propios del ataque o de la defensa.

Para Manolo Laguna (2001), el juego de defensa se construye con dos tareas básicas. Sosteniendo la idea de Cavalli, se impone como primera medida oponerse de manera intencional al movimiento de los atacantes, y, en particular, propone oponerse al movimiento del balón. Para estas dos tareas, en un primer paso, que cada jugador se reconozca como defensor con el marcaje en forma individual, es una meta fundamental a conseguir. Luego se debe reconocer colectivamente que cada jugador debe ayudar ante el error, percibir ayudas previas con procedimientos tácticos como cambios de oponentes, deslizamientos, contrabloqueos y así poder evitar que los oponentes tengan acceso a zonas eficaces de lanzamiento; y para ello deben reforzarse las zonas de peligro inmediato. Respecto del jugador con balón se deberá tener en claro cuándo puede interceptar, cuándo acosar y -más aún- cómo y cuándo disuadir al jugador con balón.

Para la construcción del ataque, el primer paso es establecer con claridad el movimiento del balón con intencionalidad y para ello se debe botar, pasar, recibir o lanzar, siempre escogiendo la mejor opción dirigida a superar al rival. El segundo paso es el movimiento intencional de los jugadores, desmarcándose, haciendo tanto fintas como fijaciones en forma individual, mientras que, en forma colectiva, el "pase y va", bloqueos, cruces, pantallas y cortinas para superar al 
rival, y así poder llegar a zona de lanzamiento con la finalidad de lograr el objetivo.

\subsection{PERSPECTIVA ESTRUCTURAL}

En base a las cuantiosas y valiosas investigaciones realizadas por Parlebas (citado en Cavalli, 2008), el campo de los deportes de conjunto incorpora una nueva perspectiva de análisis cuya lente toma una dirección hacia el estudio de los componentes estructurales de esos deportes. El punto de partida de esos trabajos es que las conductas de los jugadores se organizan en función de un sistema de obligaciones que el jugador interioriza y transmite a su cuerpo mientras juega y que le canalizan un auténtico código de comportamiento, de utilización del cuerpo y de relaciones humanas. En este sentido, lo que en este marco se postula es que el punto de referencia, la fuente a partir de la cual se genera el desarrollo de las acciones de juego es la estructura de esos deportes. Es solo a partir de ella que se puede comprender la lógica de las acciones motrices. En este contexto es importante señalar los siguientes elementos:

- Sistema de tanteo: red de aciertos, victorias o puntos conseguidos por los jugadores o los equipos de un juego deportivo. Ejemplo: puntos otorgados por conseguir el objetivo.

- Red de interacciones de marca: vías por las que se pueden alcanzar los objetivos del juego deportivo. Ejemplo: introducir la pelota en un arco, apoyarla en la meta rival, etc.

- Red de comunicación motriz: comunicación y contra comunicación motrices. Ejemplo: pase (comunicación motriz), intercepción (contracomunicación).

- Red de roles socio-motores: conjunto de comportamientos asociados a un estatus. Ejemplos: atacante con pelota, atacante sin pelota.

- Red de sub-roles sociomotores: unidad comportamental básica del funcionamiento estratégico. Ejemplo: progresar - pasar - finalizar la acción. 
- Códigos semiotores: gestemas: o signos producidos e interpretados por los sujetos que actúan con el objeto de transmitir una indicación u orden táctica o relacional. Ejemplo: levantar el brazo para indicar la jugada de ataque (básquetbol), indicar con los dedos el puesto de ataque (vóleibol).

- Códigos semiotores: praxemas: conducta motriz de un jugador interpretada como un signo, cuyo significante es el comportamiento observable y cuyo significado es el proyecto táctico. Ejemplo: corre hacia un espacio libre (significante) puede ser interpretado como una señal cuyo objetivo táctico es apoyar la continuidad del juego de ataque.

Por ese motivo, lo que procuran es poder describir con exactitud la composición de dicho sistema, de modo de conocer los mecanismos de influencia que operan sobre las acciones motrices. "... la inteligibilidad de la conducta de los jugadores solo puede captarse si se consideran los sistemas de interacción que dirigen el cumplimiento de dichas conductas" (Cavalli, 2008: 28).

Se observa en los entrenamientos, en su parte final, donde los deportistas desarrollan su partido, que el docente modifica algunas reglas para obtener un desarrollo más fluido de las técnicas dadas ese día. El docente-entrenador les dice a sus jugadores: "si lanzo en salto, el gol vale 2". De esta manera, comienzan a realizarlo de manera consiente para luego pasar a ser un gesto automatizado.

2018: Observación de entrenamiento (categoría infantiles y menores, Club M) con asistencia de estudiantes de EF de la UNPAZ.

Este tipo de análisis ha sentado las bases sobre las que otros investigadores han desarrollado sus estudios. Uno de los reconocidos continuadores de esta línea -con algunas diferencias de enfoque- ha sido Hernández Moreno (2000). Para este autor, el eje de análisis de los deportes de conjunto debe colocarse en dos aspectos: la estructura o parte estática del reglamento que se concreta en aquellos aspectos que son necesarios e imprescindibles y hacen posible su puesta en juego en algún momento -técnica, espacio, tiempo, y comunicación motriz- y el desarrollo de la acción de juego o parte dinámica -conductas de decisión o estrategia motriz- (Hernández Moreno, 2000: 33). 
Desde el punto de vista del mencionado autor, pasan a ser de consideración los siguientes aspectos:

- Reglamento: reglas y parámetros del deporte.

- Gestualidad o técnica: modelos de ejecución y usos corporales y de objetos que configuran a los diferentes deportes.

- Espacio motor: espacio de acción o de juego.

- Tiempo motor: tiempo de juego.

- Comunicación motriz: interacción o relaciones entre los jugadores.

- Estrategia motriz: decisiones estratégicas motrices.

\subsection{PERSPECTIVA ESTRUCTURAL-FUNCIONALISTA}

A su vez, Blázquez Sánchez (1999) establece otra estructura funcional de los deportes de equipo, teniendo en cuenta las posturas de varios autores que han estudiado y analizado los componentes comunes a los deportes de equipo, basándose en una concepción en la cual estructura y función se relacionan de un modo dialéctico, han determinado que existen unos elementos que se repiten y que conforman la realidad del juego.

Desde esta perspectiva, afirman que todos los deportes de equipo están sometidos a principios comunes e idénticos: es lo que se denomina "estructura funcional". Estos principios varían según el enfoque sobre el que se apoya cada tendencia. Una primera aproximación la constituirá aquella que se centra sobre la noción de duelo, es decir, el carácter de colaboración y oposición, de ataque y defensa; en este planteamiento, la estrategia o el acto táctico ocupan el centro de atención. Una segunda perspectiva sería la que gira en torno a la comunicación, positiva o negativa entre los jugadores que participan, creando un lenguaje motriz insólito y específico de los deportes de equipo. Un tercer horizonte ve en la utilización del espacio la forma de materializar de forma intencional la interpretación de un mensaje y su respuesta en forma estratégica. Por último, se situaría el reglamento, que constituye el sistema de reglas capaz 
de regular el funcionamiento del juego y de determinar cómo se gana o cómo se pierde.

Todos ellos pueden ser útiles para ayudar a construir y regular acciones que permitan progresar al niño hacia la comprensión de la lógica interna del juego, así como ser el punto de partida para la acción motriz. Así pues, se asienta la estructura funcional de los deportes de equipo sobre estos principios:

- El espacio, terreno cerrado, más o menos grande, en el interior del cual se desarrolla la competición. Constituye el límite de acción de los jugadores.

- La estrategia, tipos de conducta que puede utilizar el jugador en cuanto a las diferentes formas de actuar en ataque o defensa.

- La comunicación motriz, lenguaje que utilizan los jugadores para realizar las acciones de comunicación o de oposición.

- Las limitaciones reglamentarias, que varían según los diferentes deportes, aunque manteniendo unas características comunes.

\subsubsection{El espacio}

Xesco Espar (2001) relaciona como muchos a la iniciación con etapas y le confiere una gran importancia al espacio que en ellas se encuentra no solo nombradas, sino como puntos de referencia para la formación del niño en el campo disciplinar.

En su primera etapa -el balón como centro de atención-, ofrecerá como mensaje que los niños y las niñas seguirán al portador del balón por todos lados; al decir "por todos lados", se refiere a un espacio delimitado, pero la relación está signada por el par objeto-espacio. En la segunda -ganar terreno multidireccionalmente-, plantea la importancia de que tanto el niño y la niña como el balón circulen por todo el espacio con gran fluidez. Para la tercera etapa también propone una relación directa con el espacio: ganar terreno orientadamente; en este caso, la utilización del espacio tiene como finalidad única ir en dirección al logro del objetivo. Finalmente, juego con intencionalidad, 
es una etapa en la cual también el espacio es de suma importancia ya que se debe lograr las intenciones tácticas en relación con los espacios que no ocupa el rival.

Para Jacques Marriot (1995) el espacio se debe adecuar según el número de jugadores, esto importa ya que el juego y el jugar es siempre gestionar un espacio, teniendo en cuenta al o a los compañeros, y a o los adversarios; así se debería conservar siempre una relación espacio - número de jugadores $=$ situación cercana al juego real.

Blázquez Sánchez (1999) describe que, el lugar o espacio de acción donde se desarrolla cualquiera de los deportes de equipo posee unas características constantes; es cerrado, institucionalizado, y sus dimensiones son estrictas y precisas. Su superficie se presenta marcada por líneas en el suelo que limitan las acciones de cada jugador. El terreno suele estar dividido en sub-espacios, "áreas" o "zonas" diversas. A su vez, intervienen de forma estandarizada, obstáculos (redes), metas u objetivos (postes, porterías, cestas, etc.) que distribuyen o dividen este espacio, incitando a organizar una acción coherente. Cada jugador debe compartir este espacio con el resto de sus compañeros Aun siendo imposible poder fragmentar el espacio deportivo como escenario de toda la acción, si se puede distinguir para su estudio varios tipos de espacio que poseen características muy diferenciadas.

- El espacio como distancia a franquear o recorrer: todo espacio deportivo posee unas dimensiones exactas en las cuales el jugador debe moverse o franquearlas. La táctica está basada en unas distancias sobre las que hay que desenvolverse: desmarcar, intercambiar, combinaciones a dos, a tres, a cuatro, etcétera. Estas distancias no sólo tienen importancia en el sentido propiamente espacial, sino de una forma importante sobre las exigencias fisiológicas.

- El espacio dividido en sub-espacios diferenciados: cada jugador se encuentra enfrentado a espacios dinámicos funcionalmente unidos entre ellos, que toman un sentido propio en función de la evolución del juego y que va a condicionar su situación sobre el terreno. Entre estas zonas para 
poder moverse se pueden distinguir: zonas fijas (pueden ser "prohibidas", es decir superficies donde el jugador no puede evolucionar; y zonas en cuyo interior los jugadores están sometidos a ciertas reglas); zonas variables (pueden ser "prohibidas", en cuyo caso se trata de zonas móviles que dependen del desplazamiento de los atacantes o de los defensores, en el interior de las cuales el jugador no tiene posibilidad de jugar; zonas a utilizar por los atacantes, las cuales implican todos los espacios libres que, situados delante del jugador que lleva el balón, constituyen zonas de apoyo; y zonas a vigilar, es decir, zonas de las que por su peligrosidad el defensor va a ocuparse particularmente, para oponerse al paso del balón o del adversario). La distribución del espacio deportivo en emplazamientos diferenciados es uno de los factores que determinan la lógica del juego.

- El espacio como meta u objetivo a lograr: para ganar un partido es necesario marcar más puntos o tantos que el contrario, es decir, lograr que el balón llegue a penetrar, tocar o traspasar un blanco preciso. Estos blancos son espacios siempre fijos y corresponden a lugares preparados. Para los otros deportes colectivos, el objetivo es una portería (fútbol, balonmano, etc.), o una canasta (baloncesto). En cualquier caso, el punto o tanto se logra cuando el balón toma contacto con una zona de terreno o cuando franquea un plano vertical $u$ horizontal.

Durante el desarrollo de las defensas en dos líneas (categoría infantiles, defensa 3-3) el entrenador divide las zonas en tres espacios que serán ocupados por un defensor por zona, los atacantes designados para cada zona tienen como consigna llegar a apoyar el balón detrás de la línea final, y solo por el lapso de tres segundos podrán estar dos de ellos ocupando una misma zona, si pasa más tiempo pierden la posesión del balón...

2016: Observación de entrenamiento (categoría infantiles y menores, Club M) con asistencia de estudiantes de EF de la UNPAZ. 


\subsubsection{La estrategia}

Se entiende por estrategia un concepto más amplio que el de táctica, es decir: tipos de conducta que teniendo en cuenta todas las eventualidades posibles y sus consecuencias puede utilizar el jugador y sirve para indicarle lo que debe hacer en cualquier situación del juego. Mientras que táctica es la realización de medios de acción aplicados a determinadas situaciones -en base a un objetivo- generalmente preestablecidas de antemano. Desde este punto de vista, la táctica elimina la posibilidad de decisión e iniciativa por parte del jugador, restando valor a la riqueza interna del juego.

Mahlo (citado en Blázquez Sánchez, 1999), designa tres fases sucesivas e interdependientes de la manera como los jugadores toman en cuenta sus acciones tácticas. Estas fases son:

- Percepción y análisis de la situación: su resultado permite el conocimiento de la situación.

- Solución mental del problema: su resultado supone la representación de una acción).

- Solución motriz del problema: su resultado supone la solución práctica).

Así, estas tres fases representan una sucesión de acciones en estrecha interrelación. La acción estratégica representa, desde el punto de vista cibernético, un sistema que se auto perfecciona al mismo tiempo que resuelve el problema propuesto. Esta concepción pone en evidencia el valor educativo que posee la acción estratégica. En el modelo que ofrece Mahlo se puede apreciar el principio de autoafirmación y de autoperfeccionamiento a través de la acción estratégica.

Distinto es el caso de Bayer (1992), quien analiza la formación táctica individual desde los aspectos fundamentales de la defensa y del ataque.

- La defensa: en el lenguaje corriente, la defensa comienza con la pérdida del balón, sea por haber marcado un tanto, sea por haber fallado un punto después de una tentativa infructuosa, sea por la pérdida del balón a manos del adversario por fallos o por faltas sancionadas según el 
reglamento. En un sentido más amplio, la defensa es una acción que dura constantemente. Prever las respuestas del adversario, asegurar el equilibrio ofensivo son ya acciones que desde el mismo ataque constituyen una defensa. Para no muchos formadores, si el niño comprende la importancia de defender comprenderá más fácilmente el juego, ya que este será el comienzo de todos los parámetros que manejamos en la futura formación del jugador. En tal sentido, los principios que se reconocen fundamentales de la defensa son: recuperar el balón, evitar la progresión del adversario hacia la portería y proteger la portería de las zonas propicias al tiro.

Según los objetivos a perseguir, el sistema defensivo puede ser: defensa libre (la misma se dará en los comienzos de la formación), defensa individual (preconiza una defensa esencialmente basada sobre el individuo, esté o no en posesión del balón, que puede a su vez -en función de la situación- evolucionar hacia una defensa hombre a hombre con flotación y cambio), defensa espontánea (ya no sólo se debe tener referenciado al oponente directo sino que se debe ser responsable del portador del balón si está en la zona de influencia del defensor), defensa zonal (toma como referencia al balón, dado que todos los adversarios se desplazan en función de la circulación del balón, sin descuidar al adversario puesto que es el que está en posesión del balón).

- El marcaje: representa la regla operacional fundamental común a los diferentes juegos deportivos colectivos. Se basa en la oposición del conjunto de los defensores que por sus situaciones respectivas y sus desplazamientos intentan evitar o paralizar las iniciativas y la realización de las acciones de ataque adverso. Sobre el plan de las acciones individuales, el marcaje puede suponer: interceptar el balón en un error de los atacantes; arrebatar el balón de los pies o manos del adversario; frenar, retrasar o parar los movimientos de los atacantes hacia la portería (ocupando los espacios libres, persiguiendo al adversario que se ha adelantado para intentar cogerlo, arrinconando a esos mismos adversarios hacia espacios menos peligrosos, bloqueando a los 
atacantes en sus desplazamientos); proteger con el propio cuerpo la trayectoria del balón hacia la portería.

- Acciones educativas en la defensa: desde el punto de vista educativo, hay tres reglas fundamentales a tener en cuenta en todo momento: marcar debe ser una práctica "activa" (el defensor debe "actuar" y no seguir pasivamente las acciones del adversario); actuar "continuamente" en base a una información permanente (respecto a la totalidad del juego) que obligue a actuar constantemente; ayudar en forma colectiva, es decir teniendo en cuenta la labor de cooperación que representa el equipo.

- El ataque: un ataque se "prevé" en el tipo de defensa adoptada y en las actitudes de los jugadores. Así, una defensa donde el contraataque está ya predispuesto constituye un elemento favorable a la acción posterior. En cualquier caso, teóricamente, el punto de partida del ataque está representado por la toma de posesión del balón. El ataque se basa en los siguientes principios: conservar el balón cuando se ha recuperado; progresar hacia el objetivo perseguido; lograr el tanto.

Durante el ataque, el jugador, debe tener en cuenta los siguientes elementos: posición del balón (nunca es la misma); espacios libres para cualquier ocupante (siempre variable); situación y desplazamiento de los adversarios; situación de los compañeros; objetivo a lograr.

- El desmarque: para el jugador en posesión del balón, liberarse del adversario que lo marca es una problemática constante, y nunca igual, ya que la dinámica del juego lo llevará a tomar decisiones rápidas que lo pueden hacer perder el elemento; mientras que el jugador sin balón deberá situarse oportunamente en el terreno, de manera que haga posible los pases y facilitar la circulación del balón.

En relación con el compañero en posesión del balón y al adversario, el problema del jugador sin balón consiste en encontrar soluciones al alineamiento impuesto por el defensor, es decir, recibir el pase del compañero alejándose del sector de intervención del defensor. 
En referencia a los espacios libres para desmarcarse, se trata de estructurar el espacio de juego, buscando los espacios donde no hay nadie y donde debe elaborar sus acciones en base a sus compañeros.

- Acciones educativas en el ataque: desde el punto de vista educativo, el educador debe esforzarse en volver significativo este elemento del juego que obliga al jugador a descentrarse momentáneamente del balón e informarse de las zonas donde podrá realizar su acción.

- Continuidad y encadenamiento de las acciones: todos los principios organizadores de la actividad del jugador no resultan útiles si el jugador no se muestra capaz de encadenar las diferentes tareas. Este encadenamiento no surge al azar sino que el jugador debe informarse para saber qué hacer, dónde ir, cuándo y cómo.

- La ayuda: en este encadenamiento de tareas es necesario introducir otra noción: la ayuda. Todo juego colectivo o de equipo se caracteriza por la cooperación y comunicación entre los jugadores.

\subsubsection{La comunicación motriz}

Según Blázquez Sánchez (1999), se acostumbra a hablar de comunicación asimilando este término al lenguaje verbal, pero la palabra no es el medio normal de expresión del deportista cuando está sobre el terreno de juego; muy al contrario, es su acción motriz la que le sirve de forma de comunicación. En los deportes de equipo, el jugador ajusta constantemente su comportamiento al de sus compañeros o adversarios, y se ejerce una interacción directa entre los diferentes jugadores.

Mediante el balón, el jugador se comunica sin cesar con sus compañeros, oponiéndose, al mismo tiempo, a sus adversarios. Esta interacción directa entre varios individuos es un fenómeno capital que transforma los comportamientos motores. Al situarse en la acción de juego, el jugador se encuentra ante una variedad de signos y señales que debe interpretar. Por un lado, los que provienen 
de sus propios compañeros, es decir, la comunicación de cooperación; y, por otro lado, la que emiten sus adversarios, es decir, la contra comunicación.

Parlebas define la comunicación de cooperación como los actos de ayuda efectuados por los miembros de un mismo equipo; se trata de interacciones operatorias positivas entre compañeros. Sus formas espaciales y temporales varían de un deporte a otro según el código de juego. Según el mismo autor, las contra comunicaciones motrices corresponden a actos de antagonismo realizados por jugadores que se enfrentan entre sí. Se trata, de interacciones operatorias negativas entre adversarios. Esta comunicación de oposición admite formas muy diversificadas. Puede ser la transmisión antagonista de un objeto (balón, etc.), la ocupación o disputa de un espacio (el contacto en una tocata de rugby, etc.), o la consecución de un tanto (canasta, gol, etc.).

Existe una forma de lenguaje motor que es preciso decodificar. El jugador debe aprender a descifrar los signos y señales que se utilizan en los deportes de equipo y que le van a servir como medio de comunicación. Esta necesidad debe ser incorporada en los procesos de enseñanza e iniciación. El niño tiene que aprender que existe un lenguaje propio del deporte y que debe utilizarlo durante su práctica.

El entrenador se acerca a uno de los equipos y le sugiere a los jugadores reconocer situaciones a partir del desplazamiento de los propios compañeros: 'si tu compañero se acerca a tu zona, entonces vos te desplazás al espacio libre que deja tu compañero. A esto le vamos a llamar cruce'.

\subsubsection{Las limitaciones reglamentarias}

No constituye una novedad afirmar que los reglamentos de los deportes están confeccionados conforme a las posibilidades de comprensión y ejecución de los adultos. Pero a la hora de pensar en términos de iniciación deportiva conviene tener en cuenta esta situación, ya que muchas de las reglas y condiciones de los deportes no se adaptan a los niños y las niñas, sujetos habituales del proceso de inducción deportiva. 
No obstante lo señalado, el handball ha desarrollado un reglamento de minihandball que incorpora una mirada en la cual los niños y las niñas no son vistos desde una perspectiva "negativa", es decir desde la limitación; como se verá, se trata de un reglamento que incorpora dimensiones tan variadas como la facilitación de la enseñanza y del aprendizaje, el derecho al juego o las características perceptivas y cognitivas en la infancia. El texto que sigue es un resumen de esas modificaciones y de los criterios que las alentaron y que exime de la necesidad de adaptaciones de fondo en la práctica de la enseñanza de este deporte con niñas y niños en edad escolar. Por supuesto, esto de ningún modo impide que cada docente-entrenador incorpore en sus estrategias de enseñanza otras modificaciones que entienda puedan facilitar la apropiación de contenidos por partes de los jugadores.

Antes de comenzar con la enumeración de las modificaciones propuestas y justificarlas, nos hacemos con Sívori (2002) la siguiente pregunta: ¿cuáles son las razones por la que los niños que se inician no pueden jugar como los adultos, aunque ellos lo deseen? El autor responde con cuatro argumentos: las niñas y los niños se encuentran al inicio de la etapa social, la cual no se ha consolidado; la maduración neuromuscular no estará completa hasta los 14-16 años; la capacidad motriz de las niñas y los niños es diferente; y su inteligencia no es como la de los adultos. En base a estas cuatro razones, mencionamos las siguientes modificaciones:

- Reducción del Terreno de Juego:

Permite adaptar las dimensiones del campo de juego a las capacidades físicas de las niñas y los niños. Esto propicia, a la vez, mayores posibilidades de sostener, sobre todo, la tarea defensiva. Se favorece el trabajo perceptivo. Básicamente, porque los estímulos a atender están más próximos. 
- Reducción de las mediadas del área de arco:

Favorece el duelo entre el lanzador y el arquero. Jugar con áreas de 6 metros, como es la reglamentaria, dificultaría mucho el hecho de que más jugadores/as puedan anotar goles.

- Formato circular del área:

Aumenta la eficacia de los lanzamientos desde zonas laterales de poco ángulo.

- Reducción de las dimensiones del arco:

Favorece el duelo entre el lanzador y el arquero.

- Reducción del tamaño de la pelota:

Favorece la adaptación y la manipulación de la pelota y, a través de ello, la mejora en la ejecución de habilidades fundamentales como pasar y lanzar, y del trabajo perceptivo, en tanto permite liberar la atención consciente del jugador/a hacia otras situaciones del juego.

- Reducción del número de jugadores:

Aumenta las posibilidades de actuación de las jugadoras y los jugadores, sobre todo, permitiéndoles tomar contacto con la pelota en forma más continúa. Se facilita el trabajo perceptivo y de decisión porque, con la reducción de jugadoras y jugadores, disminuye también el número de estímulos visuales a los que hay que atender (el número de jugadores en el campo de juego será de cinco, un arquero y cuatro de campo).

- Reducción del tiempo de juego:

Permite adaptar el tiempo de juego a las capacidades físicas de las jugadoras y los jugadores.

- Saque de arco cuando se consigue un gol:

Aporta mayor dinamismo al juego. 
- Defensa individual toda la cancha:

Mejora los desplazamientos ofensivos y defensivos. Mejora los desmarques y la búsqueda de líneas de pases libres. Mejora las anticipaciones defensivas y el hecho de aprender a marcar en línea de pase. Desarrolla el aprendizaje del juego 1 versus 1 .

\subsection{BIBLIOGRAFÍA DEL CAPÍTULO}

Arnold, P. J. (1992) "Educación Física, movimiento y currículum", en: Devís Devís, J. y C. Peiró Velert (comp.) Nuevas Perspectivas curriculares en educación física. La salud y los juegos modificados. Barcelona: INDE.

Bandura, A. (1984) Teoría del Aprendizaje Social. Madrid: Espasa Calpe.

Bandura, A. (1986) Fundamentos Sociales del pensamiento y Acción. Teoría Cognitiva Social. Barcelona: Martínez Roca.

Bandura, A. y R. Walters (1974) Aprendizaje Social y desarrollo de la personalidad. Madrid: Alianza Universidad.

Bayer, C. (1987) Técnica del balonmano. Barcelona: Hispano Europea.

Bayer, C. (1992) La enseñanza de los juegos Deportivos Colectivos. Barcelona: Hispano Europea.

Blázquez Sánchez, D. (1986) La iniciación Deportiva y el Deporte Escolar. Barcelona: INDE.

Blázquez Sánchez, D. (1999) Iniciación a los deportes de equipo... del juego al deporte de los 6 a los 10 años. Barcelona: INDE.

Cavalli, D. (2008) Didáctica de los deportes de conjunto. Problemas, enfoques y modelos de enseñanza. Buenos Aires: Stadium.

Devís Devís, J. (1996) Educación Física, deporte y currículum. Investigación y desarrollo curricular. Madrid: Aprendizaje Visor. 
Devís Devís J. y C. Peiró Velert (2001) "Fundamentos para la promoción de la actividad física relacionada con la salud", en: Devís Devís, J. (Coord.) La educación física, el deporte y la salud en el siglo XXI. Alicante: Marfil.

Hernández Moreno, J. (2000) La iniciación a los deportes desde su estructura y dinámica. Barcelona: INDE.

Laguna Elzaurdía, M. (2001) Técnica-Táctica individual. Madrid: Real Federación Española de Balonmano.

Laguna, M. (2001) “Jugar y hacer jugar”, en: Comunicado $N^{\circ} 425$. Madrid: Real Federación Española de Balonmano.

Marriot, J. (1995) Balonmano. De la escuela... a las asociaciones deportivas. Lérida: Ágonos.

Parlebas, P. (2001) Juegos, deportes y sociedades. Léxico de praxiología motriz. Barcelona: Paidotribo.

Pozo, J. I. (1996) Aprendices y Maestros. La Nueva Cultura del Aprendizaje. Madrid: Alianza.

Rink, J., K. French y K. Grahan (1996) "Implications for practice and reserch", en: Journal of teaching in physical education. Champaign: Human Kinetics.

Sivori, J. (2002) La Enseñanza del Handball. Buenos Aires: EFyD. Espar, X. (2001) Balonmano. Barcelona: Martínez Roca. 
CAPÍTULO 4:

\section{INICIACIÓN DEPORTIVA}

\subsection{ALGUNOS CONCEPTOS}

Según Blázquez Sánchez (1986) desde el punto de vista educativo, el proceso de iniciación deportiva no debe entenderse como el momento en que se empieza la práctica deportiva, sino como una acción pedagógica que, teniendo en cuenta las características del niño y los fines a conseguir, van evolucionando progresivamente hasta llegar al dominio de cada especialidad. Para precisar más detenidamente este proceso, es necesario tener presente los siguientes aspectos:

En cuanto al niño:

- el grado de desarrollo o maduración

- el grado de estimulación que se le proporciona

- el grado de experimentación

En cuanto a la pedagogía utilizada:

- el método tradicional

- el método activo

Mientras Hernández Moreno (2000: 11) afirma que el período en el que el individuo empieza a aprender de forma específica la práctica de un deporte o conjunto de deportes es lo que se conoce como Iniciación Deportiva.

Sin embargo contraponiéndose a esta idea, Diem (citado en Hernández Moreno, 2000), afirma que la Iniciación Deportiva puede producirse mucho antes que el sujeto tenga contacto con ese deporte en concreto, a través de actividades facilitadoras para la posterior práctica deportiva.

La definición de Iniciación Deportiva sobre la cual afianzaremos nuestro trabajo es del autor Hernández (1986) quien expresa lo siguiente: 
"La iniciación deportiva es el proceso de enseñanza-aprendizaje, seguido por un individuo, para la adquisición de la capacidad de ejecución práctica y conocimiento de un deporte. Este conocimiento abarca desde que el individuo toma contacto con el deporte hasta que es capaz de jugarlo con adecuación a su estructura funcional".

Un individuo esta iniciado en un deporte, cuando, tras un proceso de aprendizaje, adquiere los patrones básicos requeridos por la situación motriz específica y por la especialidad de un deporte, de manera tal que además de conocer sus reglas y comportamientos estratégicos motores fundamentales, sabe ejecutar sus técnicas, moverse en el espacio deportivo con sentido del tiempo, de las acciones y situaciones, sabiendo leer e interpretar las comunicaciones motrices emitidas por el resto de los participantes en el desarrollo de las acciones motrices

\subsection{FACTORES INTERVINIENTES EN LA INICIACIÓN DEPORTIVA}

\subsubsection{El sujeto}

Tanto si el sujeto que aprende es un niño como si fuese un joven o un adulto, se deben tener en cuenta las características de ese sujeto que aprende. Dentro de esas características se deben considerar:

- El modo en que procesa la información que recibe del entorno: éste debería ser el paso más importante al momento de comenzar a formar a un futuro deportista. ${ }^{3}$

- Las capacidades físicas básicas, con especial énfasis en la formación básica anterior (si la hubiera).

- El período de la vida en que se encuentra el sujeto, teniendo en cuenta tanto el crecimiento como la maduración (ya que no es lo mismo edad cronológica que edad biológica).

\footnotetext{
${ }^{3}$ Mahlo (1974) introduce la idea de "concepto táctico" que incluye los siguientes momentos: percibir, decidir y ejecutar; esto es desarrollado y ampliado por Martineuk (1976) de la siguiente manera: información del entorno, mecanismo de percepción, mecanismo de decisión, mecanismo de ejecución, movimiento y resultado del movimiento. Este último genera un conocimiento sobre la ejecución (positiva o negativa). Esta importancia otorgada a la percepción es la que nos inclina a poner el procesamiento de la información en primer lugar.
} 
- La personalidad y el comportamiento del sujeto.

- La motivación respecto de la práctica deportiva general y, en particular, la de ese deporte en concreto (motivaciones que pueden ser intrínsecas o extrínsecas).

- El acervo motor y la experiencia motriz.

- La variabilidad individual en el aprendizaje.

- Las condiciones de salud física, psíquica y social.

- El contexto social y cultural como elemento que otorga sentidos y significados a las diferentes prácticas.

- Y todos aquellos factores que puedan influir en su personalidad y en su comportamiento.

La etapa de la pubertad va a establecer grandes diferencias entre varones 0 mujeres -en términos de crecimiento- que hasta ese momento no eran muy significativas.

\subsubsection{El deporte}

Las características del deporte, de su estructura y de su dinámica van a ser un factor significativo, pues en función de ellas se encontrarán mayores facilidades para una u otra modalidad deportiva. Si un sujeto posee las aptitudes que solicita un determinado deporte tendrá más opciones de triunfar en él.

Siguiendo a Parlebas (Citado en Cavalli, 2008), podemos decir que hay dos grandes grupos de deportes: los psicomotrices, en los que el sujeto participa de forma individual y la presencia de otros sujetos es accesoria (salto de longitud, escalada, gimnasia artística); y los sociomotores, en los que participan varios sujetos que inciden de forma directa en las conductas que desarrollan sus compañeros y adversarios.

Dentro del grupo de los deportes sociomotrices, distingue diversos tipos de deportes entre los que situamos a los deportes de cooperación (gimnasia rítmica de conjunto, carrera de relevos), de oposición (luchas, deportes de raqueta uno 
contra uno) y de oposición-cooperación (baloncesto, ciclismo en ruta por equipos). Dentro de estos últimos, ubicamos al handball como un deporte de oposición-cooperación, en equipo, con balón y de invasión de terreno (lo cual implica contacto).

Los deportes psicomotrices demandan principalmente de sus practicantes la realización de modelos de ejecución que tienen que ser lo más eficaces posibles o la copia más fehaciente de un modelo o patrón que establece el reglamento o la biomecánica de las técnicas deportivas. Por el contrario, los deportes sociomotrices, a partir de unos mínimos patrones motores que podríamos considerar como básicos, solicitan una puesta en práctica de los mismos en el momento adecuado y ante la situación precisa, en la que van a influir factores como la presencia de los compañeros o de los adversarios, la situación del móvil, la ubicación de las metas.

El tipo de deporte en el que se va a iniciar el sujeto va a ser fundamental a la hora de seleccionar las estrategias y la metodología a utilizar por el profesor/entrenador, así como las propuestas pedagógicas idóneas.

\subsubsection{El contexto}

Las características del sujeto y las de la actividad en la que se va a iniciar son elementos fundamentales y condicionales básicos, que se ven complementados con el contexto en el que se ubican ambos.

No es lo mismo si la actividad se contextualiza en un ambiente educativo como puede ser la escuela, que si éste es un ambiente eminentemente competitivo o de rendimiento como pudiera ser en el seno de un club deportivo, donde se pretende ocupar un tiempo de ocio de forma activa. Los fines de la actividad son distintos y por lo tanto las características del proceso de iniciación deportiva deben ser diferentes.

El contexto puede estar íntimamente relacionado con el sujeto porque no es lo mismo nacer en una familia cuyos miembros son jugadores federados de una determinada modalidad deportiva que en una familia indiferente ante la práctica 
deportiva. No es lo mismo, de igual manera, nacer en San Juan o en Bahía Blanca a la hora de querer practicar hockey sobre ruedas o básquetbol.

Las facilidades o dificultades que proporciona el contexto inclinarán al sujeto por una u otra modalidad deportiva. No es lo mismo estudiar en el colegio José Hernández de Villa Ballester -en el cual el handball asume devociones casi religiosas-, que hacerlo en el Colegio San Luis de La Plata donde es el rugby el que ocupa esa posición.

Las dificultades para disponer de instalaciones o materiales necesarios para la práctica de una u otra modalidad deportiva van a suponer otro elemento importante a la hora de valorar la iniciación en un deporte.

\subsection{OTROS ASPECTOS A TENER EN CUENTA EN LA INICIACIÓN DEPORTIVA}

\subsubsection{En cuanto al niño}

No se puede disociar maduración de aprendizaje. La maduración es la tendencia fundamental del organismo a organizar la experiencia y convertirla en asimilable. El aprendizaje es el medio de introducir nuevas experiencias en esta organización. Maduración y aprendizaje influyen el uno sobre el otro para obtener el desarrollo. El siguiente cuadro puede ayudar a comprender esta cuestión:

\begin{tabular}{|c|c|c|}
\hline Maduración & y aprendizaje $=$ & desarrollo \\
\hline Maduración & y no aprendizaje $=$ & no desarrollo \\
\hline No maduración & y aprendizaje $=$ & pérdida de tiempo \\
\hline No maduración & y no aprendizaje $=$ & sin efecto \\
\hline
\end{tabular}

Cuadro 3. Blázquez Sánchez, 1986 
- Desde el punto de vista pedagógico es preciso considerar:

En ciertos períodos "críticos" existen comportamientos que se adquieren con el mínimo esfuerzo y la máxima eficacia.

El niño no puede realizar actividades complejas si no ha alcanzado la edad en que las actividades básicas se realizan normalmente. El niño puede aprender más fácil y rápidamente si alcanza un nivel de madurez específico para la actividad.

La maduración del sistema neuro-muscular que se consigue hacia los seis años permite el desarrollo de las sensaciones cenestésicas, visuales y laberínticas en la estructura del esquema corporal.

Importa poco que el niño aprenda lo antes posible técnicas deportivas; mucho más importante es que amplíe las múltiples posibilidades de movimiento mediante juegos o tareas variadas. Esas habilidades y combinaciones de movimiento precozmente adquiridas se conservan en la memoria motriz, indispensable para el aprendizaje y su retención. No se trata de introducir cualquier tipo de tarea o juego; es necesario analizar y escoger las tareas o juegos a proponer de manera que resulten significativas, bien por su posible transferencia inmediata a otros ámbitos, bien por su disponibilidad de transferencia a otras tareas o juegos de mayor dificultad.

- Estimulación y experimentación

Según plantea Blázquez Sánchez (1986) si se estimula al niño, es posible que vaya adquiriendo nuevas habilidades continuamente. Como en el lenguaje, la actividad física exige una experiencia que debe adquirirse durante los primeros años de vida; por consiguiente, lo importante no es determinar la edad para iniciar al niño en los deportes, sino saber escoger la tarea apropiada y la forma de presentarla en cada momento.

Cuando el niño aprende a correr, a lanzar, a atrapar, está iniciándose -lato sensu- en el deporte, puesto que cada uno de estos aspectos forma parte 
de la práctica deportiva. Saber estimularlos y provocarlos es en definitiva empezar la iniciación deportiva.

El dominio progresivo de las situaciones de juego se consigue por el paso de una etapa evolutiva a otra más diferenciada; esto es debido a que el nivel de desarrollo determina las posibilidades de ejecución. En cualquier caso, las posibilidades de elección que un jugador efectúa sobre una gama de informaciones o percepciones dependen, en gran medida, de sus experiencias pasadas. Esta interrelación entre experimentación y nivel de evolución hace que si bien los estímulos deben ser adecuados y adaptados, la experimentación y vivencia de diferentes y múltiples situaciones es imprescindible.

\subsubsection{Aspectos a tener en cuenta en cuanto a la pedagogía utilizada}

Al igual que en las materias intelectuales, en la enseñanza deportiva se encuentra una clara oposición en cuanto a la forma de su tratamiento pedagógico. Dos grandes puntos de vista pueden ser analizados.

\section{- Los métodos tradicionales}

Según el autor Blázquez Sánchez (1986) basados en criterios de análisis de los elementos (descomposición de la materia en partes para su enseñanza), de aprendizaje sistemático de los elementos en cuestión, de dominio del juego mediante asociación de los diversos elementos, la idea central consiste en partir de lo simple para llegar a lo complejo. El educador enseña al niño un repertorio de gestos técnicos que se suponen la base del juego. Este método de enseñanza respeta el enfoque mecanicista basado en el modelo del campeón. El principiante, el niño, no puede acceder al gesto ideal que representa el gesto del campeón, por eso se descompone el gesto complejo en elementos más simples que por asociación permiten lograr la ejecución completa. En este tipo de enseñanza se utilizan las "progresiones pedagógicas". Cada una de estas progresiones está compuesta de una serie 
más o menos larga de ejercicios que comportan una graduación en la dificultad.

La relación profesor-alumno depende de los objetivos perseguidos. Así pues, dos aspectos fundamentales deben ser tenidos en cuenta: uno concerniente a la calidad de los medios utilizados (el profesor vigila la validez de los ejercicios y de las situaciones específicas); otro concerniente a las modalidades de transmisión del contenido, así como las modalidades de intervención (el profesor dirige su atención al progreso y al nivel de asimilación al que llegan los alumnos sobre el conjunto de elementos a aprender).

Este método posee una serie de obstáculos. Con la preocupación de simplificar el aprendizaje y asegurar una mínima base de gestos técnicos, el educador elimina la posibilidad de una toma de conciencia por parte del alumno, del momento, lugar y razones de la utilidad de ese gesto técnico en juego, lo que suprime la relación gesto-juego.

El niño aprende aspectos parciales y aislados del juego, pero que no se encuentra en ningún momento o en muy pocas circunstancias situado en la realidad del propio juego, lugar donde realmente se producen todas las interrelaciones y el ensamblaje de todos sus elementos.

En este sistema no existe una preocupación por el interés que pueda tener el niño, ni sus capacidades para asimilar los ejercicios propuestos.

\section{- Los métodos activos}

Continuando con los métodos, Blázquez Sánchez (1986) parten de los intereses del niño reclamando su iniciativa, imaginación y reflexión en la adquisición de unos conocimientos adaptados.

Los principios esenciales que presiden esta concepción son los siguientes:

partir de la totalidad es decir, del grupo, del equipo, considerándolo como un conjunto estructurado con vistas a la realización de un proyecto común; la 
acción individual va a tomar significación en relación con esa totalidad, de ahí la necesidad de organizar equipos constituidos por grupos estables.

Mariott (1995), propone partir de la situación de juego, ya que es a lo largo del encuentro cuando surgen las dificultades. El partido es el motor esencial, tanto si se trata de deportes como si se trata de juegos colectivos. Los jugadores así implicados en la acción deben buscar las soluciones para resolver los obstáculos. Se hace mención a la reflexión.

Los gestos técnicos corresponden a un comportamiento grupal. Estos gestos deben ser deducidos a partir de la situación de juego y respetando la disponibilidad del jugador, evitando respuestas estereotipadas.

En esta nueva acción pedagógica, los problemas que se le plantean al niño corresponden a su momento de aprendizaje. La técnica está adaptada a la situación.

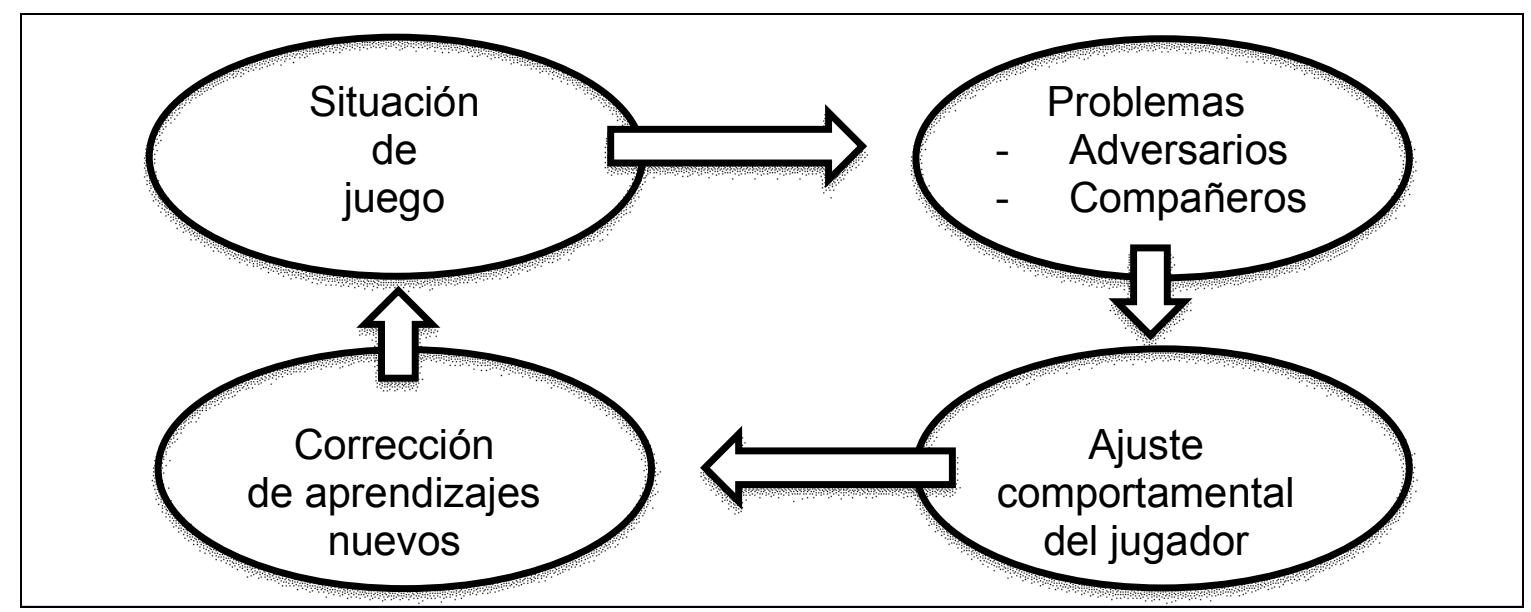

Cuadro 4. Blázquez Sánchez, 1986

El profesor pasa de ser un demostrador para ocupar un papel de animador a la reflexión y a la comprensión. Esta concepción toma en consideración el juego como elemento fundamental y a partir del cual se elabora todo el proceso didáctico. Los juegos son la actividad básica de trabajo. Partiendo de los juegos simples se va ascendiendo en la dificultad hasta llegar a los 
juegos codificados y reglamentados como escalón previo a la práctica de los diferentes deportes de equipo.

Sólo un estudio sistemático de lo que comporta y supone para el niño cada uno de los juegos y su lógica interna, acompañado de una pedagogía dirigida y encaminada a la reflexión de la situación motriz, puede dar la clave para abordar la enseñanza deportiva con la seguridad de estar colaborando al desarrollo de la inteligencia motriz y capacitando al educando para ser un jugador inteligente dentro de su propia práctica.

En la actualidad, aparece esta nueva acción pedagógica que llevada al terreno deportivo se encuentra en las antípodas de la concepción mecanicista que limita al jugador a unas respuestas precisas, impidiéndole su adaptación a las circunstancias a través de su propia reflexión. Esta mecanización queda destruida cuando el adversario no responde en el sentido esperado.

Las propuestas de las distintas escuelas de formación nos van a mostrar formas de enseñar el deporte abierto de invasión de territorio como el handball. La escuela francesa y su evolución mencionada anteriormente desembocarán en el ya presentado Marriot, quien se basa en el desarrollo de las intenciones tácticas, creando en el sujeto un nivel máximo de incertidumbre al momento de resolver. La escuela española -en manos de los ya mencionados Xesco Espar y Manolo Laguna- nos lleva a sostener que no existen las etapas, sino sólo momentos de adaptaciones al juego; por ello, se presentan esos momentos donde el balón será el centro de atención, luego se pasa al problema de cómo poder ganar terreno multidireccionalmente $y$, del logro de esto, pasar a ganar terreno orientado al arco para, finalmente, poder llegar al juego con intencionalidad.

Las escuelas alemana, rusa y yugoslava -denominaciones que sostenemos a pesar de los cambios en Europa del Este- mantienen su formación desde el campo de la técnica como objetivo prioritario para la resolución de los problemas que se presentan en el juego en sí. Kroger y Roth (1999), generan la "Escuela del balón"; en ella buscan fusionar todos los criterios posibles de 
la formación inicial para lograr un jugador que sea lo más completo, trabajando siempre desde y con el balón, acertando a objetivos fijos y móviles, transportándolo a objetivos ya establecidos, jugando en conjunto (para saber quiénes son mis compañeros y tener así una identificación más clara de los objetivos) y creando superioridad numérica en todo momento (lo que llevará a reconocer espacios y así poder superar al adversario). ${ }^{4}$ En fin son muchas las escuelas y las posibilidades que se presentan al momento de comenzar con la formación del "jugador Inteligente". Pero, ¿a qué nos referimos con "jugador inteligente"? En principio, al que puede resolver siempre bien, o mejor dicho en un deporte donde los márgenes al error son muchos, el que menos errores cometa. Conviene entonces ahora plantear los métodos que nos pueden servir a este fin.

\subsection{ETAPAS DE LA INICIACIÓN DEPORTIVA}

\subsubsection{Desde las perspectivas de las características del sujeto}

Hernández Moreno (2000) dice que, las diversas ciencias y tecnologías que abordan la enseñanza y aprendizaje de las actividades físicas (aprendizaje motor, teoría del entrenamiento, biomecánica, fisiología del esfuerzo, pedagogía del deporte, psicología del deporte, entre otros) consideran que la formación deportiva es un proceso que se extiende durante un largo período de la vida del sujeto, dependiendo su mayor o menor duración de las características del deporte de que se trate y de las capacidades de cada practicante.

Cuando la iniciación se hace con objetivos de lograr altos rendimientos deportivos, en muchos casos y en determinadas especialidades, se da una tendencia hacia la especialización precoz, como en los casos de la gimnasia rítmica y artística y en la natación. Por el contrario en otras especialidades como

\footnotetext{
${ }^{4}$ Kroger y Roth distinguen seis momentos: lanzamiento a puntos fijos y móviles (para facilitar el cálculo motor óptico), traslado del balón (pase, recepción y dribling), juegos de lanzamiento y traslado (cooperación y oposición con compañeros y rivales), creación de superioridad numérica, reconocimiento de espacios y superación del adversario.
} 
la halterofilia, el atletismo y algunos deportes de equipo, la tendencia es la inversa, es decir, que se planifica dicho proceso de iniciación con un periodo mucho más amplio. Estos planteos se diferencian no solo por la edad en que se comienza con la especialización sino también por la duración del mismo y por los planteamientos didácticos empleados. Mayor duración y métodos más activos en la especialización no precoz.

Aunque de una forma muy generalizada, el proceso de iniciación deportiva se suele afrontar tomando como referencia fundamental los periodos evolutivos del individuo, y aun siendo tal criterio necesario para proceder adecuadamente, pensamos que no es suficiente, sino que además debe unirse a ello las características de la estructura funcional del deporte, para conjugar ambas. Por ello se va a intentar una aproximación a la iniciación deportiva considerando en primer lugar la evolución del sujeto, luego la estructura del deporte, para finalmente tratar de llegar a una síntesis o unión de una y otra.

Existe un gran número de autores que han tratado el tema de la iniciación o formación deportiva desde la perspectiva de la evolución del individuo, con grandes coincidencias entre los mismos. Leali (citado en Hernández Moreno, 2000), propone cinco etapas que van desde los $7 / 8$ - 10 años hasta los 18 dividido en periodos de dos años. Mondini (1983) propone también cinco etapas que van desde los $6-8$ hasta los $18-20$ años. Por su parte, otros autores proponen tres etapas que comprenden por lo general las edades que desde los 8 - 10 años hasta los 18 - 20 años. (Hernández Moreno, 2000: 16)

Nosotros coincidimos con el criterio de estos últimos autores y sus tres etapas en el período de formación deportiva que denominamos:

- Etapa de Formación Básica.

- Etapa de Formación Específica.

- Etapa de Perfeccionamiento Deportivo.

Si bien los autores mencionados son concurrentes en el uso del término "etapa", preferimos el uso de la voz "momento", la cual nos induce a pensar en términos menos rígidos el comienzo y el fin; en todo caso, los momentos implican 
sucesiones. Así, en el primer momento, se procede a dar una formación genérica y polivalente, de manera tal que el sujeto adquiera las bases de movimiento sobre las que asentar posteriores aprendizajes. En el segundo momento enseña la estructura funcional del deporte de una manera específica. Mientras que en el tercero, se perfeccionan los aprendizajes adquiridos. Ahora bien, se puede percibir que no hemos mencionado edades, pues, en función de todo lo dicho, los que se inician, se inician en un deporte no en una edad para ese deporte. Es menester evitar que los llamados formadores queden sujetos a viejas recetas al momento de forjar nuevos deportistas: en este punto es crucial que permanezcan activas las alarmas del por qué y para qué se enseña cada contenido en cada momento de la formación. Por ejemplo: mucho se habla de las estrategias visuales, pero, ¿se sabe cómo integrarlas al proceso de formación de un jugador inteligente?

\subsubsection{Desde la perspectiva de la estructura de los deportes}

Algunos autores al analizar el proceso de formación en la iniciación deportiva lo hacen desde la perspectiva de la estructura del deporte, que exponemos a continuación.

Hein (citado en Hernández Moreno, 2000), propone un modelo dividido en cinco etapas cuyos contenidos básicos y denominaciones son las siguientes

- $1^{\circ}$ Nivel: Juego de habilidad y capacitación de base: juegos polivalentes y habilidades básicas.

- $2^{\circ}$ Nivel: Juego simplificado: prácticas simplificadas de juegos similares al deporte que se aprende.

- $3^{\circ}$ Nivel: Minideporte: el deporte de que se trate con número reducido de participantes

- 4 Nivel: Juego modificado: simplificación de las reglas de juego del deporte

- $5^{\circ}$ Nivel: Juego reglamentado: práctica del deporte como tal. 
Vankersschaver (1982) expone una estructuración en tres fases:

- $1^{\circ}$ Fase: Centración: familiarización con el espacio, técnicas básicas y elementales, estrategias simples, reglas fundamentales e interacciones sustantivas.

- $2^{\circ}$ Fase: Descentración: espacio específico básico, técnicas aplicadas, estrategias combinadas e interacciones combinadas.

- $3^{\circ}$ Fase: Estructuración: espacios combinados y aplicados, técnicas en función de la estrategia, estrategias complejas e interacciones complejas.

La iniciación deportiva, vista desde la estructura de los deportes, debe configurarse como un proceso que tenga en cuenta tanto los rasgos caracterizadores de los parámetros que configuran a dichos deportes y su mayor o menor incidencia en la referida estructura, como el tipo y modalidad de interacción o relación que se da entre estos parámetros. A esto es a lo que denominaremos complejidad estructural.

EI GEIP (Grupo de Estudio e Investigación Praxiológica) distribuye las fases del proceso de iniciación deportiva atendiendo a dos factores que consideran la complejidad estructural de los deportes. El primero señala el objetivo motor prioritario que se debe alcanzar en la realización de la tarea (deporte), estableciendo en este caso la secuencia siguiente:

- Efectuar actividades interoceptivas (no existen deportes en este grupo).

- Efectuar y/o evitar traslaciones (carreras, lanzamientos).

- Reproducir modelos y/o evitarlos (patinaje artístico, culturismo).

- Combatir cuerpo a cuerpo y/o evitarlo con o sin implemento (lucha, esgrima).

- Situar el móvil en un espacio y/o evitarlo (baloncesto, waterpolo).

Partiendo de la complejidad estructural y centrada en las condiciones para la praxis, la secuencia que parece más adecuada para la iniciación deportiva en los distintos deportes es la siguiente: 
- Deportes psicomotrices en los que el espacio en que se desarrollan es un espacio estandarizado o sin incertidumbre para el participante (salto de longitud, natación en piscina en pruebas individuales).

- Deportes de cooperación en los que el espacio en que se desarrollan es un espacio estandarizado o sin incertidumbre para los participantes (gimnasia rítmica por equipos, patinaje artístico por parejas).

- Deportes psicomotrices en los que el espacio en que se desarrollan es un espacio no estandarizado o portador de incertidumbre para el practicante (windsurf, paracaidismo).

- Deportes de cooperación en los que el espacio en que se desarrollan es un espacio no estandarizado o portador de incertidumbre para los participantes (ciclismo contrarreloj por equipo, descenso en aguas bravas por equipos).

- Deportes de oposición en los que el espacio en que se desarrollan es un espacio estandarizado o sin incertidumbre para los participantes (lucha canaria, boxeo).

- Deportes de oposición en los que el espacio en que se desarrollan es un espacio no estandarizado o portador de incertidumbre para los participantes (motocross con varios participantes a la vez en la pista, cross).

- Deportes de cooperación/oposición en los que el espacio e que se desarrollan es un espacio estandarizado sin incertidumbre par los participantes (baloncesto, rugby).

- Deporte de cooperación/oposición en los que el espacio en que se desarrollan es un espacio no estandarizado o portador de incertidumbre para los practicantes (ciclismo en ruta por equipos, vela latina). 


\subsection{EL PROCESO DE LA INICIACIÓN}

En el caso concreto de los deportes de equipo, "iniciar" supone pasar del juego de niño al juego de adulto y del inexperto al experto, y al mismo tiempo cuestionarse cómo efectuar estos pasajes. Existen, en este sentido, dos posiciones antitéticas. Por un lado, están quienes promueven la iniciación imitando directamente el juego del adulto/experto; es decir, iniciando inmediatamente a la práctica del deporte en sí, o bien partiendo de las posibilidades y características evolutivas del niño. Por otro, quienes procuran ayudar a descubrir progresivamente los principios comunes de los deportes de equipo; en este caso, se constata que, si bien las niñas y los niños despliegan en el juego una enorme actividad que le proporciona un gran placer, también se observa que las primeras veces que el niño juega un deporte de equipo ocurren algunas de de estas situaciones: los más fuertes monopolizan el balón, acostumbrándose a prescindir de los demás; los más débiles participan poco, más bien asisten al juego; inclusive, el propio educador no puede ejercer demasiada influencia a causa del desorden que se provoca.

Proponer elementos para la elaboración de un programa de iniciación a los deportes de equipo supone intentar fijar unos puntos de referencia, niveles o momentos que den una dirección y un sentido a las intervenciones pedagógicas. Supone también proponer un contenido, situaciones pedagógicas que permitan facilitar el paso de una etapa a otra. De manera análoga a lo expresado en el párrafo anterior, la práctica actual se caracteriza por dos enfoques diferentes de planteamiento. El primer modelo se basa en el juego libre y espontáneo, cuyo fundamento es la búsqueda del esparcimiento y el desahogo a las necesidades de movimiento. Esta situación, fundamentalmente recreativa, se caracteriza por sus limitadas exigencias al perfeccionamiento motor. La actitud del educador puede ir de la no directividad absoluta a una relativa organización de la actividad del niño. El segundo modelo la idea dominante es el juego con intervención del profesor, que es cuando el educador interviene para modificar la práctica de los niños. Se trata de aprender uno o muchos deportes de equipo tomando como referencia la práctica del adulto. 
La actividad libre del juego es aprovechada con dos intenciones: para aplicar determinadas técnicas o tácticas, o bien para corregir errores. Lo que caracteriza la actividad del educador es su intención de enseñar las técnicas extraídas del deporte como competición. Pero si se tiene en cuenta una concepción general del aprendizaje más unida a la renovación pedagógica, es necesario superar estas dos concepciones. Es necesario confrontar los esquemas del niño y sus acciones generales con las exigencias contenidas en la práctica de los deportes de equipo. Estas exigencias tienen un carácter específico; los deportes de equipo son fundamentalmente actividades de comunicación, de relación con vistas a una tarea a realizar. Más que transmitir un bagaje de conocimientos (técnicas) se trata de enriquecer y de transformar conductas. La evolución de las conductas hacia una mejor adaptación a los deportes de equipo supone el acceso a un comportamiento más razonado, teniendo en cuenta las diferentes variables tales como el adversario, los compañeros, el balón, etcétera.

\subsection{PROGRAMAR LA INICIACIÓN}

En el sentido de lo aquí expuesto, parece razonable tener en cuenta los siguientes elementos:

\subsubsection{Situación inicial de la que parte el aprendiz}

En principio, esta cuestión implica conocer las posibilidades de juego de cada niño y niña, y al niño mismo, del mismo modo que conocer la naturaleza del juego infantil. Es necesario reconocer que no todos los niños y las niñas participan necesariamente en el juego y que las relaciones con los compañeros asumen un modo casual.

Cuando un jugador tiene la pelota, el resto corre detrás de él, o colocándose delante de él intenta recibirla o arrebatársela. Compañeras y adversarias son contrincantes que impiden que la niña posea el balón. Por otra parte, no existe equipo en ataque o en defensa, sólo jugadores y jugadoras que quieren conseguir el balón: y la pelota pasa a menudo de un equipo a otro. Asimismo, es 
fácil comprobar que la presencia de los arcos no modifica fundamentalmente el comportamiento: la pelota va raramente de una valla a otra.

En los comportamientos de niñas y niños que comienzan a jugar, suele verse que, en ataque, quien está en posesión del balón conduce solo o sola el balón hacia el arco contrario y, si puede, lo lanza al arco; en cambio, si no puede tirar, pasa al primer compañero que esté a su lado o lanza el balón de cualquier manera. Si la defensa es tan fuerte que no le permite avanzar con el balón hacia el arco, pasa a uno de los compañeros, generalmente al que él considera el mejor. Mientras tanto, también en ataque, si no está en posesión del balón, suele permanecer inmóvil observando al que posee el balón, en ocasiones se dirige hacia el portador o la portadora y, a veces, imagina que le van a pasar el balón. La actuación en defensa suele reducirse a mirar a quien tiene el balón, situarse entre quien tiene el balón y el adversario más próximo para evitar el pase o intentar interceptar el pase si el balón pasa cerca de él.

\subsubsection{Objetivo final que se pretende alcanzar}

Siempre dentro del análisis de la propuesta que estamos considerando, resulta imprescindible tener las ideas claras sobre la evolución final del juego y el tipo de jugador que se quiere conseguir. En tal sentido hay dos elementos irrenunciables: que todos los jugadores participen activamente en el juego; y que los jugadores se organicen juntos, formen una red, un bloque y que cada uno marque a un adversario.

En la primera de ellas la participación activa de los jugadores nos muestra que la información que recibirán del entorno será mayor, su relación con los participantes será más completa al momento de tomar decisiones y tendrá un respaldo que nunca podrá lograr sin la participación lógica del juego. Respecto al segundo punto mencionado anteriormente, el juego será un nexo entre los protagonistas donde establecerán patrones de status tanto defensivos como ofensivos que harán que se asuman responsabilidades como la marca individual, las ayudas, la comprensión y el respeto por las reglas de juego, conformando así una red comunicacional no solo entre sus compañeros sino también entre sus 
oponentes. En síntesis, el objetivo final es que todos participen del juego ya que la relación entre el aprendizaje y la comprensión estará dada por su activa participación.

\subsubsection{Proceso de enseñanza}

El proceso de enseñanza implica -cualquiera sea la postura que se adopteavanzar progresivamente en etapas sucesivas. El programa educativo debe comprender, la elección didáctica de los juegos y contemplar además, como se ha señalado, el desarrollo mental e intelectual que hace emerger la capacidad de respuestas tácticas y estratégicas a cada una de las diferentes situaciones. En el capítulo siguiente desarrollaremos con detenimiento las cuestiones relativas a los métodos de enseñanza; pero, para cerrar este capítulo dedicado a la iniciación es conveniente apuntalar dos elementos centrales del proceso: la elección de los juegos y su sentido estratégico.

\section{- Elección de los juegos}

Los criterios didácticos usualmente convenidos en la selección de los juegos de iniciación aluden, en primer lugar, al potencial educativo; es decir, a su valor para la formación física general y su capacidad de desarrollo de las acciones complejas (atención, concentración, percepción, etc.). En segundo lugar se invoca a las particularidades emocionales, intelectuales y físicas de cada edad; no se trata únicamente de adaptar la materia en función de la edad, sino de tratar de ejercer una influencia adecuada y en relación con el desarrollo del niño (la enseñanza bien planteada precede al desarrollo del niño). La capacidad de los juegos para motivar puede ocupar el tercer lugar de esta lista; esta motivación cobra valor tanto desde el punto de vista del desarrollo de la personalidad como para la eficacia pedagógica. En cuarto lugar preferimos ubicar el carácter clave de ciertos juegos: la problemática y diversidad estratégica que plantean hace que puedan ser repetidos frecuentemente y que incluso pueden ser motivo de competiciones. Finalmente, todos los juegos deben servir y orientarse en función de la 
enseñanza de los deportes de equipo; debe reconocerse en cada juego una forma de preparación para la práctica de los deportes institucionalizados.

- Desarrollo de la formación estratégica

Si se toma en cuenta al desarrollo de esta tesis, no resulta difícil percibir que, en función de los argumentos ofrecidos, los modelos de enseñanza más sólida y críticamente fundamentados son aquellos en los cuales el problema de orden táctico y estratégico es preeminente respecto de aquel de naturaleza técnica. En consecuencia, la influencia del educador permitirá que el juego se desarrolle en función del objetivo propuesto si es capaza de orientar la motivación de los alumnos de manera que el objetivo pedagógico sea asumido por ellos mismos. En este marco, el entrenador-profesor debería crear una situación problemática y concienciar de ella a los aprendices; invocar sus respuestas a partir de sus propios conocimientos adquiridos en el proceso; colaborar en el análisis de la solución descubierta y utilizada. Si el profesor fija objetivos estratégicos concretos para cada juego, mejoran sus chances de desarrollar continuamente las capacidades mentales de los niños.

\subsection{BIBLIOGRAFÍA DEL CAPÍTULO}

Blázquez Sánchez, D. (1986) Iniciación a los deportes de equipo. Barcelona: Martínez Roca.

Cavalli, D. (2008) Didáctica de los deportes de conjunto. Problemas, enfoques y modelos de enseñanza. Buenos Aires: Stadium.

Espar, X. (2001) Balonmano. Barcelona: Martínez Roca.

Hernández Moreno, J. (2000) La iniciación a los deportes desde su estructura y dinámica. Barcelona: INDE.

Hernández Moreno, J. (2000) La iniciación a los deportes desde su estructura y dinámica. Barcelona: INDE. 
Hernández Moreno, J. y J. P. Rodríguez Rivas (2009) “Una praxiología, es decir... (sobre los conocimientos de la ciencia de la acción motriz y su organización), en: Acciónmotriz N³. Disponible en: file://C:/Users/user/ Downloads/Dialnet-UnaPraxiologiaEsDecirSobreLosConocimientosDeLaCien6700102.pdf

Kroger C. y K. Roth (1999) Escuela del balón. Guía para principiantes. Barcelona: Paidotribo.

Laguna, M. (2001) “Jugar y hacer jugar”, en: Comunicado $N^{\circ} 425$. Madrid: Real Federación Española de Balonmano.

Mahlo, F. (1974) La acción táctica en el juego. La Habana: Pueblo y educación. Marteniuk, R. (1976) Information, Processing and motor skills. New York: Holt, Rinehatt\& Winston.

Marriot, J. (1995) Balonmano. De la escuela... a las asociaciones deportivas. Lérida: Ágonos.

Vankersschaver, J. (1982) Football. La information dans l'eécole ou dans le club. Partie 1. Paris: Education Physique et Sport. 
CAPÍTULO 5:

\section{MÉTODOS DE ENSEÑANZA}

\subsection{RESOLUCIÓN DE PROBLEMAS}

Según Sánchez Bañuelos (1992) la enseñanza mediante la búsqueda es una idea interesante y muy sugestiva para el docente dentro del campo de la educación física y el deporte, ya que desde el punto de vista educativo pedagógico ofrece una serie de ventajas importantes que no concurren en otras técnicas de enseñanza, entre las cuales podemos citar:

- Establece una relación clara entre actividad física y actividad cognitiva

- Destaca aspectos de la educación física de carácter intelectual

- Justifica la idea de que la educación física no está preocupada solamente por el desarrollo muscular

- Favorece un proceso emancipatorio, concediendo al alumno una capacidad de decisión significativa

- Amplía el campo de acción de la docencia en la educación física y el deporte a aspectos no tenidos en cuenta hasta la aparición de este concepto de enseñanza

- Individualiza la enseñanza

Estas ventajas y algunas otras que se podrían añadir, favorecen y confirman la idea de que ciertos procedimientos didácticos pueden realzar el valor de la educación física y deportiva en el contexto de una educación integral. En consecuencia la técnica de la enseñanza mediante la búsqueda goza de una amplia aprobación y predicamento dentro del ámbito educativo; sin embargo, ha sido contemplada con cierto escepticismo desde los círculos técnicos, por ser considerada de una eficacia dudosa con respecto a la progresión en el aprendizaje.

Como todo lo que representa un cambio, esta técnica de enseñanza puede chocar en un principio, en lo que se refiere a su aplicación práctica, con una serie 
de inconvenientes. En primer lugar, con la insoslayable resistencia que origina toda situación de cambio o modificación de los esquemas de actuación que nos son habituales. En segundo lugar la falta de familiarización con la metodología especifica de aplicación que inicialmente se puede encontrar el docente, ya que una simple extrapolación de los planteamientos didácticos de la enseñanza en el aula a nuestro contexto resulta absolutamente insuficiente.

Aquellos que hayan tenido la experiencia de efectuar en la práctica un planteamiento de enseñanza mediante la búsqueda según una didáctica no especifica, pueden haber sufrido una vivencia poco satisfactoria, ya que puede ocurrir que al alumno le resulte escasamente motivante y el resultado, de un valor dudoso. El profesor puede producir un cierto desencanto si:

- la solución al problema es conocida de antemano,

- o demasiado fácil,

- o imposible de encontrar,

- o el resultado implica mucha conversación y poca actividad motriz,

- o la posibilidad de evaluar objetivamente el resultado es escasa.

Todos estos inconvenientes pueden ser superados utilizando una didáctica específica, ya que en nuestro caso se trata de resolver problemas de carácter motor, y tal como se ha visto en el capítulo 3 de esta obra, al hablar del análisis de las tareas motrices, estas tienen unas peculiaridades que hacen que la aplicación de unos procedimientos de enseñanza específicos sean una auténtica necesidad. Como inicio al planteamiento de esta técnica aplicada a la enseñanza de las tareas motrices, se va a analizar el proceso de resolución de problemas. Recordemos que los componentes o pasos de ese modelo han sido graficados en el cuadro 4.

Todos ellos proponen cuatro pasos: a) situación de juego, b) problemas respecto de los adversarios y de los compañeros, c) corrección de aprendizajes nuevos y d) ajuste comportamental del jugador; de todos ello, el tercero el más crucial respecto a la aportación de la actividad cognitiva, con independencia de si a esta actividad se la denomina "inspiración", "sugerir mentalmente posibles hipótesis", 
"producción" o "búsqueda". El último y cuarto paso es, sin lugar a dudas, una manera de decir que al final la validez de la solución ha de ser contrastada ante la realidad.

En el caso de problemas de carácter motor, en los que se trata de la realización de tareas motrices, resulta evidente que en la tercera fase del proceso descrito se produce una actividad cognitiva y física, esta actividad se autorregula en forma de circuito cerrado de la siguiente manera: la manifestación externa del proceso de búsqueda es la actividad motriz del individuo; esta manifestación externa es fruto de decisiones tomadas a nivel cognitivo; el resultado de la actividad física va a afectar la siguientes tomas de decisión, y así sucesivamente. El proceso que se acaba de analizar no tiene por qué, ni debe, en el caso de la enseñanza de nuestra materia, estar vinculado necesariamente a procesos de raciocinio verbalizado. Lo que nosotros tratamos de propiciar son procesos de tipo cognitivo motriz, en los cuales la codificación de la información debe ser no verbal, es decir, utilizando códigos de tipo perceptivo motriz.

En la utilización didáctica de este proceso como base para la enseñanza, la incidencia directa del profesor se va a centrar en las fases primera, segunda y cuarta. En la fase primera y segunda la intervención del profesor tiene dos metas:

- plantear la dificultad u obstáculo a superar (planteamiento del problema)

- ayudar a definir y analizar las características y magnitudes del problema planteado.

El profesor puede encauzar, guiar o direccionar la búsqueda, proporcionando una mayor o menor información acerca del problema propuesto. En la cuarta fase la intervención del profesor, cuando ésta se produzca, está relacionada con un posible ajuste en la dirección de la búsqueda; en caso que ésta se encuentre excesivamente desviada, el profesor puede decidir dar algún tipo de información complementaria para reencausarla adecuadamente. 


\subsubsection{Condiciones básicas de los problemas}

La identificación de las características de las situaciones-problema que vamos a proponer a los alumnos para su resolución, es el primer paso para la puesta en práctica de la técnica de enseñanza. Sobre este particular hay que destacar ante todo que el carácter y dificultad del problema tiene que ser fundamentalmente motor. No se debe olvidar bajo ningún concepto que en cualquier otra materia el alumno va a tener la oportunidad de desarrollar su capacidad cognitiva y afectiva, pero que la oportunidad de enriquecerse motrizmente solo se la brindan las actividades que, como la nuestra, están relacionadas con el ejercicio físico y esta oportunidad no debemos negársela en ningún caso al alumno. Esto significa, que si se proponen problemas que no presentan al alumno ningún tipo de dificultad en su ejecución motriz, aunque impliquen un cierto uso de la capacidad cognitiva, pueden carecer de sentido y motivación para el alumno dentro del contexto de una clase de Educación Física. Será preciso resaltar que el punto de partida de esta técnica de enseñanza aplicada a nuestra área de enseñanza docente es el planteamiento de problemas motrices; cuando la dificultad del problema sea exclusivamente cognitiva hay que pensar que puede estar fuera de lugar.

Otro aspecto importante a considerar es el número de soluciones válidas que tenga el problema que vamos a plantear. Como se ha visto en los capítulos anteriores, cuando un problema tiene una única solución muy concreta esto origina la aparición de un modelo bien definido; en este caso, según todos los indicios, la técnica de enseñanza más conveniente respecto a la eficiencia en el aprendizaje seria la instrucción directa. Lo ideal es que un problema tenga varias soluciones que puedan abordarlo adecuadamente. No importa que en una circunstancia en concreto se destaque una como la mejor, si en general son varias las que puede resolver el problema convenientemente. Cuando el problema es de un carácter tan amplio que prácticamente cualquier solución lo resuelve, esto también puede ser motivo de falta de motivación, ya que no hay obstáculo incluso cuando se le insista al jugador de que no se trata sólo de encontrar una solución, sino que tiene que hallar la más eficaz o significativa posible. 
5.1.2. Metas y aplicaciones específicas de la enseñanza mediante la búsqueda Dentro de la propuesta que estamos considerando, para una utilización didáctica correcta de una técnica de enseñanza, lo primero que se ha de tener claro son los objetivos de aprendizaje que se pueden cubrir de una manera eficiente con esa técnica, e inmediatamente después, cuáles son las aplicaciones que ofrecen más garantías al plantear las metas adecuadas. Así, decir que la técnica de enseñanza mediante instrucción directa tiene como objetivo primordial el aprendizaje de modelos y que su aplicación más generalizada es la enseñanza de las técnicas deportivas, se está delimitando con suficiente precisión objetivos y aplicaciones. Si acerca de la técnica de enseñanza mediante la búsqueda se dice simplemente que su objetivo es la resolución de problemas motores, no se habrá precisado suficientemente cuál puede ser su aportación más efectiva en el desarrollo de la habilidad motriz, ya que en principio la ejecución de cualquier movimiento representa un problema motor a uno u otro nivel. Sin embargo, no podemos dejar de estar conscientes de que los objetivos de esta técnica de enseñanza tienen un carácter más amplio; las siguientes consideraciones pueden resultar esclarecedoras al respecto:

- en la enseñanza de modelos, la teoría de la transferencia que se está aplicando es la de los elementos idénticos;

- actuando de esta forma el individuo necesita hipotéticamente haber tenido muchos aprendizajes específicos para alcanzar una riqueza motriz de tipo general;

- con el planteamiento de problemas se intenta que se produzca una transferencia por generalización o transpolación;

- esto implica que la resolución de problemas lleva al individuo al descubrimiento de principios, conceptos de movimiento o relaciones mecánicas que le van a capacitar para ser operativo en una serie de situaciones, en las cuales, esos principios, conceptos o relaciones resultan de aplicación.

El uso indiscriminado y especulativo en la enseñanza de la transferencia por generalización o transpolación ha sido y es objeto de severas críticas por 
numerosos especialistas. Asumir que ésta se va a producir puede resultar una suposición muy aventurada: la constatación de que se han alcanzado las metas previstas se hace, a veces, imposible. Por todo esto, los planteamientos didácticos al respecto no deben ser excesivamente genéricos, sino ceñirse a unas categorías significativas que engloben aspectos específicos en el desarrollo de la habilidad motriz susceptibles de ser tratados mediante este procedimiento de enseñanza.

El análisis de las tareas motrices efectuado en el capítulo 3 puede ser de gran utilidad, para delimitar con más precisión las áreas en las cuales pueden centrarse de una manera más concreta los objetivos y aplicaciones de la enseñanza mediante la búsqueda. En la cadena senso-motriz, los mecanismos perceptivos, de decisión y de ejecución-control representan bloques operativos con una problemática propia muy concreta en cada uno de ellos. Como ya se ha visto, la dificultad de las tareas motrices con respecto a los tres mecanismos es diferencial; según se analizó en su momento, las tareas con una dificultad significativa en los mecanismos perceptivo y de decisión son más susceptibles a planteamientos de enseñanza mediante la búsqueda. Dentro de este contexto, se destacan algunos objetivos específicos como:

- Interpretación correcta de los estímulos que proporciona el entorno en relación con el movimiento propio.

- Desarrollo de la capacidad de ajuste del movimiento del individuo en el contexto espacio-tiempo.

- Desarrollo de la capacidad de decisión en la realización de tareas motrices (aspectos cognitivo-motores).

- Desarrollo de la capacidad de utilización inteligente del movimiento en situaciones complejas (lógica motriz).

Estos objetivos son planteados en una gran variedad de situaciones, las cuales exigen la capacidad de adaptar la conducta motriz a las exigencias de la circunstancia. Es evidente que esta técnica de enseñanza tiene, por tanto, como campo de aplicaciones fundamental la formación en el sujeto de conductas motrices adaptativas ante estímulos genéricos. La técnica de enseñanza de 
instrucción directa no debe considerarse, dentro de una aplicación didáctica adecuada de la misma, como contrapuesta a la de búsqueda sino complementaria, ya que tal como se ha analizado sus áreas de aplicación eficiente se encuentran bien diferenciadas.

El nivel de aprendizaje del alumno, junto con su grado de desarrollo motor y cognitivo, es otro factor importante a considerar a la hora de establecer una aplicación correcta de esta técnica de enseñanza. Cuando la resolución de un problema motor esté vinculada estrechamente con el encadenamiento o secuencia de una serie de movimientos (elementos), si estos elementos no han sido aprendidos previamente, es obvio que no será posible resolver el problema. Por ejemplo, si dentro de la enseñanza de un deporte estamos tratando de que el alumno resuelva un problema táctico, en el cual es necesario que sepa ejecutar correctamente una serie de fundamentos, para poder abordar el problema tendrá que haber aprendido con anterioridad dichos fundamentos. No será necesario por otra parte, insistir en que el alumno tiene que tener la disposición necesaria para poder resolver el tipo de problemas que se le plantea. Esto quiere decir que el nivel de exigencia del problema tiene que estar ajustado a los condicionamientos y necesidades de la etapa evolutiva en que se encuentre el alumno.

\subsubsection{Planteamiento del problema}

En el caso de la técnica de enseñanza mediante la búsqueda, la primera fase en el proceso de interacción docente-discente la constituye el planteamiento del problema. En principio, el docente tendrá que reflexionar acerca del grado de ayuda o dirección que va a proporcionar al alumno en la búsqueda. Toda situación en la que un profesor plantee un problema a sus alumnos implica en sí misma un cierto encauzamiento de la búsqueda. A nuestros efectos, sólo en una situación genuinamente autodidacta consideraremos que la resolución de un problema se enmarca en una búsqueda totalmente libre.

Muy vinculado con lo anteriormente expuesto se encuentra el tema del nivel de dificultad del problema. Un mismo problema puede representar una dificultad 
muy diversa para su resolución, dependiendo de la cantidad de información que sobre la misma parte el profesor. En el planteamiento del problema, el quid de la cuestión se encuentra por una parte en no proporcionar demasiada información, para promover así una auténtica actividad de búsqueda, pero por otra parte que sea suficiente como para no enlentecer innecesariamente el proceso de aprendizaje. Dentro de este orden de ideas, será útil considerar lo que dice Rubenstein (citado en Cavalli, 2008) al respecto, exponiendo, que la dificultad más común en la resolución de problemas no es la carencia de información, sino la falta de capacidad del sujeto para usar adecuadamente la información que posee. En el proceso de desarrollo de la habilidad motriz, la información básica se encuentra en nuestro cuerpo y en el entorno; el problema del profesor a este respecto es la de tomar la decisión de hasta qué punto va a hacer consciente al alumno de esa información y hasta qué punto le va a indicar como utilizarla.

Quizá en este punto no esté de más indicar que la enseñanza mediante la búsqueda, para algunos profesores imbuidos de una cierta filosofía educativa, puede constituir una gran tentación de asignar al proceso toda la importancia pedagógica y dejar de lado la importancia del resultado. Estos profesores deberían considerar que un proceso cuyos resultados son estériles o carecen de significado puede resultar en sí un proceso estéril y asimismo desprovisto de sentido.

De acuerdo con lo dicho anteriormente, se desprende que el modelo propone las siguientes directrices didácticas para el planteamiento de problemas:

- Tiene que suponer un reto para el alumno, de forma que provoque en él una disonancia cognoscitiva que le motive a la búsqueda de soluciones.

- El objetivo a conseguir tiene que ser alcanzable para el alumno para que haga un esfuerzo razonable en la búsqueda.

- La dificultad motriz del problema tiene que ser significativa. La búsqueda debe representar un esfuerzo físico apreciable.

- Son aconsejables las presentaciones a través de juegos o formas jugadas que favorecerán la motivación por la búsqueda. 
- Las normas o límites dentro de los cuales el problema ha de ser resuelto tienen que ser expuestas con claridad y precisión al alumno (la integridad del alumno puede depender en algunos casos del establecimiento de dichas normas).

- Se debe proporcionar suficiente información para que la búsqueda no se alargue en exceso y el alumno pierda interés.

- Los resultados de la búsqueda deben ser susceptibles de autoevaluación por parte del alumno y de constatación por parte del profesor.

En general el procedimiento para plantear los problemas tendrá carácter verbal ya que la información de tipo visual podría fácilmente dar en un gran número de ocasiones una idea global de la solución o destacar una solución peculiar, invalidando la búsqueda o coartando la creatividad del alumno.

En los párrafos anteriores se ha expuesto las características que debe tener la información que se le proporcione al alumno acerca del planteamiento del problema, así como una de las bases metodológicas sobre el procedimiento que el profesor puede utilizar en caso de que esta información la transmita de un modo directo, es decir, utilizando únicamente sus propios medios.

El profesor puede también plantear el problema por medio de procedimientos de carácter indirecto, mediante los cuales se va a tratar de conducir una cierta cantidad de información al alumno en forma no verbal. Las condiciones del entorno en el cual se va a desenvolver la búsqueda influyen de una manera apreciable tanto en el proceso como en el resultado de la misma. El docente puede tener en la estructuración y disposición del entorno de enseñanza y de aprendizaje una incidencia considerable. Como se va a estudiar en el siguiente apartado, esto va a constituir un recurso de un inapreciable valor en esta técnica de enseñanza.

Cavalli (2008) plantea que una situación problema puede ser pensada como una situación que demanda una respuesta adaptada que el jugador no puede proporcionar ejecutando de forma automática alguno de los gestos deportivos de los que dispone en ese momento. La riqueza de este tipo de situaciones, 
reside en su potencialidad para desarrollar en los alumnos la capacidad de adaptación frente a la nuevo e inesperado.

\subsubsection{Bases teóricas y psicopedagógicas del modelo}

El modelo de las situaciones-problema hunde sus raíces en el marco de la psicología cognitiva. Según Riviere (citado en Sánchez Bañuelos, 1992), lo más general y común que se puede decir de esta psicología es que refiere la explicación de la conducta a estados, procesos y disposiciones de naturaleza mental. A su vez, en el interior de este programa de investigación -en el cual conviven tradiciones diversas-, las teorías que mejor parecen sentar las bases del modelo y ayudar a comprender su funcionamiento son las del procesamiento de información.

Lo que caracteriza a estas últimas, es la concepción del ser humano como un procesador de información -que deviene de la aceptación de la analogía mentecomputadora-, y su preocupación por estudiar la secuencia y ejecución de los hechos cognoscitivos que se producen entre la recepción del estímulo y la producción de la respuesta por parte del sistema.

El modelo de ejecución motriz de Marteniuk (citado en Sánchez Bañuelos, 1992), resulta paradigmático respecto de esta caracterización, ya que representa el aprendizaje motor como un sistema de procesamiento de información que contiene: un mecanismo perceptivo -de los estímulos provenientes del medio-, un mecanismo de decisión, un mecanismo de ejecución motriz y unos mecanismos de retroalimentación, que actúan de forma secuencial.

En el mismo texto, Sánchez Bañuelos nos señala que el primero de los mecanismos se ocupa de discernir los aspectos esenciales, relevantes y significativos de una situación y de abstraer lo accesorio. El segundo, de seleccionar, de entre un número de alternativas posibles, aquella respuesta motriz que pueda resultar más eficiente para alcanzar el objetivo de la tarea. El tercero, en cambio, es el encargado de la realización del movimiento a partir de la coordinación y puesta en acto de un conjunto de acciones musculares tipificadas previamente. Los mecanismos de retroalimentación, finalmente, 
implican un desarrollo y un estado de conocimiento sobre los propios procesos de aprendizaje, y designan una serie de operaciones, actividades y funciones cognoscitivas que permiten recabar, producir y evaluar información, a la vez que hacen posible que una persona pueda conocer, controlar y autorregular su propio funcionamiento intelectual.

\subsubsection{Objetivos del modelo}

La propuesta analizada contempla los siguientes objetivos:

- Permitir el desarrollo de los gestos técnicos manteniendo el balance entre mecanización y plasticidad en el aprendizaje.

- Desarrollar la capacidad de adecuación de dichos gestos técnicos a las condiciones de incertidumbre propias del entorno de los deportes de conjunto.

- Desarrollar la capacidad de "lectura" de las situaciones motrices, en tanto competencia, para interpretar los estímulos provenientes del juego.

- Desarrollar y optimizar la capacidad de decisión en el marco de situaciones motrices adecuadas a tal fin.

- Estimular los procesos de autocontrol y monitoreo efectivo sobre las respuestas motrices y sobre los resultados de las mismas.

- Facilitar la transferencia de los aprendizajes en tanto, el aprendizaje centrado en un problema permite aplicar posteriormente el conocimiento de una manera más flexible e imaginativa

A su vez Onofre (1998), en referencia al estilo de resolución de problemas dice que, significa un paso más en la profundización del descubrimiento guiado, pues mientras que en este ultimo la esencia está constituida por los indicios del profesor y las respuestas del alumno, en aquel se pretende que el alumno encuentre por sí mismo la respuesta con total independencia del profesor, por lo que el proceso heurístico es completo. De ahí que este estilo represente el nivel 
más avanzado de los estilos de enseñanza, pues tan solo se tiene la dependencia del profesor en el diseño de los problemas.

La estrategia consiste fundamentalmente en la búsqueda de alternativas para la revolución de problemas motrices, estimulando así la creatividad del alumno, lo que significa para él una gran independencia con respecto al maestro. En consecuencia, es fundamental una buena selección de los problemas a resolver, de tal manera que sean relevantes tanto desde el punto de vista de la materia, como de la preparación y experiencia del sujeto o grupo.

La ejecución de la estrategia supone que los problemas planteados deben ajustarse a la experiencia, disposición e interés del alumno; esto es, han de ser significativos, ya que el propósito de resolver problemas no es la repetición de respuestas conocidas de antemano; en tal sentido, el profesor debe saber el grado de dominio de sus alumnos para ajustar adecuadamente una serie de problemas en donde la solución nunca debe ser conocida por los alumnos.

El estilo se pone en marcha mediante la presentación del problema a los alumnos, a lo que sigue una fase de actuación individual de éstos de acuerdo a su ritmo y capacidad, para más tarde habilitar un tiempo de reflexión y aclaración sobre la naturaleza del problema, así como de espera para la toma de decisiones, finalizando con el momento de refuerzo de las respuestas positivas de los alumnos.

A medida que este proceso avanza el alumno alcanza un mayor nivel de individualización en todos los aspectos, acrecentando su capacidad para enfrentarse a nuevas situaciones y resolver los consiguientes problemas que surgen durante el periodo de aprendizaje, siendo cada vez más autónomo.

La enseñanza de los deportes colectivos proporciona muchas oportunidades para el empleo de este estilo, sobre todo en aspectos relacionados con la táctica y la estrategia, ya que la esencia de un tema de dicha naturaleza es la de carácter problemático. ${ }^{5}$

\footnotetext{
${ }^{5}$ Hemos elegido a autores que están en clara sintonía, quienes apuestan en favor de un proceso de autonomización del jugador, proceso en el cual percepción del problema y toma de decisiones
} 


\subsection{INSTRUCCIÓN DIRECTA}

Según Sánchez Bañuelos (1992), haciendo referencia al concepto de instrucción directa, dice que en muchas tareas motrices, el rendimiento mecánico es un factor vital para que el objeto propuesto se pueda conseguir eficazmente. Imaginémonos, por ejemplo, que se trata de desplazarse en línea recta de un punto a otro en un terreno plano; existen multitud de soluciones para lograr ese objetivo básico, pero si el factor rendimiento entra en juego, en menos tiempo, con el menor esfuerzo posible, las soluciones válidas se reducirán a muy pocas, en este caso, a la marcha o a la carrera.

Este tipo de problemas motores se le plantean al jugador principiante muy pronto, y en general, no tiene mucha dificultad en descubrir por sí mismo una serie de soluciones a partir de la información que el medio ambiente le proporciona. El mecanismo de Aprendizaje por imitación es de gran importancia en este sentido: el niño se encuentra con unas dificultades que superar, percibe cómo los otros las resuelven y trata de imitarlos.

La mayoría de los problemas motores que se plantean de forma natural exigen un cierto grado de eficacia; esto hace que una serie de soluciones idóneas se acepten de modo generalizado. Cuando en la realización de una tarea motriz interviene además el componente ludo-competitivo, la necesidad de rendimiento alcanza su máxima expresión.

Se sabe que hay problemas motores cuya solución eficiente se concreta en una alternativa de ejecución motriz que puede ser bien definida. Cuando el profesor, ante la enseñanza de este tipo de problemas motores, proporciona al alumno una información directa sobre la solución de ese problema, concretándose cómo debe realizar su ejecución, diremos que está utilizando una técnica de enseñanza mediante instrucción directa. Esta técnica define un procedimiento

lo incumbe centralmente (Blázquez Sánchez, Marteniuk, Onofre, entre otros). Sería justo reconocer que todos ellos son deudores de una obra inaugural en este campo como lo fue $\mathrm{La}$ enseñanza de la Educación Física. Del comando al descubrimiento, de Muska Mosston, cuya primera edición en lengua castellana es de 1981 y su edición original en inglés es de la década anterior. 
de enseñanza muy concreto y bien conocido, con dos puntos de arranque que pueden sintetizarse de la siguiente forma:

- Existencia de una solución de probado rendimiento y bien definida.

- Comunicación por parte del profesor al alumno de esa solución.

Como se puede deducir, esta técnica de enseñanza es, en principio, aplicable solamente a la resolución de aquellos problemas motores que cumplan la premisa expuesta en el primer punto sin la cual no se podría lógicamente proceder al siguiente.

\subsubsection{Objetivos y aplicaciones de la instrucción directa}

Cavalli (2008) habla refiriéndose a que existe una fuerte tendencia, en el interior del campo de la didáctica de los deportes de conjunto, a asociar el modelo descompositivo con el conductismo en general, y con la teoría del condicionamiento operante -formulado por Skinner- en particular. El carácter atomista y elementalista de ese programa de investigación, derivado directamente del núcleo asociacionista, por el que toda conducta, por compleja que sea, es siempre reducible a una serie de asociaciones entre elementos simples, ha colaborado intensamente con el sostenimiento de esa creencia. No obstante ello, cuando releva el lugar fundamental que aquel autor le otorga a los programas de refuerzo, y la forma de aplicación del modelo en el campo de las prácticas pedagógicas, la asociación mencionada se debilita.

Según Le Boulch, el modelo descompositivo -o técnica del dril- halla sus orígenes en los formatos de aprendizaje de la destreza en los contextos laborales

“... la adquisición de destreza en las profesiones es lo que ha inspirado los más célebres trabajos en este ámbito; los de Carrard en Francia y el método TWI en los Estados Unidos. Carrard describe esa forma de aprendizaje de la siguiente manera: 'La preocupación por evitar todo falso movimiento conduce a una descomposición de los ejercicios. La secuenciación de esos ejercicios y su grado de dificultad deben combinarse de modo que pueda adquirirse insensiblemente el automatismo del gesto. La repetición del gesto le asegura, 
poco a poco, la regularidad, la precisión y el ritmo impuesto..." (Cavalli, 2008: 77)

Sánchez Bañuelos (1992) al hablar de la existencia de soluciones muy concretas a determinados problemas motores acaba conformando técnicas de ejecución muy precisas de más eficiencia que las alternativas y que, por lo tanto, se constituyen en "modelo" a seguir. Cuando para la consecución del objetivo previsto, el rendimiento de ejecución motriz es indispensable, la preproducción de estos modelos por parte del individuo resultará insoslayable, tal es el caso del deporte.

Es patente que la técnica de enseñanza por instrucción directa ofrece bastantes garantías de éxito, al responder de una forma adecuada a las demandas de información que se le plantean al individuo, cuando el objetivo se consigue eficazmente mediante la reproducción precisa de un modelo de movimiento.

De acuerdo con este supuesto, Cavalli (2008) dice que entonces, la solución al problema de cómo crear en los alumnos un repertorio óptimo de actos complejos descansa, básicamente, en el diseño de programas que les permitan -luego de una serie de aproximaciones sucesivas- llegar a su pleno dominio y adquisición. Lo que si debiera quedar en claro, finalmente, es que la rigurosidad en la aplicación del modelo debe balancearse de manera tal, como para permitir que los niveles de mecanización o automatización de los gestos técnicos no atenten contra la posibilidad de utilizarlos en situaciones cambiantes y dinámicas como las que presentan los deportes de conjunto. Entonces, se trata de:

- Facilitar la adquisición de técnicas deportivas de gran dificultad motriz.

- Desarrollar altos niveles de precisión y control sobre las ejecuciones motrices.

- Formar un esquema mental preciso del modelo a ejecutar.

- Eliminar o minimizar las posibilidades de aparición de errores durante el proceso de aprendizaje.

- Permitir la adquisición de respuestas, de forma más o menos rápida y segura. 


\subsubsection{Planteamiento del modelo}

Acerca del planteamiento del modelo se pueden considerar fundamentalmente tres aspectos: el primero de ellos, afecta al carácter general pedagógico que se quiere imprimir a la enseñanza; el segundo, afecta a la distribución de los contenidos para la enseñanza del modelo; y el tercero, afecta a la forma y medio en la que se va a comunicar al alumno la información de referencia para la ejecución. Estos son:

- Carácter general de la enseñanza.

- Estrategia en la práctica.

- Procedimiento y medios para dar la información al alumno.

\subsection{MODELO COMPRENSIVO}

En cuanto a este modelo, Cavalli (2008) dice que los principios tácticos no se adquieren de forma aislada sino que se aprenden, normalmente, en los contextos mismos del juego. Por medio de estos últimos, se favorece y estimula la posibilidad de que los alumnos los descubran por sí mismos, e identifiquen las situaciones motrices en las cuales deben aplicarlos.

\subsubsection{Bases teóricas y psicopedagógicas del modelo}

Según investigaciones realizadas en Inglaterra a principios de la década del 70 , se vino desarrollando un enfoque para la enseñanza de los deportes de conjunto dominado "comprensivo o centrado en la táctica". Este enfoque hunde sus raíces en la psicología de la Gestalt. El punto de partida de esta corriente psicológica es que los objetos y los acontecimientos se perciben como un todo organizado.

Partiendo entonces de los supuestos que la conducta es una totalidad organizada y que la comprensión parcelada y fraccionaria de la realidad deforma y distorsiona la significación del conjunto, postularon que tan importante o más que entender los elementos aislados de la conducta, tiene que ser comprender 
las relaciones de codeterminación que se establecen entre los mismos a la hora de formar una totalidad significativa.

En el marco de estas ideas, se apoya uno de los postulados centrales del enfoque comprensivo para la enseñanza de los deportes de conjunto y, más específicamente, de los aspectos tácticos, como dicen los autores Devís Devís y Peyro Velert (citado en Cavalli, 2008). ${ }^{6}$

El contexto y los problemas del juego son inseparables y ambos se relacionan con su táctica hasta el punto que, para resolver los problemas motrices que surgen dentro del contexto de juego, será necesario comprender los principios tácticos básicos. Por lo tanto, una enseñanza para la comprensión en los juegos deportivos debe abordar el aprendizaje de los aspectos tácticos. Desde esta última visión, la comprensión es entendida como la habilidad de pensar y actuar con flexibilidad a partir de lo que uno sabe.

La asunción de una visión de la comprensión vinculada con el desempeño ha permitido pensar en la posibilidad de la transferencia de los principios tácticos al interior de un conjunto de deportes cuya naturaleza problemática es similar.

En suma, la lógica del modelo comprensivo enfatiza, en primera instancia, la necesidad de pensar la enseñanza desde los contextos mismos de juego, en tanto los aprendizajes aislados no tendrían sentido para los jugadores. $Y$ en segunda, el requisito de desarrollar, a partir de tales situaciones, los procesos

${ }^{6} \mathrm{Del}$ mismo modo que los autores que proponen modelos basados en la resolución de problemas y el descubrimiento son deudores de Mosston, es oportuno decir que el llamado modelo comprensivo tiene en David Kirk uno de sus principales exponentes, no para un deporte en particular, sino para la enseñanza de la Educación Física en general. Algunos de sus trabajos más significativos son:

- "Throwing and Catching as RelationalSkills in Game Play: SituatedLearning in a ModifiedGameUnit", de Ann MacPhail, David Kirk, Linda Griffin, publicado en Journalofteaching in physicaleducation, Vol. 27, No 1, 2000.

- "ChildrensExperiencesofFun and EnjoymentDuring a Seasonof Sport Education", de Ann MacPhail, TrishGorely, David Kirk, Gary D. Kinchin, publicado en Researchquarterlyforexercise and sport, Vol. 79, № 3, 2008.

- Sport Education, CriticalPedagogy and LearningTheory: TowardanIntrinsicJustificationforPhysicalEducation and Youth Sport, de David Kirk, publicado en Quest, Vol. 58, № 2, 2006.

- "Enseñanza de los juegos para la comprensión: perspectiva situada en el aprendizaje de los estudiantes", de David Kirk, Ross Brooker, Sandy Braiuka, publicado en Ágora para la educación física y el deporte, № 2-3, 2003. 
de reconocimiento y comprensión de los principios tácticos comunes a cada categoría en los que se dividen los juegos deportivos.

\subsubsection{Objetivos del modelo}

La propuesta analizada contempla los siguientes objetivos:

- Favorecer la comprensión del sentido de las acciones motrices en función de las situaciones reales de juego.

- Favorecer el desarrollo y la aplicación de esquemas tácticos en la resolución de situaciones de juego.

- Desarrollar la percepción y el análisis del espacio-tiempo de juego en el marco de las acciones globales de los juegos deportivos, en general, y en función de la creación, la ocupación y el aprovechamiento del espacio motor, en particular.

- Facilitar el aprendizaje situado, global o vivencial, de manera de dotar de significatividad a los contenidos y actividades.

- Facilitar la transferencia de tipo horizontal entre aquellas disciplinas deportivas de similar condición o naturaleza problemática.

- Favorecer la contextualización de las habilidades técnicas.

\subsubsection{Principios básicos}

Arnold (1990) dice que, se debe facilitar la adquisición contextual de las habilidades técnicas. Una habilidad técnica sólo tiene sentido en un contexto y es dentro de él donde debe aprenderse y donde adquiere completo significado.

Otros autores opinan que la comprensión de la naturaleza de los juegos deportivos se consigue situando al alumno frente a situaciones motrices que respeten la naturaleza problemática y contextual del deporte. El contexto de juego es el que presenta problemas a los jugadores y, es el medio en el cual los aprendizajes adquieren completo significado. 
Finalmente Devís Devís y Peiro Velert (1992) consideran como punto de partida el juego, el énfasis se pone en el reconocimiento y la comprensión por parte de los alumnos de los principios o aspectos tácticos comunes a cada categoría en las que se dividen los juegos deportivos en función de problemáticas generales similares.

\subsection{MODELO ESTRUCTURAL}

Hernández Moreno (2000) opina que debemos llegar a la conclusión de que en la enseñanza de la actividad física y deportiva, es necesario hacer una transformación radical de la gran mayoría de los conceptos en uso, de manera que se acepte que no se enseñan tareas, gestos, fragmentos de habilidades, montajes comportamentales, sino estructuras, incluso reglas o principios organizadores de nuestros movimientos.

\subsubsection{Bases teóricas y psicopedagógicas del modelo}

Según Cavalli (2008) las bases del modelo estructural pueden hallarse en el rechazo a dos supuestos: por un lado, que el conocimiento tiene una naturaleza acumulativa, y por otro, que cualquier actividad o conducta puede descomponerse en sus partes constitutivas.

En oposición al elementalismo y al asociacionismo, los partidarios de esta corriente se empeñan en estudiar los rasgos estructurales y globales de los deportes de conjunto. Al admitir que estos últimos no son simples acumulaciones de elementos o rasgos desvinculados entre si -que pueden ser adquiridos por separado y luego reunidos por medio de asociaciones-, el modelo estructural deviene en un enfoque de tipo molar que se preocupa por estudiar los fenómenos en su totalidad. A su vez, estos principios y postulados apoyan la creencia de que solo la adquisición de los rasgos estructurales de este tipo de deportes permite la solución de los problemas que emanan del juego.

Teniendo en cuenta estos conceptos, en referencia a las propuestas de enseñanza, Hernández Moreno (citado en Cavalli, 2008) dice que estas deben 
asumir una orientación particular, siendo así que las tareas que se diseñen deben, por lo general, tener significación práxica, para que así los practicantes se enfrenten a la resolución de situaciones motrices en las que predomine la adquisición de conceptos y estructuras en vez de la realización de ejercicios y gestos.

La difusión de estos estudios ha permitido tomar conciencia de que los deportes de conjunto presentan como rasgo más significativo el hecho de que se da simultáneamente la cooperación y la oposición entre sujetos, con lo que las interacciones son a la vez negativas y positivas, y que como consecuencia de ello el factor de decisión o comportamiento estratégico se convierte en predominante para la puesta en acción o desarrollo práctico.

\subsubsection{Objetivos del modelo}

La propuesta analizada contempla los siguientes objetivos:

- Facilitar el reconocimiento y la comprensión, por parte del jugador, de la estructura funcional del deporte y su lógica interna y su aplicación al desarrollo de situaciones de juego (Hernández Moreno, 2000).

- Desarrollar en los alumnos la competencia para comprender rápidamente el sentido de la situación y actuar con eficacia (Bonnefoy, Lahuppe y $\mathrm{Ne}$, 2000).

\subsubsection{Principios básicos}

Hernández Moreno (citado en Cavalli 2008) haciendo referencia al modelo estructural, dice que para un adecuado proceso de iniciación deportiva será necesario, tomar como referencia la estructura de los deportes y el grado de complejidad de la misma. Considerando que la estructura de los deportes de conjunto da cuenta de la presencia y ordenamiento de un conjunto de componentes, elementos, miembros y partes, la enseñanza debiera poder pensarse de forma tal que todos ellos estén presentes en la situación motriz que se plantee a los jugadores. No obstante ello, desde una visión sistémica, se debe 
tener en cuenta, la parte dinámica de estos deportes. Es decir, que las acciones de juego están gobernadas por conductas de decisión o estrategia motriz y que la exigencia de este tipo de conductas no puede estar ausente en las propuestas de trabajo.

\subsection{BIBLIOGRAFÍA DEL CAPÍTULO}

Arnold, P.J. (1990) Educación Física, movimiento y curriculum. Buenos Aires: Morata.

Bonnefoy, G., H. Lahuppe, y R. Ne (2000) Enseñar Balonmano para jugar en Equipo. Barcelona: INDE.

Cavalli, D. (2008) Didáctica de los deportes de conjunto. Problemas, enfoques y modelos de enseñanza. Buenos Aires: Stadium.

Devís Devís y Peiro Velert (1992) "Fundamentos para la promoción de la actividad física relacionada con la salud", en: Devís Devís, J. (Coord.) La educación física, el deporte y la salud en el siglo XXI. Alicante: Marfil.

Hernández Moreno, J. (2000) La iniciación a los deportes desde su estructura y dinámica. Barcelona: INDE.

Le Boulch, J. (1997) El Movimiento en el Desarrollo de la Persona. Barcelona: Paidotribo.

Le Boulch, J. (1991a) El deporte educativo. Psicocinética y aprendizaje Motor. Barcelona: Paidós.

Le Boulch, J. (1991b) Hacia una ciencia del movimiento humano. Barcelona: Paidós.

Sánchez Bañuelos (1992) Bases para una didáctica de la educación física y el deporte. Madrid: Gymnos.

Onofre, R. (1998) Didáctica de la Educación Física. España: Inde 
CAPÍTULO 6:

CONCLUSIONES

\subsection{EN RESPUESTA A LAS PREGUNTAS DE INVESTIGACIÓN}

Para la redacción de estas conclusiones hemos de tomar en cuenta en primer lugar las preguntas que formulamos en oportunidad de presentar el proyecto de tesis. Comenzaremos con las preguntas específicas para pasar, al final de las mismas, a la pregunta general que orientó el trabajo.

6.1.1. ¿Cómo se inscribe la propia experiencia de jugador previa a la de entrenador en la toma de decisiones sobre las formas de enseñanza?

La experiencia previa de los entrenadores como jugadores se traduce de manera muy personal, el tiempo que transcurre entre los momentos de jugador al de entrenador estará relacionado con el continuo almacenamiento de acciones positivas y negativas producidas por el juego. La información adquirida dará respuestas a las acciones de juego de la mejor manera guardada como registro de valor. Ahora bien, la experiencia personal como jugador podría influir de manera negativa al momento de decidir sobre las acciones que se presentan en el juego. Si nos apoyamos solo en nuestra experiencia para transmitir los alcances positivos del cómo hacer -y tal como establecimos en los modelos de enseñanza más abiertos y flexibles-, estaremos postergando el descubrimiento personal del qué y cuándo hacer del propio jugador. Conviene situar nuestra experiencia no tanto como referencia, sino en tanto vínculo entre el conocimiento pedagógico y el tránsito hacia el descubrimiento personal. Como entrenadores, informar el cómo sería dar respuestas basados en el hacer que ya tenemos registrado: son preferibles las actividades jugadas donde el aprendiz descubra el camino; las actividades presentadas siempre deben poseer en ella la respuesta y así ayudar a que cada uno inicie su descubrimiento de forma natural. Cuando en este trabajo referenciamos a Marteniuk y a Mahlo, lo hacemos porque ellos describen con mucha claridad lo importante de la percepción: percibir todo 
(o casi todo) lo que va sucediendo en los deportes abiertos, donde el flujo de información es mucho y muy variado; es por eso que si además los entrenadores intervienen incorporando más información se estaría demorando de manera muy directa la toma de decisión por parte de los aprendices.

En este marco, las coincidencias en torno a que el entrenamiento más eficaz es el que mejor se adapta a las características de la edad del deportista y del deporte que se quiere practicar son amplias. Recordemos que la propuesta de nuestros autores es que cuando llevamos los entrenamientos a la mejora de la táctica individual, esta mejora será, sobre todo, en la de la toma de decisión en el juego. El propósito será centrarse en una buena ejecución, que será la mejora de la técnica, la que sin lugar a dudas me posibilitaras poder tomar mejores decisiones.

6.1.2. ¿Cuál es la incidencia de la formación académica y técnica en la toma de decisiones sobre las formas de enseñanza?

La observación de entrenamientos no nos ofrece respuestas concluyentes a esta pregunta. No obstante, como se refirió, existen situaciones en las cuales los entrenadores privilegian la toma de decisión de sus jugadores durante el juego. A pesar de de la falta de certidumbres, no renunciamos a dar una opinión de lo que pensamos -en base a los autores consultados y a la propia experiencia- del entrenamiento para mejorar la toma de decisiones. Seguramente el tiempo matizará, e incluso refutará, alguna de las cosas que aquí expresamos.

Por nuestra parte, creemos que quienes transitan los playones y las canchas de taraflex intentan construir una idea con los datos que van tomando de la experiencia en esos espacios junto con la bibliografía a la que han podido acceder. No obstante, también está presente la idea intuitiva de que "cuantos más conocimientos se tenga, mejor"; pero esta idea al momento de tomar decisiones choca rápidamente con sus propios límites. Nuestros autores parecen aconsejar a los entrenadores de esta manera: los entrenadores no deberían preocuparse tanto en cargar de información a los jugadores, sino más bien adecuar la información para que al momento de ser incorporada tenga sentido. 
En realidad se trata de establecer patrones adecuados que conecten y jerarquicen la información para así facilitar al acceso a ella. Muchos jugadores tienen múltiples conocimientos y mucha dificultad para manejarlos al momento de tomar decisiones y es por ello es que fallan en similares momentos.

\subsection{3. ¿Cómo visualiza el profesor/entrenador las distintas corrientes y qué valor} le asigna a cada una de ellas?

Partimos de la idea de que todas las corrientes tienen un valor determinado en el proceso de enseñanza: en ciertos momentos, unas, y en otros, otras, la apertura al conocimiento y la experiencia desarrollada por los formadores debe ser un coctel que se bebe con lentitud, y no todos están preparados para salir de su círculo de confort. Tratamos de establecer a lo largo de estas páginas un respeto por todas las corrientes sin adherir a un modelo ecléctico: valoramos los modos de enseñanza directa para ciertas etapas o momentos, pero aspiramos a que los alumnos/deportistas se autonomicen a través de modelos más ligados a la resolución y comprensión que a la imitación y repetición. Los profesores/entrenadores que construyen sus modos de enseñanza desde la experiencia tomada de su época de deportistas tienen una mirada muy parcial del cómo: los tiempos cambian de manera vertiginosa y las formas de enseñar van mutando de la misma forma ( $\mathrm{y}$, tal vez, su experiencia, valiosa en un momento, resulte menos valiosa en otro). Los "no académicos" suelen limitarse a transmitir su experiencia como única forma de enseñanza: a los jugadores, sólo le queda jugar como el profesor quiere. Por su parte, los entrenadores con mayor grado de formación académica sumada a su experiencia se destacan por encima de los otros, ya que los jugadores logran participar entendiendo cómo jugar y no todos los equipos lo harán de la misma manera ya que se respeta el desarrollo y el momento de formación de cada uno de ellos.

Mostrar el camino en lugar de decir cómo se lo debe recorrer parece ser la clave de la formación de jugadores con identidad y capacidad de tonar decisiones. Esto es equivalente a algo que escuchamos entre los entrenadores: pasar del jugador que "no se entera de lo que pasa", o del que "observa y reacciona a lo 
que pasa", al jugador que "condiciona lo que pasa en el juego y se anticipa a lo que va a pasar". Otro entrenador lo decía de un modo aún más gráfico: "no se debe formar jugadores que al momento de tomar una decisión lean muy bien el juego, sino todo lo contrario: ¡que lo escriban!"

6.1.4. ¿Cómo enseña en sus entrenamientos/sesiones/clases y cómo conduce, planifica y evalúa los procesos el profesor/entrenador?

Nuestras observaciones nos han permitido constatar que los entrenamientos/sesiones/clases se van modificando, en muchos casos sin saber por qué y para qué. Como contraparte, hay que destacar que, con el paso del tiempo, vemos también que los entrenadores ven que únicamente con proponer ejercicios para la mejora de la táctica individual no alcanza, y que lo que se trabaja tiene que estar en consonancia con lo que se pretende mejorar.

Las propuestas de situaciones abiertas que además acepten múltiples respuestas es un camino a seguir acorde con la propuesta de los autores consultados. Pero persiste la incógnita: ¿cuáles son los mejores ejercicios que el profesor puede y debe usar? ¿Acaso todos? Pues sí: todos. Ya que el problema no es el ejercicio en sí, sino si responde a las características del jugador, al sentido del juego, al momento de la formación. Y claro: al objetivo de formar jugadores con autonomía. En los deportes abiertos no parece suficiente programar el trabajo adecuado. Si fuese así, bastaría con copiar los ejercicios de "los buenos" para obtener sus mismos resultados. Las transformaciones en los jugadores se producen en parte por el trabajo que realizan, pero también por su interacción con el entorno, por cómo se relaciona con lo que le rodea y las consecuencias cognitivas y emocionales que esto conlleva.

La información no se guarda de forma "neutra", sino "marcada" inconscientemente por la huella emocional con la que fue recibida en el momento en que se captó, y esta huella luego es fundamental a la hora de elegir. Estos "marcadores" están influidos no solo por los conceptos previos de los entrenadores, sino también por sus propósitos, deseos, inquietudes y temores. En este sentido, la información de la que el jugador se apropia -y el modo en 
que se apropia- no depende únicamente del trabajo que se hace sino del contexto en que se produce ese trabajo y, más allá de esto, del contexto en que se mueve el grupo, no sólo durante los entrenamientos, sino durante cualquier actividad del equipo. Los equipos crecen basándose en criterios comunes y formas de actuar donde unos condicionan a otros y, al final, esta interacción es transcendente en la evolución de todos.

6.1.5. ¿Qué visiones de la infancia y de la formación predominan entre los profesores/entrenadores?

Si consideramos que al momento de la formación de los profesores/entrenadores deben afrontar diferentes situaciones de aprendizaje, y que no cuentan con las herramientas necesarias para resolver las mismas, se concluye que esto se debe a la predominancia de un modelo de enseñanza, que seguramente fue el que adoptaron en su infancia y es con el que más seguros se sienten al momento de transmitirlo. Así, muchas veces, se le brindan/ofrecen/imponen al futuro jugador algunos conocimientos ya incorporados y conocidos desde su paso por la formación, automatizando movimientos, pero no desarrollando la capacidad de analizar y resolver de la forma más eficiente y eficaz la situación a la que se afronta en ese momento seguramente, pues se ve muchas veces el hacer sin saber el por qué hacer.

La visión y dominio de un modelo de ejecución ideal, adquirido desde su formación infantil corre con el riesgo de que el profesor/entrenador transmita al jugador un conocimiento que lo limite a reflexionar sobre cómo resolver la lógica del juego. Esto suele suceder, por ejemplo, cuando durante la enseñanza de esquemas tácticos o habilidades motrices deportivas, la información que se le brinda se reduce a señalar la correspondencia entre la acción por él efectuada y el modelo preestablecido por los profesores/entrenadores.

Otra situación a revisar ocurre cuando la valoración desmesurada de un modelo técnico aprendido e incorporado desde temprana edad por el profesor/entrenador y utilizado dentro de los parámetros de la enseñanza como 
una fórmula mágica, el resultado será un obstáculo entre la relación con el jugador tanto como con los compañeros.

La Educación Física como espacio curricular, puede contribuir para que los adolescentes realicen aprendizajes motores con sus compañeros. Se espera que en las clases, los alumnos puedan comunicarse, en forma constructiva, solidaria y respetuosa, intentando superar aquellas prácticas que, a través de tareas realizadas, con frecuencia en forma individual, llevan a los alumnos a poner atención en modelos corporales y de comportamiento motor externos, muchas veces ajenos a sus necesidades, intereses y posibilidades.

6.1.6. ¿De qué manera construyen los entrenadores y profesores sus modelos de actuación profesional en especial a lo relativo a los modos en que enseñan el deporte?

Evidentemente la construcción que hacen los entrenadores de sus modelos de actuación durante los primeros pasos como formadores, son aquellas con la cuales se sienten más cómodos, las que dominan de manera más segura, la que tienen más fresca en su memoria o la que recuerdan como vivencia positiva. Sin lugar a dudas, cada uno de ellos va a mutar de modelo cuando se sienta seguro de los posibles resultados, del dominio que tiene sobre los nuevos modelos incorporados. Los entrenadores/profesores suelen adaptar los modos de enseñanza a las edades, a los contextos que se presentan, de un modo "natural", pero no necesariamente reflexivo.

Cuando se quiere conseguir que los jugadores aprendan un gesto técnico o descubran las conductas que resuelven los problemas planteados, algunos comienzan a percibir que el principal recurso a emplear no es la descripción detallada, sino las condiciones impuestas por el propio ejercicio/juego. 


\subsection{CONSIDERACIONES FINALES}

(PARA DARLE VOZ AL ENTRENADOR QUE LLEVO ADENTRO)

Fue un gran esfuerzo escribir estas páginas tomando distancia del entrenador y profesor que fui y soy. Me quiero dar el gusto de proponer en pocas líneas una breve síntesis de mis conocimientos adquiridos a través de la experiencia y el estudio.

Vistas, analizadas y llevadas a la práctica, distintas formas de mejorar la iniciación, creemos conveniente aclarar que todas ellas pueden comulgar en este proceso de formación siempre que tengamos muy claro qué tareas debemos ofrecer e informar a los que se inician. Anteriormente, mencionamos a las estrategias visuales como un punto de referencia fundamental en el proceso de iniciación deportiva; los modelos de ejecución motriz nos llevan a la información más rápida por medio de la observación: en esos momentos estaremos siempre dispuestos a tomar decisiones, las mismas que nos ayudarán a avanzar en este proceso de formación.

En los deportes colectivos como el balonmano, las estrategias visuales defensivas mejorarán en el principiante y posteriormente en la continuidad de su desarrollo una mejora en la captación de la información de los elementos relevantes del juego. Ampliación del campo visual y desarrollo de la visión periférica, con el objeto de aumentar la capacidad del jugador de percibir simultáneamente la mayor cantidad de informaciones posibles defensivas. Los jugadores utilizarán estas estrategias de acuerdo a una elección táctica determinada y de forma alternada. El alumno-jugador recibirá solamente una instrucción u objetivo para generar una determinada estrategia visual.

Si recorremos a los distintos autores, observamos que nos muestran un comienzo donde el balón es la atracción total y es por ello que proponemos un modelo de trabajo basado en la relación directa entre el desarrollo del campo visual, la toma de decisión, la técnica individual y el juego propiamente dicho.

Es ahora el momento de poner en relación a todos estos principios y transformarlos en un modelo de trabajo para la formación de los futuros deportistas. Instrucciones como recuperen el balón se escuchan con mucha 
frecuencia, tanto en los partidos como en los entrenamientos. Ahora bien, ¿saben cómo? ¿Saben en qué momento? ¿Saben a qué distancia del arco? La recuperación del balón estará vinculada siempre al trabajo defensivo, esto para muchos no es ninguna novedad; pero para el niño que comienza -y que solo está interesado por tener en su poder la pelota- este factor no es menos importante a otros como no identificar a sus compañeros o el lugar al que debe dirigirse para lanzar. Es muy común verlo a él y a sus compañeros correr en una misma dirección, y esa será siempre donde esté el balón: he aquí la primera forma de recuperar el balón, con la defensa libre, la cual está en estrecha relación con el modo más rudimentario de exploración visual llamada central iterativo, ya que pasa de objetivo a objetivo. Esto se realiza por medio de movimientos sacádicos, es decir de movimientos que se ilustran mediante el ojo -los humanos no miran una escena de forma estática por lo general-; en este caso, buscamos escenas interesantes que irán construyendo un mapa mental de referencia: la consigna será debes recuperar la pelota. El iniciado estará listo para pasar a un nivel defensivo mayor cuando su comportamiento visual esté relacionado con mantener constantemente la mirada focalizada sobre un objetivo. Pero, ¿cómo sabemos cuándo ese joven está listo para tomar otras responsabilidades en el juego? Cuando se reconozca defensor y atacante, cuando identifique a sus compañeros y su orientación sea al arco rival. Como se puede apreciar, todos estos puntos tienen que ver directamente con el reconocimiento visual de las situaciones y las acciones. Preseleccionado su oponente directo, el jugador al que debe marcar, su comportamiento visual será el de saber siempre dónde está su adversario: él deberá mantener el control continuo del mismo desde el plano visual y espacial. Será en este momento cuando podemos comenzar a hablar de la defensa individual, la cual les dará a los jugadores una gran oportunidad de conocer cuando están en ataque y cuando están en defensa. Al observar estos cambios, podemos decir que los jugadores ya están en una nueva etapa, que llamaremos central continuo, su defensa será nominal; por lo tanto el control visual y las decisiones que tome estarán dadas sobre su oponente directo, lo cual no durará mucho tiempo (según su maduración), y podremos ver que el control central será relativo a dos 
objetivos preseleccionados: balón y oponente. Esto es lo que nos permite hablar de central alterno, pues estará transitando el camino entre la defensa nominal y la defensa espontánea no nominal.

Cuando comenzamos a ver que en defensa nuestros jugadores toman distancia de sus oponentes tenemos enfrente nuestro primer indicio de que la etapa tercera está comenzando. En este momento la utilización de la visión es periférica: la mirada está sobre el balón y la visión periférica sobre su oponente directo; es el comienzo de la defensa espontanea, donde deberá elegir qué es más importante y por qué. Este momento lo llamamos periférico intermitente. En los deportes como el balonmano de características muy dinámicas los desplazamientos son muy importantes y en este caso no dejan de serlo ya que deberán combinar los desplazamiento del tren inferior disociado del superior y la mirada; en este último caso sería algo del siguiente tipo: desplazamiento de la atención sin desplazamiento de la mirada (ya que esta última permanece fija en un punto del espacio no informativo, punto de perspectiva en función de las situaciones relativas de él mismo, del balón y del oponente, para mantener a estos dos últimos en su campo periférico y de ser posible en el campo binocular). Por lo tanto esta etapa o momento será periférico iterativo.

La evolución de las adquisiciones ofensivas será, como siempre, la consecuencia del incremento de la oposición defensiva. En este sentido, la defensa individual en todo el campo va a exigir a los atacantes un importante esfuerzo perceptivo.

Hay que considerar que las estrategias visuales implicadas en la conducta táctica traducen una evolución continua de los estados atencionales, de modo que es totalmente artificial individualizarlas cómo vamos a implementarlas. Sin embargo, no hay otro medio de abordar esta difícil cuestión ya que las fluctuaciones de los procesos atencionales en un sujeto implicado en una situación táctica pueden ser extremadamente rápidas, alternando en el mismo segundo varias estrategias visuales. 


\section{BIBLIOGRAFIA GENERAL}

Arnold, P.J. (1990) Educación Física, movimiento y curriculum. Buenos Aires: Morata.

Arnold, P. J. (1992) "Educación Física, movimiento y currículum", en: Devís Devís, J. y C. Peiro Velert (comp.) Nuevas Perspectivas curriculares en educación física. La salud y los juegos modificados. Barcelona: INDE.

Bandura, A. y R. Walters (1974) Aprendizaje Social y desarrollo de la personalidad. Madrid: Alianza Universidad.

Bandura, A. (1984) Teoría del Aprendizaje Social. Madrid: Espasa Calpe.

Bandura, A. (1986) Fundamentos Sociales del pensamiento y Acción. Teoría Cognitiva Social. Barcelona: Martínez Roca.

Barbero González, J. I. (1993) "Introducción”, en Barbero González, J. I. (comp.), Materiales de sociología del deporte. Madrid: Ediciones de la Piqueta.

Bayer, C. (1987) Técnicas del balonmano. Barcelona: Hispano-Europea.

Bayer, C. (1992) La enseñanza de los juegos deportivos colectivos. Barcelona: Hispano Europea.

Blanchard, K. y A. Cheska (1986) Antropología del deporte. Barcelona: Ediciones Bellaterra.

Blázquez Sánchez, D. (1986) Iniciación a los deportes de equipo. Barcelona: Martínez Roca.

Blázquez Sánchez, D. (1999) Iniciación a los deportes de equipo... del juego al deporte de los 6 a los 10 años. Barcelona: INDE.

Blázquez Sánchez, D. (Dir) (1999) La iniciación deportiva y el deporte escolar. Barcelona: INDE.

Blázquez, D. y J. Hernández, (1984) "Clasificación o taxonomías deportivas" (monografía). Barcelona: INEF. 
Bonnefoy, G., H. Lahuppe, y R. Ne (2000) Enseñar Balonmano para jugar en Equipo. Barcelona: INDE.

Bouet, M. (1968) Signification du sport. París: PUF.

Bourdieu, P. (1990) “¿Cómo se puede ser deportista?”, en Sociología y Cultura. México: Grijalbo.

Brohm, J-M. (1993) "20 Tesis sobre el deporte”, en Barbero González, J. I. (comp.), Materiales de sociología del deporte. Madrid: Ediciones de la Piqueta.

Cagigal, J. M. (1979) Cultura intelectual y cultura física. Buenos Aires: Kapelusz. Cagigal, J. M. (1985) "Pedagogía del deporte como educación”, en: Revista de Educación Física. Renovación de teoría y práctica (3). Madrid.

Carballo, C. y N. Hernández (1999) "Acerca del concepto de deporte. Alcances de su(s) significado(s)", en: Educación Física \& Ciencia, año 6. La Plata: Departamento de Educación Física, Facultad de Humanidades y Ciencias de la Educación, Universidad Nacional de La Plata.

Castejón, F. J. (2001). Iniciación deportiva. Aprendizaje y enseñanza. Madrid: Pila Teleña (edición electrónica).

Cavalli, D. (2008) Didáctica de los deportes de conjunto. Problemas, enfoques y modelos de enseñanza. Buenos Aires: Stadium.

Cavalli D. (2014) Enseñar Handball en la escuela. Una aproximación lúdica e inclusiva. Buenos Aires: Stadium.

De la Rica, M. J. (1993) “El deporte en la educación física”, en: AA.VV. (Ed.) Fundamentos de Educación Física para enseñanza primaria (Vol. II). Barcelona: INDE.

Devís Devís, J. (1996) Educación Física, deporte y currículum. Investigación y desarrollo curricular. Madrid: Aprendizaje Visor.

Devís Devís, J. y R. Sánchez (1996) "La enseñanza alternativa de los juegos deportivos: antecedentes, modelos actuales de iniciación y reflexiones finales", en Moreno Murcia, J.A. y P. L. Rodríguez (Eds.) Aprendizaje deportivo. Murcia: Universidad de Murcia. 
Devís Devís, J. y C. Peiro Velert (2001) "Fundamentos para la promoción de la actividad física relacionada con la salud", en: Devís Devís, J. (Coord.) La educación física, el deporte y la salud en el siglo XXI. Alicante: Marfil.

Dunning (1993) "Reflexiones sociológicas sobre el deporte, la violencia y la civilización” en Barbero González, J. I. (comp.), Materiales de sociología del deporte. Madrid: Ediciones de la Piqueta.

Durand, G. (1968) El adolescente y los deportes. Barcelona: Paideia.

Elias, N. y E. Dunning (1986) Deporte y ocio en el proceso de la civilización. Madrid: Fondo de Cultura Económica.

Espar, X. (2001) Balonmano. Barcelona: Martínez Roca.

García Ferrando, M. (1990) Aspectos sociales del deporte: una reflexión sociológica. Madrid: Alianza.

Giménez, F. J. (2002). "El deporte dentro del ámbito recreativo: iniciación deportiva para todos", en: Rebollo (Ed.) Deporte para todos. Huelva: Diputación de Huelva. Área de deportes.

Hernández Moreno, J. (1994) Fundamentos del deporte. Análisis de las estructuras del juego deportivo. Barcelona: INDE.

Hernández Moreno, J. (1999) La diversidad de prácticas. Análisis de la estructura de los deportes para su aplicación a la iniciación deportiva. Barcelona: INDE.

Hernández Moreno, J. (2000) La iniciación a los deportes desde su estructura y dinámica. Barcelona: INDE.

Hernández Moreno, J., U. Castro, G. Gil, H. Cruz, G. Guerra, M. Quiroga y Cols. (2001). "La iniciación a los deportes de equipo de cooperación/oposición desde la estructura y dinámica de la acción de juego: un nuevo enfoque”, en: Lecturas: Educación Física y Deportes, Revista digital, 33. http://www.efdeportes.com/efd33/inicdep.htm

Hernández Moreno, J. y J. P. Rodríguez Rivas (2009) "Una praxiología, es decir... (sobre los conocimientos de la ciencia de la acción motriz y su organización), en: Acciónmotriz №3. Disponible en: file://C:/Users/user/ 
Downloads/Dialnet-UnaPraxiologiaEsDecirSobreLosConocimientosDeLaCien6700102.pdf

Kroger C. y K. Roth (1999) Escuela del balón. Guía para principiantes. Barcelona: Paidotribo.

Laguna Elzaurdía, M. (1996) Clinic deporte de base. Madrid: Real Federación Española de Balonmano.

Laguna Elzaurdía, M. (2001) “Jugar y hacer jugar”, en: Comunicación Nº 425. Madrid: Real Federación Española de Balonmano.

Laguna Elzaurdia, M. (2001) Técnica-Táctica individual. Madrid: Real Federación Española de Balonmano.

Lasierra, G., J. M. Ponz y F. Andrés (1995) 1013 ejercicios y juegos aplicados al balonmano. Volumen I. Barcelona: Paidotribo.

Le Boulch, J. (1991) El deporte educativo. Psicocinética y aprendizaje Motor. Barcelona: Paidós.

Le Boulch, J. (1991) Hacia una ciencia del movimiento humano. Barcelona: Paidós.

Le Boulch, J. (1997) El Movimiento en el Desarrollo de la Persona. Barcelona: Paidotribo.

Lüschen, G. y K. Weiss (1976) Sociología del deporte. Valladolid: Miñón.

Mahlo, F. (1969) La acción táctica en el juego. La Habana: Pueblo y Educación.

Marriot, J. (1995) Balonmano. De la escuela... a las asociaciones deportivas. Lérida: Ágonos.

Marteniuk, R. (1976) Information, Processing and motor skills. New York: Holt, Rinehatt \& Winston.

Onofre, R. (1998) Didáctica de la Educación Física. España: Inde Parlebas, P. (2001) Juegos, deportes y sociedades. Léxico de praxiología motriz. Barcelona: Paidotribo. 
Pozo, J. I. (1996) Aprendices y Maestros. La Nueva Cultura del Aprendizaje. Madrid: Alianza.

RAE (1992) Diccionario de la Lengua Española. Madrid: Espasa Calpe.

Rink, J., K. French y K. Grahan (1996) “Implications for practice and reserch", en: Journal of teaching in physical education. Champaign: Human Kinetics.

Rodríguez, M. G. (1996) "Minuto, juez. Deporte, sociedad y escuela", en: Revista CD Books en la Educación Física y el Deporte, número octubre 1996. Buenos Aires: CD Books.

Rodríguez, M. G. y C. Carballo (2015) "Deporte Moderno, Deporte Federado, Deporte Espectáculo y de Alto Rendimiento", en: Carballo, C. (compiladoreditor) Diccionario Crítico de la Educación Física Académica. Rastreo y análisis de los debates y tensiones del campo académico de la educación física en Argentina. Buenos Aires: Prometeo Libros.

Romero Cerezo, C. (1997) "Una nueva perspectiva de iniciación al fútbol en la escuela”, en: Training Fútbol (16).

Romero Granados, S. (2001) Formación deportiva: nuevos retos en educación. Sevilla: Universidad de Sevilla.

Sánchez Bañuelos (1992) Bases para una didáctica de la educación física y el deporte. Madrid: Gymnos.

Sánchez Bañuelos, F. (2000) "Análisis del deporte en edad escolar y una alternativa para el futuro", en: Díaz García, J. (Ed.) Actas del I Congreso Nacional de Deporte en edad escolar. Dos Hermanas: Ayuntamiento de Dos Hermanas.

Sivori, J. (2002) La Enseñanza del Handball. Buenos Aires: EFyD.

Thomas, R., A. Haumont y J. L. Levet (1988) Sociología del deporte. Barcelona: Ediciones Bellaterra.

Vankersschaver, J. (1982) Football. La formation dans l'école ou dans le club. Partie 1. Paris: Education Physique et Sport.

Velert Peiró, C. (1992) Nuevas perspectivas curriculares en educación física: la salud y los juegos modificados. Barcelona: INDE. 
Volpicelli, L. (1967) Industrialismo y deporte. Buenos Aires: Paidós.

Willis,P. (1980) "Notas sobre el método", en: Hall, S. et al. (ed.) Culture, Media, Lenguaje. Londres: Hutchinson. 


\section{AGRADECIMIENTOS}

Llegó uno de los momentos más difíciles de redactar para mí. Seguramente para muchos puede ser un punto de natural emoción, de gratos recuerdos y de saludos personalizados; pero para mí es un verdadero desafío: el desafío de no olvidarme de nadie, de recordar a todos los que transitaron y transitan por mi vida, los que están, los que no están y contemplan desde algún lugar mis triunfos y mis derrotas. A todos ellos les quiero agradecer, a los que muchas veces, como suele decirse, "pusieron piedras en el camino", porque me enseñaron a seguir y nunca bajar la cabeza, a poner mayor entereza en todo lo que emprendía, a ver que la vida no es un camino suave y ligero, sino que seremos nosotros mismos los que haremos que así sea si nos lo proponemos.

A los que pasaron por mi vida sin dejar más que lo necesario también les digo gracias: pude ver en el tiempo que fueron un pilar importante para construir parte de lo que soy hoy. A los que me marcaron a fuego esta pasión por el deporte y la docencia, moldearon lo que fui como deportista y lo que soy como profesional: a Ricardo Wrotniack, quien me llevo al Club Estudiantes de La Plata a jugar al handball; a todos los docentes que me formaron en mis estudios secundarios; al gran Ángel Pedro Chiche Orbe (Chapeau!), al cual recuerdo todos los años en mis clases contando alguna anécdota -creo que es una manera de que siga a nuestro lado-. A todos los que jugadores de handball con los que compartí canchas, torneos, viajes... y la vida. A mis entrenadores de selección: a ellos que juntos a los del club creyeron en mí como persona y como jugador; a los dirigentes, a los padres de esos pequeños grandes jugadores que seguramente hoy ya son hombres y llevan a sus hijos por el mismo camino que los llevaron a ellos. Gracias Esteban Kaplanian por creer en mí, por ir a buscarme para jugar durante once años en la Unión General Armenia, gracias a esa hermosa época. ¡Gracias, Broder! (lo escribo así porque tu voz cubana lo pronunciaba de esa forma). Yo sé que estarías muy orgulloso de saber de mis logros; después de conocernos en 1981, la hermosa vida del deporte nos juntó en 1994. Gracias por tu amistad y tu profesionalismo, por tus charlas interminables sobre tu Cuba querida y sobre las maneras en que podríamos mejorar el handball en mi país. 
Debo reconocer que no dejo de lagrimear al momento de escribir esto. Gracias Roberto el Broder Casuso Mariño.

Gracias a Manolo Laguna: gracias por tu bondad, por responder a todas las preguntas, por no guardarte nada de tu infinitos conocimientos, por transmitirnos esa locura de analizar y buscar respuestas en cada juego que vimos, por tu alegría y tus siempre sabias palabras, esas que siempre nos ayudan y ayudarán a caminar por este deporte, y por las buenas y malas cervezas compartidas... iy las que seguiremos compartiendo!

Agradezco a todos los que me soportar hablando de handball todos los días -o mejor dicho, nos soportamos mutuamente-: Fernando Capurro, Alejandro De La Quintana, Tano Comparone, Gustavo Sciglitano, Jorge Botejara, Gabriel Klein, Manolo Laguna. También quiero agradecer a un docente muy especial, a Jorge Bigotón Meccia, un profesional de los que ya es muy difícil encontrar, el que no descansa, el que me incentiva todos los días a seguir estudiando, a seguir buscando, el que llega a la universidad y te dice "leí este artículo, ¿lo viste?", pregunta letal, porque me lo pasa y lo leo... y después de ese trae otro y otro, nunca termina, me pregunto si duerme. Gracias por reseñarme cuando fuiste mi entrenador y ahora por ser mi maestro en la universidad.

Gracias a todos los docentes que me formaron en la Universidad Nacional de La Plata, a todos. ¡Sí! Porque de todos rescaté lo mejor. A todos mis compañeros de esta hermosa promoción 1984, a todos: Qué lindo es poder contar con ustedes, siempre, siempre. $\mathrm{Y}$ entre ellos, a mi director de tesis, mi amigo, mi hermano, ese que la vida te pone y vos te das cuenta que por más que pasen los años, y no lo veas siempre, él va a estar; con él recordábamos no hace mucho que preparamos la última materia juntos y ahora después de muchos años -no vamos a decir cuántos- volvimos a terminar juntos este momento de ambos a nivel profesional. Gracias Carlitos Carballo, porque sigue siendo Carlitos, por compartir tus conocimientos, por tu profesionalidad, por tu bondad y por tu amistad.

A todos los compañeros con los que hoy compartimos la grata tarea de formar docentes en la Universidad Nacional de José C. Paz: al Lic. Julián Bernaule, con 
quien atravesamos buenas y malas, con quien luchamos y seguimos luchando para hacer grande nuestra profesión y nuestra Universidad; gracias por creer en mí, gracias por insistir en que debía hacer mi maestría, escribir el libro y no sé cuántas cosas más (que iré haciendo paso a paso). Gracias también por el respeto y por algo que para mí es muy importante: tu amistad. Gracias. Gracias también a la Lic. Amalia Guchi Lapolla, por las charlas, por compartir estos años de trabajo, por las discusiones con este tano calentón, por la paciencia, por estar, por creer en mí como profesional y lo más importante, por tu amistad. Gracias al Lic. Pablo Pascualini, al Lic Facundo Ragusa, al Lic. Juan Pablo Galo, al Lic. Ezequiel Martínez. Y un agradecimiento muy especial a Emilio Massabeu.

Seguramente me acordaré de muchos más y será el momento de pedir disculpas, pero eso será en otro momento.

Llegó el momento que de solo pensarlo se me nubla la vista y siento las lágrimas correr por mis mejillas, esto es literal: quiero agradecer a la vida que viví y sigo viviendo, a mis abuelos maternos Sara e Isaías, a los paternos al nono Juan (el que me hacia los juguetes de madera en su banco de trabajo, el que me sentaba y me cantaba en italiano, "eran las tres Orelas y tres eran de amor. Ineta la piu Bela..." y continuaba su canto mientras trabajaba, el que me pedía que le alcanzara las herramientas solo para que conociera su nombre, y no porque el no pudiera alcanzarlas) y a mi petisa adorada mi abuela Elena, "la abuela", la que siempre estaba esperado que llegara para tomar la leche o para almorzar con ella a mi regreso de la facultad, la que tenía todo listo para malcriarme, la que me contaba sus historias de vida, gracias nona por vivir en mí hasta hoy y hasta mi último día.

A mis padres, a Coca y Tito, que se desvivieron para que fuera lo que soy hoy, porque fueron los que me acompañaron en cada paso que di, porque fueron y son los que me guían a cada momento: sé que estarían orgullosos de mí como persona y como profesional, solo puedo decirles gracias, gracias, gracias por ser mis padres. Los amos y los extraño muchísimo. 
Gracias a Luis Angel Onetti, quien fue siempre un padre para mí cuando el mío nos dejó: él fue, es y será el mejor suegro que me podía tocar. Gracias a Sara Ríos por quererme y apoyarme durante tantos años... iy los que faltan todavía! Y ahora llegó el momento de lo más lindo que me dio esta vida, mi hijos. Gracias, Camila, gracias, Guido, por dejarme aprender junto a ustedes dos a ser padre: ojalá sea el mejor del mundo, no lo sé, pero lo intento todos los días, y espero que pueda llegar a serlo. Nunca olvido que esto es un trabajo que construimos juntos, pues como dijo Mafalda, yo me recibí de padre el mismo día que ustedes se recibieron de hijos. Los amo con toda el alma. Y algo más: ¡sean felices!

Y para finalizar, gracias al ser más importante de mi vida, la que me acompaña desde hace treinta años, la persona que cuando me voy de mi eje me acomoda en él, la que siempre tiene la palabra apropiada, la que compartió buenas y malas, la que luchó codo a codo para construir esta hermosa familia, la que me dio el tesoro más preciado del universo, dos hermosos hijos. La que tiene miles de proyectos en los cuales siempre estoy incluido -pero juro que no voy a tejer ni a bordar, (por lo menos por ahora)-. Te amo y soy muy feliz de verte feliz y de saber que continuamos con la misma ilusión de aquel 25 de noviembre. Ella es Sandra Vivian Onetti, no es mi mujer, es la mujer. 